UNIVERSIDADE DE SÃO PAULO

ESCOLA DE ENFERMAGEM

CRISTINA SILVA SOUSA

AVALIAÇÃO DO USO DE UMA TECNOLOGIA EDUCATIVA NA EDUCAÇÃO PERIOPERATÓRIA DE CIRURGIA ORTOGNÁTICA: ENSAIO CLÍNICO RANDOMIZADO.

SÃO PAULO 
CRISTINA SILVA SOUSA

\title{
AVALIAÇÃO DO USO DE UMA TECNOLOGIA EDUCATIVA NA EDUCAÇÃO PERIOPERATÓRIA DE CIRURGIA ORTOGNÁTICA: ENSAIO CLÍNICO RANDOMIZADO.
}

\author{
Tese apresentada ao Programa de Pós-graduação em \\ Enfermagem na Saúde do Adulto (PROESA) da Escola de \\ Enfermagem da Universidade de São Paulo, para obtenção do \\ titulo de Doutor em Ciências. \\ Área de Concentração: Enfermagem na Saúde do Adulto \\ Orientadora: Prof. ${ }^{a}$ Dr ${ }^{a}$ Ruth Natalia Teresa Turrini
}

\section{SÃO PAULO}




\section{AUTORIZO A REPRODUÇÃO E DIVULGAÇÃO TOTAL OU PARCIAL DESTE TRABALHO, POR QUALQUER MEIO CONVENCIONAL OU ELETRÔNICO, PARA FINS DE ESTUDO E PESQUISA, DESDE QUE CITADA A FONTE.}

Assinatura:

Data:

\section{Catalogação na Publicação (CIP)}

Biblioteca "Wanda de Aguiar Horta"

\section{Escola de Enfermagem da Universidade de São Paulo}

Sousa, Cristina Silva

Avaliação do uso de uma tecnologia educativa na educação perioperatória de cirurgia ortognática: ensaio clínico randomizado / Cristina Silva Sousa. São Paulo, 2015.

$135 \mathrm{p}$.

Tese (Doutorado) - Escola de Enfermagem da Universidade de São Paulo.

Orientadora: Prof. ${ }^{\text {a }}$ Dr. ${ }^{\text {a }}$ Ruth Natalia Teresa Turrini

Área de concentração: Enfermagem na Saúde do Adulto

1. Ensaio clínico controlado randomizado. 2. Educação em saúde. 3. Educação do paciente. 4. Ansiedade. 5. Enfermagem perioperatória. I. Título. 
Sousa CS. Avaliação do uso de uma tecnologia educativa na educação perioperatória de cirurgia ortognática: ensaio clínico randomizado. [Tese]. São Paulo: Escola de Enfermagem, Universidade de São Paulo; 2015.

\section{ERRATA}

$\begin{array}{cccc}\text { Página } & \text { Linha } & \text { Onde se lê } & \text { Leia-se } \\ 19 & 7 & \text { vertical maxilar } & \text { vertical mandibular } \\ 39 & 13 & \text { sagital maxilar } & \text { sagital mandibular } \\ 58 & 21 & \text { grupo intervenção } & \text { os grupos } \\ 63 & 7 & \text { Apêndice VI } & \text { Apêndice V }\end{array}$


Nome: Cristina Silva Sousa

Titulo: Avaliação do uso de uma tecnologia educativa na educação perioperatória de cirurgia ortognática: ensaio clínico randomizado.

Tese apresentada ao Programa de Pós-graduação PROESA da Escola de Enfermagem da Universidade de São Paulo para obtenção do título de Doutora em Ciências.

Aprovado em:

\section{Banca Examinadora}

Prof. Dr. Instituição:

Julgamento: Assinatura:

Prof. Dr. Instituição:

Julgamento: Assinatura:

Prof. Dr. Instituição:

Julgamento: Assinatura:

Prof. Dr. Instituição:

Julgamento: Assinatura:

Prof. Dr. Instituição:

Julgamento: Assinatura: 


\section{DEDICATÓRIA}

Aos partadores de deformidade dentofacial, que buscam na cirurgia ortognática a resoluçãa da sua dor fésica $e$ emocional. Zue minha pesquisa venha auxiliar mais pacientes que corajosamente enfrentam as anos de tratamenta. 


\section{AGRADECIMENTOS}

A Profa. Dra. Ruth Natalia Teresa Turrini pela arientaçãa e compartilhamenta de seu conhecimento durante todos esses anos.

A Aline Uchoa e a Thaylis Esteves, que participaram do processa de coleta de dados.

Ao estatística Bernarda dos Santos, pela paciência e atençãa.

A todos aqueles que direta on indiretamente fizeram parte deste trabalho.

A BMF adontalogia pela permissãa de compartilhar seus pacientes e pelos anos de visita aa consultória.

As minhas amigas pela paciência e auxilio na conduçäa deste trabalho.

Aos pacientes que participaram desta pesquisa e me permitiram acompanhar sua trajetória. 
"Os educadores, antes de serem especialistas em ferramentas do saber, deveriam ser especialistas em amor: intérpretes de sonhos" 
Sousa CS. Avaliação do uso de uma tecnologia educativa na educação perioperatória de cirurgia ortognática: ensaio clínico randomizado. [Tese]. São Paulo: Escola de Enfermagem, Universidade de São Paulo; 2015.

\section{RESUMO}

Introdução: as tecnologias educativas podem ser aplicadas por meio de materiais educativos, folhetos, vídeos, jogos ou qualquer outra estratégia que tenha por objetivo auxiliar a compreensão e aumentar o conhecimento de pacientes sobre sua saúde ou tratamento. Objetivo: avaliar a eficácia de uma tecnologia educativa impressa na redução de sinais e sintomas perioperatórios em pacientes submetidos à cirurgia ortognática. Método: trata-se de um ensaio clínico randomizado controlado desenvolvido no período de janeiro de 2013 a agosto de 2015, dividido em duas fases: um estudo piloto sem randomização para teste da intervenção e instrumentos, com oito pacientes; e, em segundo momento, o estudo clínico com as alterações decorrentes do estudo piloto. A amostra randomizada por blocos foi constituída de quarenta pacientes (vinte experimental e vinte controle), com seguimento de 45 dias. No grupo experimental, foi realizada a orientação préoperatória pela enfermeira com auxílio da tecnologia educativa construída previamente para esse perfil de paciente e com orientação sobre os cuidados pós-operatórios (higiene oral, dieta, exercícios faciais, hidratação labial, exposição ao sol, abertura limitada da cavidade oral, controle da dor, repouso, banho e curativos), além da orientação habitual do cirurgião. O grupo controle recebeu somente as orientações rotineiras do cirurgião. Para a análise da intervenção, foram aplicados instrumentos para avaliar o conhecimento sobre os cuidados pós-operatórios, ansiedade pré e pós-procedimento pelo inventário de ansiedade IDATE traço e estado, sinais e sintomas do pós-operatório por instrumento de avaliação clínica. Na análise estatística, foi aplicado teste modelo de efeitos mistos para investigação dos dados do inventário de ansiedade traço-estado, teste de conhecimento e avaliação clínica, com exceção das medidas de peso corporal e dor para os quais foram utilizados GEE $(\alpha=5 \%)$. Resultados: em relação ao teste de conhecimento observou-se melhora significativa do conhecimento no grupo experimental $(\mathrm{p}=0,000)$, o Inventário de ansiedade IDATE estado não apresentou diferença estatística entre a evolução nos dois grupos ( $\mathrm{p}=0,818)$, e também no IDATE traço $(\mathrm{p}=0,906)$. Na avaliação dos sinais e sintomas por meio da análise clínica, não se observou diferença significativa entre a evolução dos grupos em todos os itens avaliados, mas notou-se no grupo experimental reduções mais expressivas entre o primeiro 
e segundo retorno em alguns sinais e sintomas do que no grupo controle. Esses pacientes também apresentaram menor dificuldade em realizar as refeições, iniciaram os exercícios faciais precocemente e utilizaram métodos de conforto para dormir e respirar melhor, itens correspondentes na orientação e na tecnologia educativa impressa aplicada. Conclusão: a estratégia de orientação e aplicação da tecnologia educativa para pacientes submetidos a cirurgia ortognática foi efetiva para o conhecimento dos pacientes sobre a cirurgia e o autocuidado. Observou-se melhora dos desfechos avaliados e sua implantação merece ser considerada para auxiliar o pós-operatório desses pacientes. NCT01803204.

Descritores: Ensaio clínico controlado randomizado; educação em saúde; prospecto para educação de pacientes; escala de ansiedade frente a teste; enfermagem perioperatória. 
Sousa CS. Evaluation of an educational technology in the perioperative education orthognathic surgery: a randomized clinical trial. [Thesis]. São Paulo (SP), Brasil: Escola de Enfermagem, Universidade de São Paulo; 2015.

\section{ABSTRACT}

Introduction: educational technologies can be applied through educational materials, brochures, videos, games or any other strategy which has the objective of assisting the understanding and raise awareness of patients about their health or treatment. Objective: To evaluate the efficacy of a printed educational technology in reducing signs and symptoms in perioperative patients undergoing orthognathic surgery. Method: this is a randomized controlled clinical trial carried out from January 2013 to August 2015, divided into two phases: A pilot study without randomization to test the intervention and instruments with eight patients, and the second time, the study clinical with the changes arising from the pilot study. A random sample of blocks consisted of 40 patients (20: experimental and 20: control), with follow-up of 45 days. In the experimental group the preoperative orientation was conducted by nurse with the help of educational technology previously built for this patient profile and guidance on post-operative care (oral hygiene, diet, facial exercises, lip hydration, sun exposure, aperture limited the oral cavity, pain control, rest, bathing and dressing), besides the usual surgeon orientation. The control group only received routine guidance of the surgeon. To evaluate the intervention were implemented instruments to assess knowledge about post-operative care, pre and the post-procedure Anxiety Inventory STAI trait and state anxiety, signs and symptoms postoperatively by clinical assessment tool. Statistical analysis: applied testing mixed-effects model for data analysis inventory of Statetrait anxiety, knowledge test and clinical evaluation, with the exception of body weight measurements and pain that were used GHG $(\alpha=5 \%)$. Results: in relation to knowledge we observed significant improvement of test knowledge in the experimental group $(\mathrm{p}=0.000)$, the state STAI Anxiety Inventory showed no statistical difference between the evolution in both groups $(\mathrm{p}=0.818)$, and also in trace IDATE $(\mathrm{p}=0.906)$. In the evaluation of the signs and symptoms through clinical evaluation there was no significant difference between the evolution of groups in all items, but was noted in the experimental group more decreases between the first and second return in signs and symptoms than in group control. These patients also had less difficulty in performing meals, facial exercises began early and comfort of methods used to sleep and breathe better by matching items in orientation and printed educational technology applied. Conclusion: the orientation of strategy proposed and 
application of educational technology for patients undergoing orthognathic surgery was effective in patients' knowledge about surgery and self-care. There was a significant improvement in outcomes, although without statistical significance and the use of educational technologies deserve to be considered to assist the postoperative these patients. NCT01803204.

Descriptors: Randomized controlled Trial; Health education; Patient education handout; Test anxiety scale; Perioperative nursing 


\section{LISTA DE ILUSTRAÇÕES}

Figura 1 - Discrepâncias maxilomandibulares (retrognatismo, ausência de simetria facial, prognatismo e mordida aberta).

Figura 2 - Fluxograma do seguimento proposto neste estudo. São Paulo, 2013.

Figura 3 - Mapa da distribuição dos itens de acordo com o grau de dificuldade e das pessoas de acordo com a habilidade. São Paulo, 2013.

Figura 4 - Diagrama Consort. São Paulo, 2015

Figura 5 - Evolução dos grupos na mensuração de conhecimento sobre o procedimento cirúrgico. São Paulo, 2015.

Figura 6 - Porcentagem de acertos por questão do pré e pós-teste de conhecimento do grupo experimental nos momentos propostos. São Paulo, 2015.

Figura 7 - Porcentagem de acertos por questão do pré e pós-teste de conhecimento do grupo controle nos momentos propostos. São Paulo, 2015.

Figura 8 - Evolução dos grupos quanto à dificuldade em fazer as refeições. São Paulo, 2015.

Figura 9 - Evolução dos grupos quanto a orientação de execução do exercício facial. São Paulo, 2015. 82

Figura 10 - Evolução dos pacientes quanto ao uso de métodos para melhora do padrão de sono e respiratório. São Paulo, 2015. 


\section{LISTA DE TABELAS}

Tabela 1 - Valores médios e desvio padrão do inventário de ansiedade traço-estado (IDATE) em três momentos. São Paulo, 2013 46

Tabela 2 - Dados da avaliação clínica $(n=8)$ nos momentos de pós-operatório. São Paulo, 2013.

Tabela 3 - Dados do pré e pós-teste de conhecimento (n=8). São Paulo, 2013 ........... 50

Tabela 4 - Resultados da análise de Rasch para os itens. São Paulo, 2013.

Tabela 5 - Resultados da análise de Rasch para as pessoas (respondentes). São Paulo, 2013.

Tabela 6 - Pacientes do ensaio clínico quanto a técnica cirúrgica. São Paulo, 2015.. 61

Tabela 7 - Resultados do pré e pós-teste de conhecimento nos momentos propostos, segundo grupo. São Paulo. 2015.

Tabela 8 - Respostas corretas por questão para os grupos experimental e controle no pré-operatório. São Paulo, 2015.

Tabela 9 - Resultados da análise do inventário de ansiedade IDATE. São Paulo, 2015.

Tabela 10 - Resultados dos itens de avaliação clínica $(n=40)$ a cada retorno segundo o grupo de estudo. São Paulo. 2015. 72

Tabela 11 - Questões realizadas nos momentos de retorno pós-operatório. São Paulo, 2015. 


\section{SUMÁRIO}

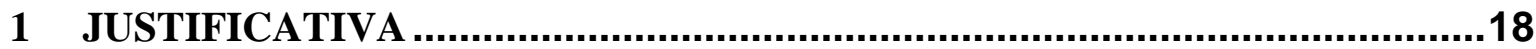

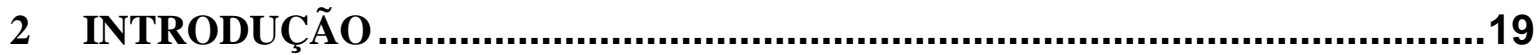

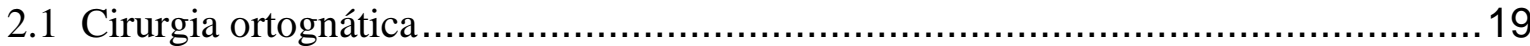

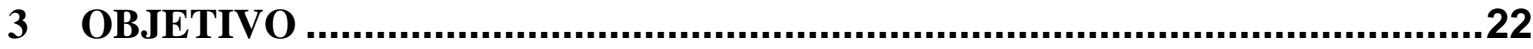

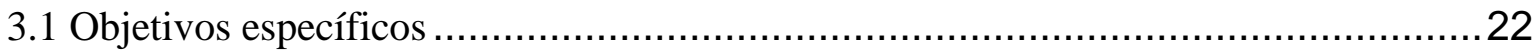

4 HIPÓTESE .............................................................................................23

5 FUNDAMENTAÇÃO TEÓRICA .............................................................24

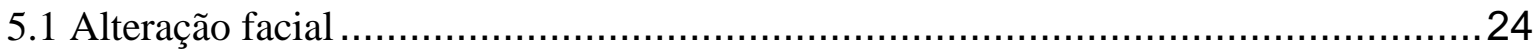

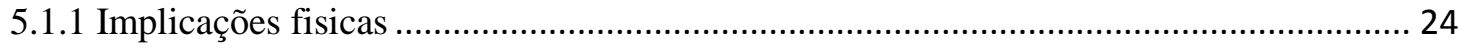

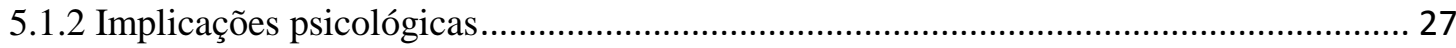

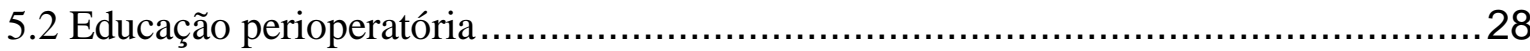

5.2.1 Aplicação de materiais educativos ............................................................................... 29

5.2.2 Cirurgia ortognática para pacientes - tecnologia educativa para essa intervenção......... 33

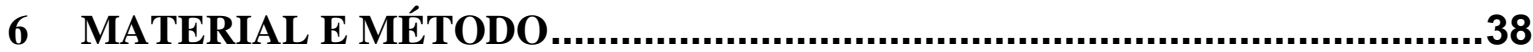

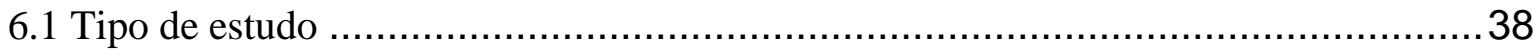

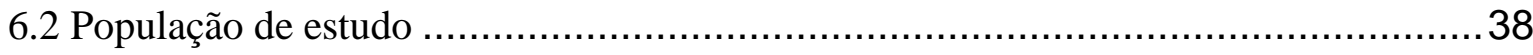

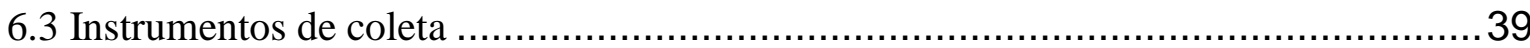

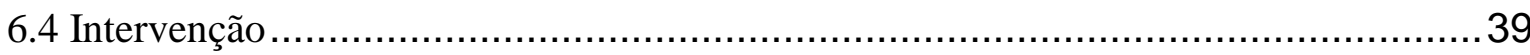

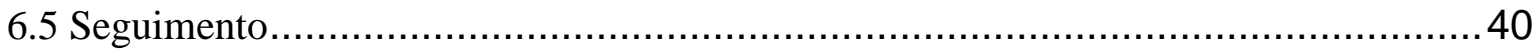

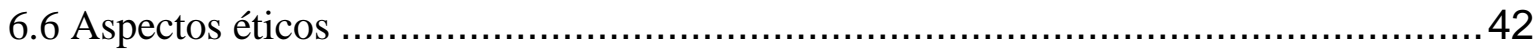

7 PRIMEIRA FASE - ESTUDO PILOTO ...................................................... 43

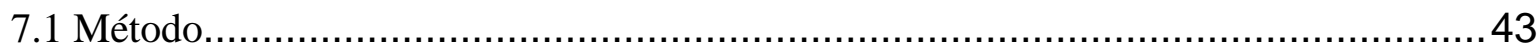

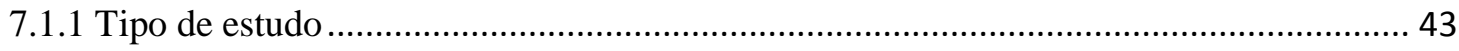

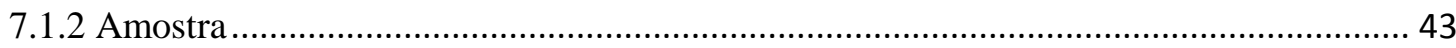

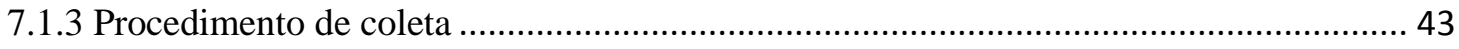

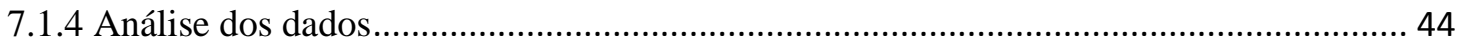




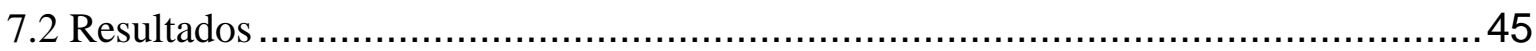

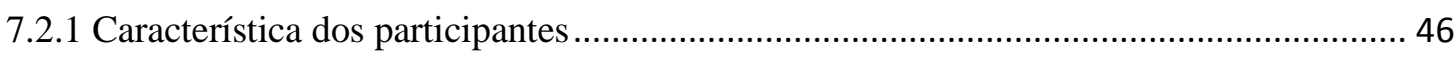

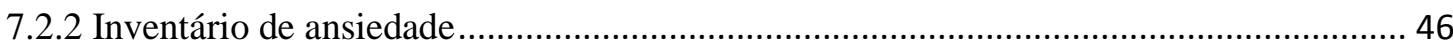

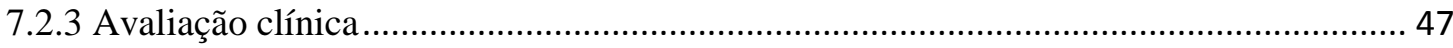

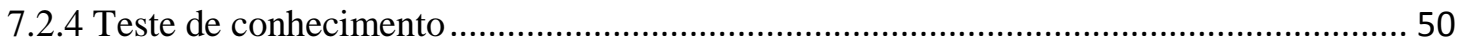

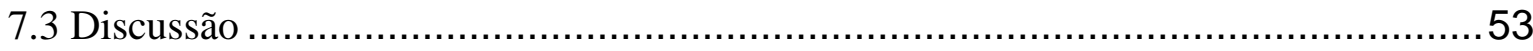

8 SEGUNDA FASE - ENSAIO CLÍNICO RANDOMIZADO .............................55

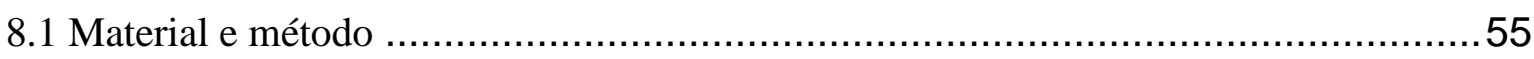

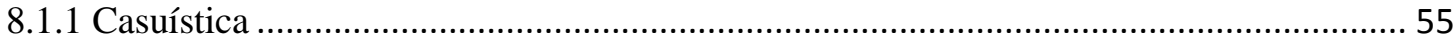

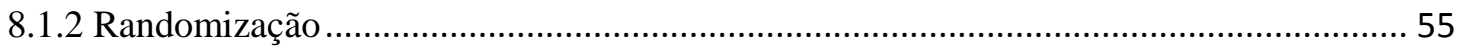

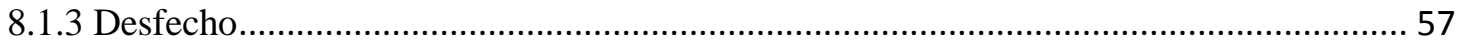

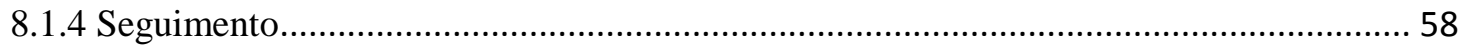

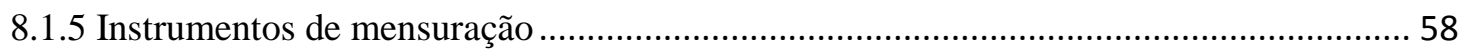

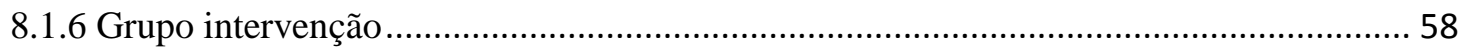

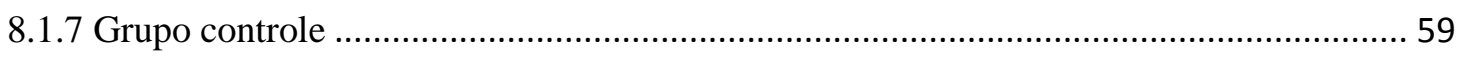

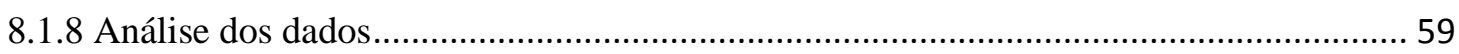

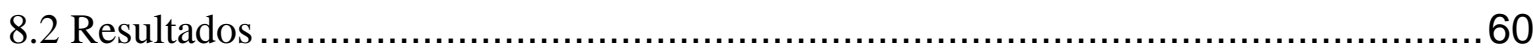

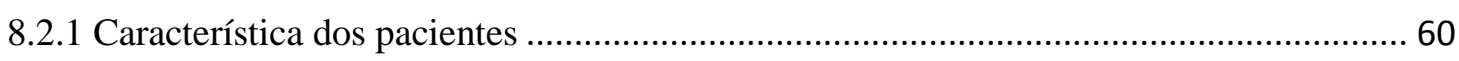

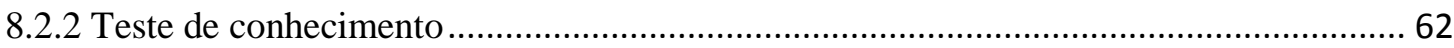

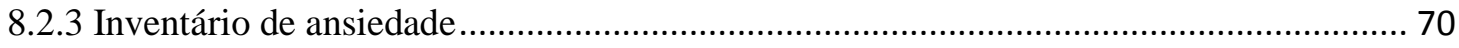

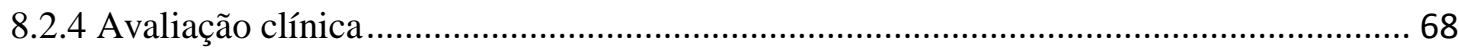

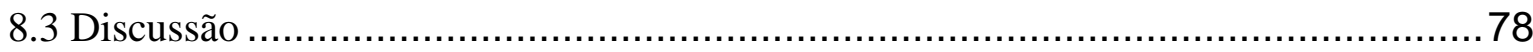

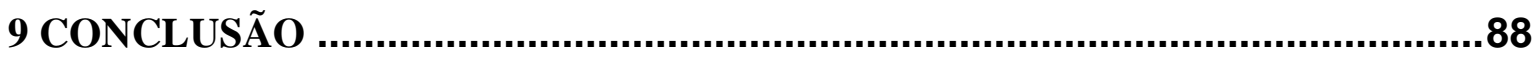

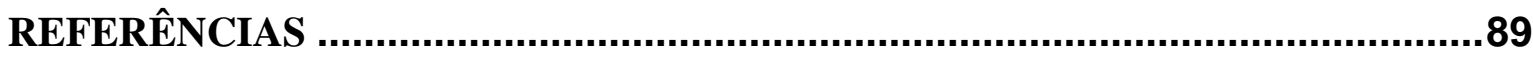

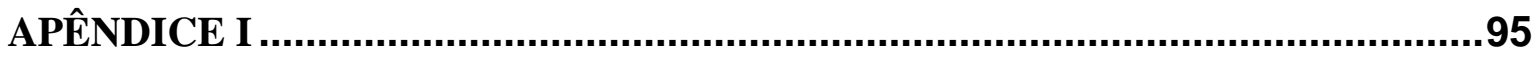

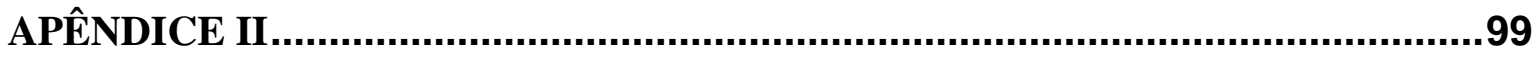

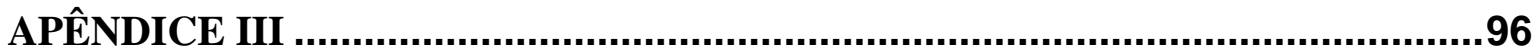

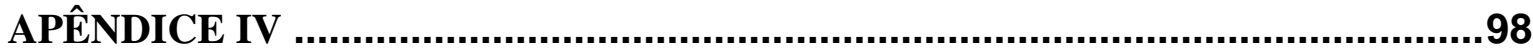

APÊNDICE V ......................................................................................... 105

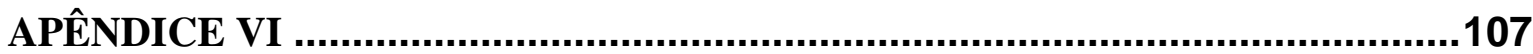


ANEXO I

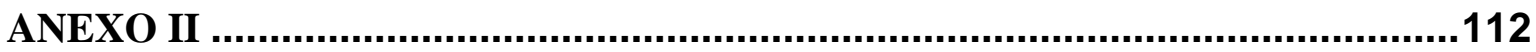




\section{JUSTIFICATIVA}

Tecnologias educativas são instrumentos facilitadores do processo de ensino e aprendizagem utilizados como meio de transferência de conhecimento, para propiciar ao indivíduo a participação na troca de experiências conducente ao aprimoramento de habilidades $^{1}$. Na saúde, a aplicação dessas tecnologias assistenciais com adjunto da orientação verbal tem demonstrado melhores resultados na compreensão da saúde ou do tratamento por parte do paciente.

Este estudo visa a aplicação de uma tecnologia educativa (material impresso) sobre cuidados pós-operatórios para cirurgia ortognática construído durante o curso de pósgraduação stricto sensu com a dissertação intitulada "Educação pós-operatória: construção e validação de uma tecnologia educativa para pacientes submetidos a cirurgia ortognática ${ }^{2}$. No presente estudo, essa tecnologia assistencial aplicada no período perioperatório para um grupo experimental foi comparada a um grupo controle quanto a eficácia na redução de sinais e sintomas perioperatórios em pacientes submetidos à cirurgia ortognática.

O fator motivacional para a realização deste estudo é decorrente da minha experiência profissional como enfermeira de centro cirúrgico e a pouca informação do paciente a respeito do perioperatório da cirurgia ortognática. Pressupõe-se que essa intervenção pode melhorar o conhecimento e o manejo dos sinais e sintomas do pósoperatório e prover uma recuperação mais rápida e eficaz, assim como reduzir os níveis de ansiedade e minimizar as possíveis complicações decorrentes de cirurgia.

Este estudo poderá auxiliar na ampliação do campo de atuação da enfermagem em educação em saúde e uso de tecnologias assistenciais como recurso para orientação perioperatória. 


\section{INTRODUÇÃ O}

\subsection{CIRURGIA ORTOGNÁTICA}

O termo ortognática é originado do termo Grego ortho e significa "em linha reta, normal, de forma adequada"; gnatho refere-se a mandíbula. Assim, a cirurgia ortognática é um procedimento cirúrgico para corrigir a maxila e a mandíbula. Essa deformidade dos maxilares e terço médio da face é resultante de um desalinhamento dentofacial e leva os pacientes a uma dificuldade funcional e estética que pode ser corrigida por meio da combinação de ortodontia e cirurgia ortognática ${ }^{3}$ (Figura 1).
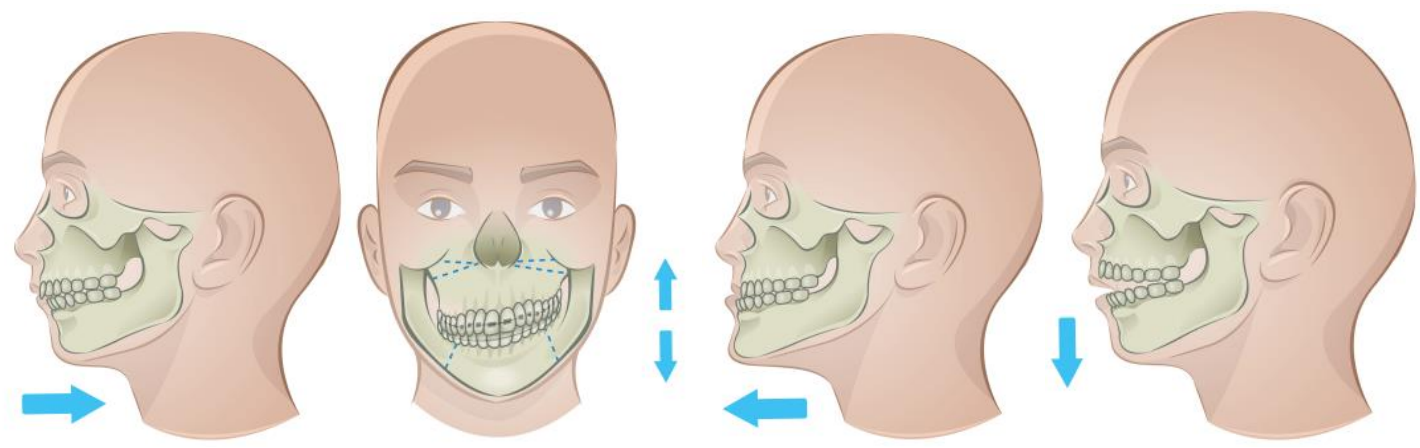

Figura 1 - Discrepâncias maxilomandibulares (retrognatismo, ausência de simetria facial, prognatismo e mordida aberta).

Fonte: Sousa CS. Educação pós-operatória: construção e validação de uma tecnologia educativa para pacientes submetidos a cirurgia ortognática. [dissertação]. São Paulo: Escola de Enfermagem da Universidade de São Paulo; 2011.

Anatomicamente, para melhor função e estética, os dentes superiores devem encaixar precisamente com os dentes inferiores. Se por alguma disfunção de crescimento, trauma ou resultados de hábitos funcionais o encaixe de maxila e mandíbula não forem proporcionais, o paciente desenvolverá a má oclusão, o que afeta a mastigação, a função articular, a permeabilidade de vias aéreas e a estética facial. Discrepâncias e crescimento ósseo podem causar a mordida aberta e apenas o tratamento ortodôntico não é suficiente para correção, com indicação de intervenção cirúrgica ${ }^{3}$. E por esse motivo, o tratamento da deformidade dentofacial requer o tratamento ortodôntico pré e pós-cirurgia e a integração do ortodontista e do cirurgião para realização do planejamento cirúrgico. 
A cirurgia ortognática compreende diferentes técnicas cirúrgicas, que também podem estar combinadas entre si: osteotomia bilateral do ramo sagital maxilar, osteotomia do ramo vertical maxilar, osteotomia Lefort I, osteotomia combinada, com aplicação ou não de mentoplastia e osteotomia segmentar da maxila (disjunção maxilar) ${ }^{4}$.

O procedimento cirúrgico ocasiona a alteração funcional da mastigação, da deglutição, da fala e da respiração, e também a alteração estética da face ${ }^{5}$. Pacientes que completaram o processo de procedimento cirúrgico ortodôntico relatam uma variedade de benefícios psicológicos, como melhora na autoconfiança, autoestima e atratividade facial. Essa melhoria estética funcional contribui com o relacionamento interpessoal ${ }^{6}$.

Entre as possíveis complicações cirúrgicas são descritas: lesão de nervos, infecção, problemas com material de fixação, disfunção temporomandibular, fratura indevida, alteração na cicatrização, hemorragia, osteotomia, dor exacerbada, absorção condilar, laceração de tecido mole, mordida aberta, recidiva cirúrgica, lesão dentária, desvio de septo nasal e má oclusão ${ }^{7}$.

Se como resultado funcional a cirurgia ortognática promove uma harmonia estéticaocluso facial, estudos têm demonstrado mudanças positivas nas relações interpessoais, na autoestima, no bem-estar psicológico, no autoconceito, com maior integração social, estabilidade social, redução de ansiedade e mudanças na qualidade de $\operatorname{vida}^{5,8}$.

Durante o pós-operatório, a avaliação do paciente deve considerar a evolução funcional das estruturas bucais devido a edema, abertura limitada da mordida, possíveis prejuízos neurais, avaliação da sensibilidade, motricidade, controle da dor, detecção precoce das complicações e manejo dos sintomas relacionados ao pós-operatório ${ }^{3,8,9}$.

A osteossíntese é realizada por meio de fixação interna rígida com titânio, com miniplacas e miniparafusos, que, por sua vez, demanda precisão nos movimentos, pois o mal posicionamento dos fragmentos ósseos ou dos côndilos mandibulares dificilmente pode ser compensado por manipulação da oclusão dentária com elásticos ${ }^{10}$. Por isso, é comum o uso de elásticos ortodônticos no pós-operatório para contenção oral, controle da mordida e compensação do edema pós-operatório ${ }^{3}$.

O acompanhamento do pós-operatório costuma ocorrer por cerca de dois meses, com a liberação do cirurgião há o encaminhamento para o ortodontista para iniciar o refinamento ortodôntico, e por fim concluir o processo de reestabelecimento da função maxilar. A 
aplicação da ortodontia pós-operatória tem por objetivo aperfeiçoar a estética oral e requer consentimento do ortodontista e cirurgião bucomaxilofacial para trabalharem em conjunto com as expectativas do paciente após o tratamento ${ }^{6}$. 


\section{OBJETIVO}

Avaliar a eficácia de uma tecnologia educativa na redução de sinais e sintomas perioperatórios em pacientes submetidos à cirurgia ortognática.

\subsection{OBJETIVOS ESPECÍFICOS}

- Avaliar o conhecimento do paciente sobre o procedimento ortognático antes e após a intervenção

- Avaliar os níveis de ansiedade com inventário de Ansiedade Traço-Estado antes e após a intervenção

- Avaliar clinicamente o autocuidado no manejo de sinais e sintomas pósoperatórios.

- Comparar o grupo experimental e controle quanto ao autocuidado no manejo de sinais e sintomas pós-operatórios. 


\section{HIPÓTESE}

O uso da tecnologia educativa contribuirá para a diminuição da ansiedade, melhor manejo dos sinais e sintomas e maior conhecimento sobre o pós-operatório da cirurgia ortognática. 


\section{FUNDAMENTAÇÃO TEÓRICA}

\subsection{ALTERAÇÃO FACIAL}

Alterações faciais podem melhorar a atratividade física do ser humano e afetar não somente a autoestima como o valor social para o outro. Uma das motivações do paciente com deformidade dentofacial para realizar a cirurgia é a alteração na atratividade $^{11}$.

O estereótipo "o que é bonito é bom" dá à questão da atratividade a inferência de qualificar como melhor, pois pessoas consideradas atraentes passam a impressão de serem mais felizes e com melhor vida profissional do que pessoas consideradas menos atraentes ${ }^{12}$. No caso da deformidade dentofacial, pacientes que requerem a cirurgia ortognática são passíveis de exclusão pela sociedade, pois não apresentam simetria facial e aparentam ser menos atrativos. Ainda, eles podem recorrer a estratégias de ocultamento e, em casos extremos, manifestar fobia social traduzida em sentimentos de medo e insegurança emocional nas relações interpessoais ${ }^{8}$.

Entretanto, esse perfil de paciente também apresenta alterações funcionais que impactam em sua rotina diária. Dessa forma, os aspectos físicos e psicológicos desses pacientes são discutidos a seguir, apresentando as dificuldades vivenciadas pelos pacientes.

\subsubsection{Implicações físicas}

No pós-operatório imediato, o paciente se depara com a nova realidade de sua face; apesar da sensação de torpor causada pela anestesia geral, é possível sentir o edema facial, o desconforto na cavidade oral relacionado a manipulação dessas estruturas, a parestesia no terço inferior da face e a limitação da abertura da boca.

$\mathrm{Um}_{\text {estudo }}^{3}$ realizado no Colorado comenta que os primeiros sinais e sintomas que o paciente apresenta nas duas primeiras semanas de pós-operatório são edema e hematomas iniciados após a cirurgia e com regressão gradativa. Muitos pacientes referem cansaço devido a anestesia geral, perda sanguínea e perda calórica (impossibilidade de se alimentar corretamente); a perda sanguínea não ultrapassa 500 ml, mas associada ao estresse cirúrgico 
leva o paciente a sentir fadiga. A dor é pouco referida, mas é significante. Na verdade, os pacientes referem sensação de peso e desconforto.

Estudo $^{13}$ qualitativo com uso da teoria fundamentada dos dados abordou jovens submetidos a cirurgia ortognática na Dinamarca para explorar as percepções subjetivas e valores desses pacientes em relação a sua deformidade dentofacial. A categoria central observada foi a satisfação dos pacientes com o resultado do procedimento, apesar de experiências difíceis que vivenciaram no perioperatório. Em associação a categoria central, seis outras categorias emergiram: experiências compartilhadas por aqueles que já tenham sido submetidos ao procedimento, choque da família e dos amigos próximos no hospital, dificuldade para se alimentar, dor causada pelo tratamento ortodôntico, medo causado pelo edema e por complicações, sorriso e autoconfiança.

Esses achados são semelhantes ao estudo sobre as necessidades de pacientes que usam a busca na internet como fonte de informação e apresentou como resultados dúvidas relacionadas a recuperação, parestesia, custos, edema, medo e resultado final da cirugia ${ }^{14}$.

Em uma avaliação do impacto da cirurgia ortognática com pacientes do Reino Unido, foram evidenciados como efeitos físicos da cirurgia náuseas, dor, edema, hematomas e dificuldades para comer, falar e deglutir ${ }^{15}$.

O edema foi tema de uma investigação em Boston, com análise de 49 pacientes submetidos à Lefort I e Osteotomia Ramo Sagital Bilateral quanto à evolução do edema pósoperatório por meio de radiografias sequenciais em 3D. Observou-se, no acompanhamento, redução de 50\% do edema após três semanas e, após três meses, $20 \%$ dos pacientes ainda persistiam com edema, havendo redução em até um ano de pós-operatório ${ }^{16}$.

Nas situações cirúrgicas de bloqueio maxilomandibular, por ocasião dos ajustes realizados no consultório juntamente com os elásticos do aparelho ortodôntico, o paciente vivencia um desconforto na função da mastigação e da fala. Em um estudo ${ }^{11}$ brasileiro para avaliar o grau de satisfação dos pacientes submetidos a cirurgia ortognática no quesito mastigação, os autores perceberam durante o pós-operatório que os pacientes referiram bastante dificuldade em sua função oral devido ao uso de fixação intermaxilar com elásticos.

Investigação ${ }^{9}$ realizada no Brasil com o objetivo de identificar as necessidades de informação do paciente sobre o período pós-operatório da cirurgia ortognática, por meio de 
um grupo focal, relata que dentre as dificuldades vivenciadas pelo paciente no pós-operatório estão a parestesia, abertura de boca, edema, higiene oral e alimentação, como as mais abordadas.

No estudo ${ }^{17}$ do Reino Unido, com abordagem qualitativa e uso de entrevista semiestruturada com dezoito pacientes, o relato de alteração na função da mastigação, na dentição e no sorriso foram alguns dos aspectos físicos percebidos pelo paciente no pósoperatório.

O relato da dor no pós-operatório difere entre os estudos. Um estudo ${ }^{18}$ de coorte realizado no Brasil avaliou 52 pacientes quanto a dor pós-operatória na cirurgia ortognática. Em seus resultados, 27,6\% dos pacientes relataram dor pós-operatória, destes, 62,5\% eram do sexo masculino, mas não houve diferença estatística significativa entre os sexos.

Em Taiwan, uma investigação ${ }^{19}$ sobre a avaliação visual analógica da dor pósoperatória nos pacientes submetidos à Osteotomia Ramo Vertical e outro grupo submetido à Osteotomia Ramo Vertical combinado com Mentoplastia mostrou que os Paciente relatam dor considerada aceitável e controlada. Não houve diferença estatística entre os grupos quanto a técnica cirúrgica utilizada.

Na Coreia, um estudo ${ }^{20}$ com 47 pacientes submetidos a Osteotomia do Ramo Sagital Bilateral e Lefort I, ambas combinadas ou não com mentoplastia, avaliou a recuperação natural de lesão neurológica após procedimento com base na avaliação subjetiva. Os autores concluíram que a alteração sensorial é uma complicação inevitável e pode se resolver espontaneamente com o tempo, e, apesar dessa alteração ser mais frequente em pacientes submetidos a procedimento combinado com a mentoplastia, a diferença não foi estatisticamente significativa.

Nota-se que as alterações físicas para esse paciente são semelhantes em diferentes culturas e, após a cirurgia, o paciente precisa se reajustar para respirar, comer, falar e conviver com a dificuldade de abertura de boca, limitada e temporária, presente nas próximas semanas. Dessa forma, é recomendável que, durante esse período, o paciente seja encorajado a manter-se ativo, retornar ao trabalho e manter um estilo de vida normal, apesar do desconforto, da parestesia e da presença de edema facial ${ }^{3}$. 
5.1.2 Implicações psicológicas

O tratamento ortodôntico associado à cirurgia ortognática, além de proporcionar melhora na estética facial nas funções mastigatórias e fonéticas, e redução de dores articulares e miofaciais, pode promover o bem-estar psíquico desses pacientes.

Quando a estética facial se constitui como o principal motivo do tratamento, este pode estar relacionado com as necessidades afetivas do paciente (sentir-se valorizado, atrativo, entre outros). Assim, o desejo de melhorar a aparência é acompanhado por expectativas de benefícios psicológicos. Porém é preciso reconhecer que, embora as expectativas positivas sejam uma componente importante na motivação do paciente, não preparam para lidar com as circunstâncias imediatas do pós-operatório ${ }^{8}$.

Nessa perspectiva, um estudo ${ }^{21}$ do Reino Unido concluiu que pacientes com indicação da cirurgia ortognática são menos felizes com seu sorriso e sua aparência facial do que indivíduos com aparência simétrica. Outro resultado semelhante foi visto em um estudo qualitativo em que os pacientes tinham a expectativa de serem mais felizes, sentirem-se mais confiantes e relaxados por não terem de se preocupar com o defeito facial ${ }^{17}$.

A atratividade não é o único sentimento modificado com o procedimento cirúrgico. Um estudo qualitativo do Reino Unido identificou os impactos psicológicos da alteração da face nos pacientes submetidos à ortognática e os autores obtiveram relatos sobre alteração na autoconfiança, na autoestima, na pressão externa sobre a aparência, no ajuste social, na confiança social e no suporte familiar ${ }^{15}$.

Os pacientes com grave deformidade dentofacial apresentam uma prevalência maior de instabilidade emocional, introversão, ansiedade e insociabilidade, o que os torna reservados, inseguros, com baixa autoconfiança e autoestima. Isso leva a capacidade reduzida de adaptação à vida social, levando-os a evitar comportamentos de liderança e contatos sociais. Tais perfis psicológicos podem desencadear depressão e reações psicológicas adversas que trazem complicações no tratamento ortognático ${ }^{22}$

A ansiedade é um sentimento que pode estimular ou impedir o estado de ação e, quando paralisam o ser humano, este deixa de fazer coisas simples da rotina diária por causa do desconforto que sente. Esse estado de ansiedade desencadeia reações emocionais transitórias que levam a alteração da frequência cardíaca, do padrão respiratório e da pressão 
arterial, além de inquietação, nervosismo, tremores e aumento de sudorese ${ }^{23}$.

Indivíduos que se percebem pouco atraentes têm exibido maiores níveis de ansiedade e esses níveis alterados podem repercutir negativamente na interação social, na autoestima e podem tornar o indivíduo introvertido e solitário ${ }^{24}$.

A alteração de humor é outro fator observado nesses pacientes. A maioria deles demonstra depressão e irritabilidade após a cirurgia, devidas a presença de edema, hematomas, dor, dificuldade de se alimentar e inconveniência de manipular os elásticos do aparelho ortodôntico. Esses sentimentos são comumente referidos nos terceiro e quarto dias de pós-operatório; após o sétimo dia de pós-operatório, quando os pacientes começam a comer e manipular os elásticos com facilidade, esses sentimentos começam a melhorar ${ }^{3}$.

A perturbação dismórfica corporal é característica de pacientes com excessiva preocupação com a aparência. Em estudo ${ }^{25}$ norte-americano, a presença desse distúrbio e sua relação com ansiedade, depressão e transtorno obsessivo compulsivo foi avaliada em 99 pacientes do ambulatório de cirurgia ortognática e obteve como resultado treze pacientes com triagem positiva para perturbação dismórfica corporal; os sintomas de depressão, transtorno obsessivo compulsivo e ansiedade foram relatados pelos pacientes.

Baseado na premissa das alterações do bem-estar psíquico, toda a carga emocional que acompanha o paciente na situação de cirurgia deve ser considerada no pré e no pósoperatório, pois em caso de alteração psíquica previa é recomendado o acompanhamento psicológico ou psiquiátrico durante o período de tratamento ${ }^{8}$.

A autoconfiança e a plenitude desses estados emocionais podem trazer segurança para enfrentar o longo tratamento da cirurgia e auxiliar no período de recuperação pósoperatória. Alcançar esses resultados depende de cada indivíduo, mas o profissional de saúde pode auxiliar o paciente com a educação em saúde.

\subsection{EDUCAÇÃO PERIOPERATÓRIA}

A educação em saúde surgiu em 1909 nos Estados Unidos da América (EUA) como uma estratégia para prevenção de doenças; assim, responsabilizava os indivíduos pelos seus problemas de saúde, apenas transmitindo o conhecimento. Até o início dos anos 1980, a educação em saúde era utilizada para eliminar ou diminuir a ignorância da população sobre 
a causa biológica das doenças ${ }^{26}$. No decorrer dos anos 1980, há uma mudança desse conceito e a educação em saúde ganha status de prática social, que consiste em visão cultural de valores, crenças e concepções de mundo, comprometida com a promoção da saúde ${ }^{26}$.

Nesse contexto, o profissional de saúde se torna um ator político-social que, por meio da educação em saúde dialogada, respeita e potencializa a autonomia do paciente na luta por melhores condições de saúde, inclusive no pré-operatório. Essa construção ocorre com o diálogo entre profissional e paciente, diálogo esse orientado a partir dos temas propostos pelo próprio paciente ${ }^{27}$.

A atividade educativa do enfermeiro cirúrgico tem a sua origem no século XIX e abrange o período perioperatório. Ao desenvolver suas condutas, o enfermeiro utiliza a comunicação e a interação com pacientes para orientar e informar, considerando as particularidades de cada ser humano. Assim, esse profissional conduz um cuidado especifico de acordo com as necessidades individuais e expectativas do paciente cirúrgico ${ }^{28}$.

A educação pré-operatória é uma intervenção provida pela equipe de saúde para o procedimento cirúrgico e para o impacto no pós-operatório até cerca de seis meses da cirurgia. Pode ser acompanhado do uso de tecnologias educativas para auxiliar na orientação e acarretar redução na estadia hospitalar, no medo, na ansiedade, na insegurança, na dor, e aumentar a satisfação do paciente ${ }^{29}$.

Os objetivos da educação pré-operatória são garantir que o indivíduo tenha conhecimento dos cuidados pós-operatórios após a alta hospitalar, promover apoio emocional, inserir o paciente e a família no processo de recuperação ${ }^{30}$ e fazê-los compreender as condições de saúde, a cirurgia e a recuperação, prevenindo complicações pós-operatórias e reduzindo custos de hospitalização pela antecipação da alta hospitalar ${ }^{31}$.

A educação proporciona ao paciente o conhecimento sobre sua saúde, o que resulta em satisfação, diminuição de riscos e possíveis complicações. Entretanto, avaliar as condições de aprendizagem do paciente deve ser parte de uma das atividades do profissional em enfermagem de perioperatório, pois as necessidades dos pacientes relacionadas ao aprendizado sobre sua saúde são diferentes e nem todos precisam ou querem saber tudo.

Uma revisão integrativa sobre o trabalho do profissional em enfermagem na educação de pacientes encontrou estudos que revelaram ausência de consideração da 
educação do paciente como parte da rotina diária dessa equipe. Há uma dificuldade de entender o processo educativo e, apesar do entusiasmo para educar, falta conhecimento para $\operatorname{tanto}^{32}$.

Na Turquia, um estudo para determinar as práticas educativas da enfermeira na clínica hospitalar obteve como resultado que $83 \%$ das enfermeiras não têm um plano e um tempo definido para educação do paciente; $98 \%$ não fazem registro dessa atividade; e $83 \%$ não incluem o paciente e família na educação. Ao achados mostram que essas profissionais não implantam adequadamente o processo de educação do paciente ${ }^{33}$.

No Irã, um estudo sobre as barreiras e os facilitadores para educação do paciente com enfermeiros e estudantes de enfermagem observou que $87,3 \%$ dos enfermeiros realizam a educação do paciente e, entre as barreiras, foram mencionados a pesada carga de trabalho, o tempo inadequado e a falta de instalações educacionais ${ }^{34}$.

Estudos e educadores enfatizam que a melhor forma de ensinar indivíduos adultos é o uso de tecnologias educacionais complementares como reforço das informações verbais, pois as pessoas retêm $20 \%$ do que ouvem, $30 \%$ do que veem, $50 \%$ do que ouvem e veem, $70 \%$ do que ouvem, veem e dizem e $90 \%$ do que ouvem, veem, dizem e fazem ${ }^{35}$.

Na era da sociedade tecnológica, entender a amplitude e a implicação da educação do paciente atrelada ao uso de tecnologias assistenciais - como dispositivos para medicação de processos de cuidar - aplicadas por profissionais com os usuários dos sistemas de saúde facilita a fundamentação do enfermeiro para exercer o papel de educador ${ }^{36}$.

Diferentes estratégias são aplicadas como recursos para auxiliar a desenvolver a educação do paciente. Em um estudo de revisão sobre as tecnologias aplicadas na educação do paciente, os autores relataram que a transmissão de informação é essencial para minimizar dúvidas ou modificar o comportamento de risco ${ }^{36}$. Assim, o objetivo dos materiais educativos deve ser facilitar o trabalho da equipe de saúde na comunicação e na orientação dos pacientes e familiares, na busca do aprendizado do educando.

A cartilha ou softwares são os produtos mais aplicados pela enfermagem para a educação. Cartilha é um material educativo impresso que auxilia o paciente com informações sobre saúde, satisfação e adesão ao tratamento, e desenvolve a capacidade de autonomia nos cuidados de saúde ${ }^{37}$. Sites, softwares e vídeos são ferramentas que possibilitam a aquisição 
de saberes pela interação, além de estimular a reflexão e o aprendizado ${ }^{38}$. Assim, a escolha da estratégia e sua aplicação devem ser adaptadas às necessidades do paciente, o que aumenta a chance de modificar crenças e comportamentos errôneos, bem como de acrescentar novas concepções e ideias.

\subsubsection{Aplicação de materiais educativos}

Os materiais educativos possuem algumas vantagens: para o leitor é possível controlar a velocidade de ler e compreender a informação; marcar o material impresso nos pontos que possui dúvidas ou que requerem atenção, manter este como referência e consulta a qualquer momento; para os profissionais de saúde, são um método auxiliar nas orientações verbais; e para as instituições de saúde, um meio para informar sobre os serviços disponíveis ${ }^{39}$.

Uma investigação do Brasil com objetivo de avaliar o conhecimento de mulheres mastectomizadas sobre o câncer de mama aplicou um material educativo específico para esse perfil de pacientes e mensurou o conhecimento por meio de pré e pós-teste. Os resultados mostram um aumento de $11 \%$ no conhecimento das mulheres após a leitura do material apresentado ${ }^{40}$.

No Texas, um estudo randomizado aplicou um livreto para pacientes com intuito de auxiliar na decisão cirúrgica, optando por três grupos (livreto e tempo de intervenção de vinte minutos com 69 pacientes; livreto, intervenção de 45 minutos e DVD com setenta pacientes; e DVD, orientação profissional e intervenção de sessenta minutos com 69 pacientes). Notou-se que a decisão no pré-operatório para os três grupos não teve diferença significativa, mas um conceito melhor sobre a decisão pelo tratamento cirúrgico no pósoperatório para os grupos DVD e livreto e DVD e acompanhamento profissional ${ }^{41}$.

Outro estudo randomizado da China sobre intervenção no pré-operatório para redução de ansiedade e promoção da recuperação, aplicado a 135 pacientes (76 intervenção e 77 controle), propôs a intervenção com livreto dois a três dias antes da cirurgia, com dez a quinze minutos de intervenção, e mensurou resultados com sete dias de pós-operatório; os níveis de ansiedade e depressão foram medidos com a escala de ansiedade e depressão hospitalar (HADS) e dor com inventário breve de dor. Notou-se menores níveis de ansiedade 
e depressão nos pacientes submetidos a intervenção, mas não houve diferença nos escores de dor entre os grupos ${ }^{42}$.

Em Israel, um estudo randomizado multicêntrico sobre o efeito da educação préoperatória para pacientes de revascularização do miocárdio com 504 pacientes de intervenção e 520 controle mediu a qualidade de vida, por meio do instrumento MacNew Heart Disease Health-related Quality of Life Questionnaire, escala de ansiedade e depressão hospitalar (HADS), exames laboratoriais e informações médicas. Para os pacientes de intervenção, a orientação levou dez minutos em consulta individual com entrega do livreto; novas medidas foram feitas de duas a três semanas de pós-operatório por telefone. Concluiuse que pacientes submetidos a intervenção obtiveram melhores níveis no instrumento que avaliou a qualidade de vida ${ }^{43}$.

Na Turquia, um estudo quase experimental para comparar a eficácia de informação escrita versus informação verbal e escrita para pacientes com doença reumatologica que recebem tratamento com a Cochinchina mensurou o conhecimento com pré e pós-teste em dois grupos, um que recebe informação escrita e outro que recebe a informação escrita e orientação verbal. Observou-se um aumento significativo nos níveis de conhecimento dos pacientes, sem diferença estatística significativa entre os grupos ${ }^{44}$.

Uma revisão sistemática de 1986 a 2007 sobre a educação pós-operatória encontrou 58 estudos que atendiam ao critério de inclusão (pacientes adultos, submetidos a cirurgia, com intervenção voltada ao autocuidado e resultados que mensurassem experiência, autocuidado e aprendizagem). Desses, 43 estudos utilizaram a técnica de educação usual, ou seja, a equipe de enfermagem fornece todas as informações necessárias; treze usaram a técnica de orientação individualizada, em que o paciente informa o que deseja saber e é orientado conforme sua necessidade; e dois utilizaram a forma combinada, que mistura a usual com a individualizada. Nesses achados, 27 estudos usaram o material educativo de apoio e concluíram que a educação pós-operatória foi benéfica para o autocuidado e para diminuir os sintomas do pós-operatório ${ }^{31}$.

Na Austrália, um ensaio clínico randomizado e controlado sobre uma estratégia educativa para pacientes com acidente vascular cerebral e seus familiares teve por objetivo avaliar a eficácia do aprendizado por meio de tecnologias assistências. O grupo controle recebeu as orientações verbais rotineiras de vários membros da equipe de saúde e o grupo 
experimental, acesso a um programa de computador mais material educativo impresso e orientação verbal em grupo, em três sessões antes da alta hospitalar. A avaliação dos processos de educação foi realizada com pré e pós-teste sobre o acidente vascular cerebral, escala de autoeficácia desenvolvida pelo pesquisador, ansiedade e depressão hospitalar (HADS) e qualidade de vida com a escala Stroke and Aphasia Quality of Life Scale-39 Generic (SAQOL-39g) antes da alta hospitalar e após três meses. Como resultado, os pacientes do grupo experimental apresentaram melhor autoeficácia para informações sobre a patologia, maior satisfação com a informação recebida, sem diferença entre os grupos para os demais resultados ${ }^{45}$.

Esses diferentes estudos mostraram a eficácia da educação em saúde e o uso de tecnologias como parte da estratégia de ensino para alavancar o conhecimento dos pacientes. Nota-se que, independentemente do método escolhido, os resultados foram positivos e benéficos para os pacientes.

5.2.2 Cirurgia ortognática para pacientes - tecnologia educativa para essa intervenção

A tecnologia assistencial de escolha para essa intervenção foi um material educativo impresso elaborado a partir da identificação da necessidade de informação dos pacientes de cirurgia ortognática por meio de grupo focal, buscas em meio virtual (blogs) e conhecimento das orientações dadas pelos cirurgiões habitualmente ${ }^{2}$.

O texto desse material foi construído seguindo informações sobre construção de material educativo para $\operatorname{leigos}^{46}$, respeitando a literacia destes, simplificando palavras técnicas e uso de ilustrações para elucidar o texto.

O primeiro esboço do material foi submetido a validação de conteúdo e pertinência das informações com equipe multiprofissional (cirurgiões bucomaxilofaciais, nutricionistas, enfermeiras e fonoaudiólogas), com avaliação dos itens: conteúdo, ilustrações, linguagem, leiaute, motivação e cultura, por meio da técnica Delphi; foram necessárias três rodadas para a finalização do material por esse grupo de juízes ${ }^{47}$.

Posteriormente, o material produzido foi submetido a validação de compreensão por um grupo de pacientes submetidos a cirurgia ortognática, com instrumento que utilizou 
os mesmos itens de avaliação aplicados para a equipe multiprofissional. Esse processo não evidenciou a necessidade de alterações e procedeu-se à impressão final da tecnologia educativa ${ }^{2}$.

A tecnologia educativa, constituída de um livreto ilustrado e colorido em papel couché com 24 páginas, compreende informações sobre a cirurgia (o que é a cirurgia ortognática); quem precisa fazer a cirurgia; como é feita; preparo pré-operatório e rotina hospitalar até a alta; possíveis complicações cirúrgicas e cuidados pós-operatórios (higiene oral, dieta, abertura bucal, aplicação de gelo, exercícios, umidificação dos lábios, exposição ao sol, banho e curativos, dor, repouso); e inclui perguntas frequentes feitas pelos pacientes.

A higiene oral rigorosa pode ser um diferencial no cuidado pós-operatório, uma vez que a incisão cirúrgica é realizada intraoralmente e a presença de alimentos em cavidade pode predispor a uma infecção ${ }^{3}$. Nos cuidados pós-operatórios da presente investigação, são descritos como o paciente deve proceder para a higiene oral, a escova de dente adequada e o uso do antisséptico bucal sem álcool.

Em relação à dieta, o paciente é submetido a uma dieta líquida no pós-operatório para evitar acúmulo de resíduos e proliferação bacteriana, bem como para favorecer o repouso no local $^{48}$. Entretanto, muitas vezes, a dieta não é balanceada, o que acarreta desnutrição e perda de massa corpórea significativa, com comprometimento da cicatrização da ferida operatória. Com isso, a orientação do paciente e da família sobre a importância da manutenção da dieta e da hidratação otimiza o processo de cura ${ }^{3}$.

As orientações sobre o tipo de dieta (líquida, cremosa, pastosa etc.) são descritas conforme os dias de pós-operatório, com exemplos sobre os tipos de alimentos que podem ser inseridos paulatinamente e como podem ser oferecidos (uso de seringas ou colheres). A hidratação também é citada, favorecendo a dieta com suporte calórico adequado para o processo de recuperação.

A abertura bucal é retomada aos poucos, o uso de elásticos no aparelho ortodôntico tem a função de controlar a mordida durante o pós-operatório, compensar o edema que tende a se deslocar com a mordida do paciente, auxiliar a movimentação dentária e dar suporte a articulação temporomandibular ${ }^{3}$. 
No material educativo, orienta-se o paciente sobre a importância do uso dos elásticos, e sua manipulação deve ser seguida conforme orientação do cirurgião ou ortodontista. Optou-se por não demonstrar "como fazer" no material impresso para não confundir o paciente ou permitir complicações na estrutura maxilomandibular nesse momento.

O edema, apesar de esperado no pós-operatório imediato devido à manipulação dos tecidos da face, pode se tornar uma complicação importante em uma combinação de edema de lábios, bochechas, parte superior da cervical, intraoral e presença de fixação e bloqueio mandibular, o leva o paciente a obstrução de via aérea e emergência respiratória ${ }^{49}$.

Para auxiliar a redução do edema, o uso da crioterapia pode ser recomendado ao paciente. O uso terapêutico do frio é benéfico ao tratamento de dor, inflamação e edema; lentifica os impulsos dolorosos enviados ao cérebro, diminui o espasmo muscular, reduz a atividade de enzimas inflamatórias e provoca vasoconstrição, o que pode também reduzir sangramentos e hematomas ${ }^{50}$.

O uso de bolsas de gelo é orientado para os primeiros dias de pós-operatório e foi inserido no material. Recomenda-se o uso de uma proteção de tecido entre o gelo e a pele para evitar queimaduras pelo gelo. Nessa página, um trecho-chave no texto chama a atenção do paciente para respeitar o tempo que o frio deve ficar em contato com a pele para não ocasionar lesões.

Outra intervenção prevista no material está relacionada ao repouso e ao período de sono com cabeceira elevada. Manter a cabeceira elevada nas primeiras semanas do pósoperatório pode auxiliar a reduzir o edema ${ }^{3}$. Recomenda-se, no material impresso, dormir com dois a três travesseiros, manter repouso com a cabeça em posição mais alta, permanecer sentado e realizar atividades leves nesses primeiros dias. Quanto menos o paciente abaixar a cabeça no período pós-operatório menor é o fluxo sanguíneo para a região operada.

Evitar a exposição ao sol pode contribuir para o controle do edema e encontra-se dentro das orientações fornecidas ao paciente.

No dia seguinte a cirurgia, o paciente pode tomar banho normalmente; alerta-se para evitar água quente e tempo prolongado, pois são condições que podem aumentar o edema e o desconforto. 
Alterações neurossensoriais normalmente são percebidas no pós-operatório imediato, sendo resultado da tração do nervo infraorbitário e do trauma direto aos nervos alveolares ântero, médio e pósteros superiores, ao nervo nasopalatino e ao nervo palatino descendente ${ }^{7}$. Estas podem ser temporárias, com duração de seis a doze meses, mas alguns pacientes podem experimentar lesões permanentes.

A orientação de exercícios faciais para auxiliar a mobilidade e a sensibilidade foi sugerida por uma fonoaudióloga e um cirurgião maxilofacial. As formas de atuação realizadas para modificações musculares podem ser a mioterapia e a terapia miofuncional. $\mathrm{Na}$ mioterapia, uma ação especifica no músculo a ser modificado utiliza exercícios isotônicos e/ou isométricos, e na terapia miofuncional trabalha-se diretamente com as funções que se quer modificar ${ }^{51}$.

No material impresso, orientam-se três tipos de exercícios faciais com a bochecha: enchê-la de ar e movimentá-lo de um lado para outro; com a língua para sentir os lábios inferior e superior, posicionar a língua no palato, sentir as novas estruturas orais e reconhecer o novo posicionamento destas; com os lábios, alternar mimica labial de bico e sorriso. Alerta-se para a busca de um profissional especializado para auxiliar o tratamento e a terapia com fonoaudióloga no final das recomendações dos exercícios.

A manipulação cirúrgica e o uso de afastadores no intraoperatório, podem ocasionar uma laceração ou uma contusão traumática dos lábios ${ }^{52}$. Orienta-se o paciente quanto a utilização de vaselina líquida, cremes protetores ou pomadas de assadura de bebê oleosa para lubrificar e proteger a região no período pós-operatório. Os pequenos traumatismos de forma geral evoluem para a cura e, muito raramente, infecções secundárias podem ocorrer.

A dor pós-operatória é difícil de ser avaliada, pois pode estar relacionada a fatores psicológicos antes e após o procedimento e, no pós-operatório, deve ser avaliada conforme descrição do paciente. Entretanto, estudos ${ }^{19}, 53$ mostram que a dor pós-operatória é controlada. Pacientes ansiosos no pré-operatório tendem a experimentar uma dor mais significativa no pós-operatório ${ }^{19}$.

Por não se tratar de dor moderada ou intensa, não se recomendam medidas paliativas para alívio da dor, mas o paciente pode discutir esse tratamento com o cirurgião. No material, a orientação relativa a dor no pós-operatório sugere ao paciente buscar contato com o cirurgião caso a dor não cesse com o uso dos analgésicos prescritos, e o paciente é 
orientado sobre a presença do desconforto devido a manipulação cirúrgica da área, edema e fixação mandibular.

Sabe-se que o pós-operatório compreende o período mais longo do perioperatório e o preparo para vivenciar essa fase se inicia no pré-operatório. Dessa forma, o paciente necessita compreender melhor as informações e orientações sobre o autocuidado. Acreditase na eficácia da educação do paciente baseada no fato de que o maior conhecimento sobre o assunto terá impacto nas suas atitudes e comportamentos e trará resultados positivos. 


\section{MATERIAL E MÉTODO}

\subsection{TIPO DE ESTUDO}

Trata-se de um ensaio clínico randomizado controlado, desenvolvido no período de janeiro de 2013 a agosto de 2015, dividido em duas fases: um estudo piloto sem randomização para avaliação da intervenção e, em segundo momento, o estudo clínico randomizado com as alterações realizadas após o estudo piloto.

O estudo piloto não randomizado foi proposto para avaliar a viabilidade da intervenção e dos instrumentos escolhidos para medir o efeito da intervenção nos pacientes submetidos a cirurgia ortognática.

\subsection{POPULAÇÃO DE ESTUDO}

Foi constituída por pacientes originários de um ambulatório de cirurgia e traumatologia bucomaxilofacial localizado no município de São Paulo.

Critérios de inclusão: pacientes submetidos a cirurgia ortognática (técnica cirúrgica: osteotomia bilateral do ramo sagital maxilar, osteotomia do ramo vertical maxilar, osteotomia Lefort I, osteotomia combinada, com aplicação ou não de mentoplastia e disjunção maxilar) pela mesma equipe cirúrgica, provenientes de consultório de cirurgia e traumatologia bucomaxilofacial localizado no município de São Paulo e com intervenção cirúrgica em hospitais de pequeno, médio e grande porte, públicos ou privados, localizados também no município de São Paulo.

Critérios de exclusão: pacientes submetidos a reoperação de cirurgia ortognática; portadores de fissura labiopalatina.

Plano de recrutamento dos pacientes: os pacientes atendidos no consultório de cirurgia e traumatologia bucomaxilofacial localizado no município de São Paulo com indicação para a cirurgia ortognática foram abordados pelo pesquisador pessoalmente e convidados a participar da pesquisa de intervenção. Para controle de viés foram incluídos no estudo pacientes de uma mesma equipe cirúrgica, para assegurar a mesma técnica cirúrgica aplicada e conduta de orientação pós-operatória pelo cirurgião. 


\subsection{INSTRUMENTOS DE COLETA}

Para a coleta de dados, foram utilizados os seguintes instrumentos: avaliação clínica do paciente, escala de ansiedade traço-estado e teste de conhecimento sobre a cirurgia ortognática.

O instrumento de avaliação clínica consistiu de três partes: características sociodemográficas do paciente, expectativas da cirurgia no pré-operatório e uma avaliação para o pós-operatório que incluiu exame clínico da cavidade oral e manejo dos sintomas pósoperatórios (foram registradas as condições da cavidade oral, presença de edema, mobilidade e abertura da boca, avaliação da dor, considerações sobre padrão do sono, padrão respiratório e nutrição) (Apêndice I).

Os níveis de ansiedade foram mensurados no pré e pós-operatório pelo inventário de ansiedade traço-estado IDATE (desenvolvido por Spielberger em 1970), que avalia duas dimensões de ansiedade, o estado transitório e o estado relativamente estável da personalidade do paciente. Essa escala consiste em vinte afirmações e, para cada afirmação, o paciente deve assinalar uma das quatro alternativas, indicando como se sente: absolutamente não; um pouco; bastante; muitíssimo (na escala Idate-estado); quase nunca; às vezes; frequentemente; quase sempre (na escala Idate-traço) ${ }^{54}$. O escore total é caracterizado por baixo grau de ansiedade (20-30 pontos), grau médio de ansiedade (31-49) e alto grau de ansiedade (50 ou mais) ${ }^{55}$ (Anexo I).

O instrumento de teste do conhecimento do paciente sobre a cirurgia consistiu em dez questões de múltipla escolha sobre a cirurgia e os cuidados necessários no pósoperatório. Foi desenvolvido pelo pesquisador e validado por dois profissionais enfermeiros perioperatórios e aplicado ao paciente no pré e pós-operatório (Apêndice II).

\subsection{INTER VENÇÃO}

Educação perioperátoria do paciente submetido a cirurgia ortognática composta de orientação verbal individualizada no pré-operatório sobre os cuidados pós-operatórios com apoio de tecnologia educativa impressa: um livreto de 24 páginas intitulado Cirurgia 
ortognática para pacientes ${ }^{\mathrm{a}}$, que compreende informações sobre a cirurgia (o que é a cirurgia ortognática); quem precisa fazer a cirurgia; como é feita; preparo pré-operatório e rotina hospitalar até a alta; possíveis complicações cirúrgicas e cuidados pós-operatórios (higiene oral, dieta, abertura bucal, aplicação de gelo, exercícios, umidificação dos lábios, exposição ao sol, banho e curativos, dor, repouso) incluindo algumas perguntas frequentes feitas pelos pacientes.

\subsection{SEGUIMENTO}

Para evitar custos adicionais de transporte e para aumentar a possibilidade de adesão ao acompanhamento, optou-se por realizar as avaliações no consultório e durante o retorno com o cirurgião. Dessa forma, o paciente não precisaria se deslocar mais de uma vez para avaliação, o que possibilitaria maior adesão aos retornos de avaliação, porque estava relacionado ao retorno pós-operatório com o cirurgião.

O primeiro contato com o paciente ocorreu durante o pré-operatório, na consulta para marcação da cirurgia, quando se orientou sobre a pesquisa e, após o aceite, realizou-se a entrevista e a aplicação do pré-teste de conhecimento e inventário de ansiedade para todos os pacientes.

No pós-operatório, houve quatro momentos de contato com o paciente, com intervalos regulares: três a sete dias (corresponde ao primeiro retorno); dez a quinze dias (segundo retorno); 25 a trinta dias (terceiro retorno); e 45 dias de pós-operatório (quarto retorno).

No estudo piloto, somente existiu o grupo intervenção sem randomização, e no ensaio clínico ocorreu a randomização e os grupos foram divididos em experimental e controle (Figura 2).

a'Sousa CS, Turrini RNT. Cirurgia Ortognática para pacientes. 2011. ISBN 978-85-912862-0-1(Anexo II). 


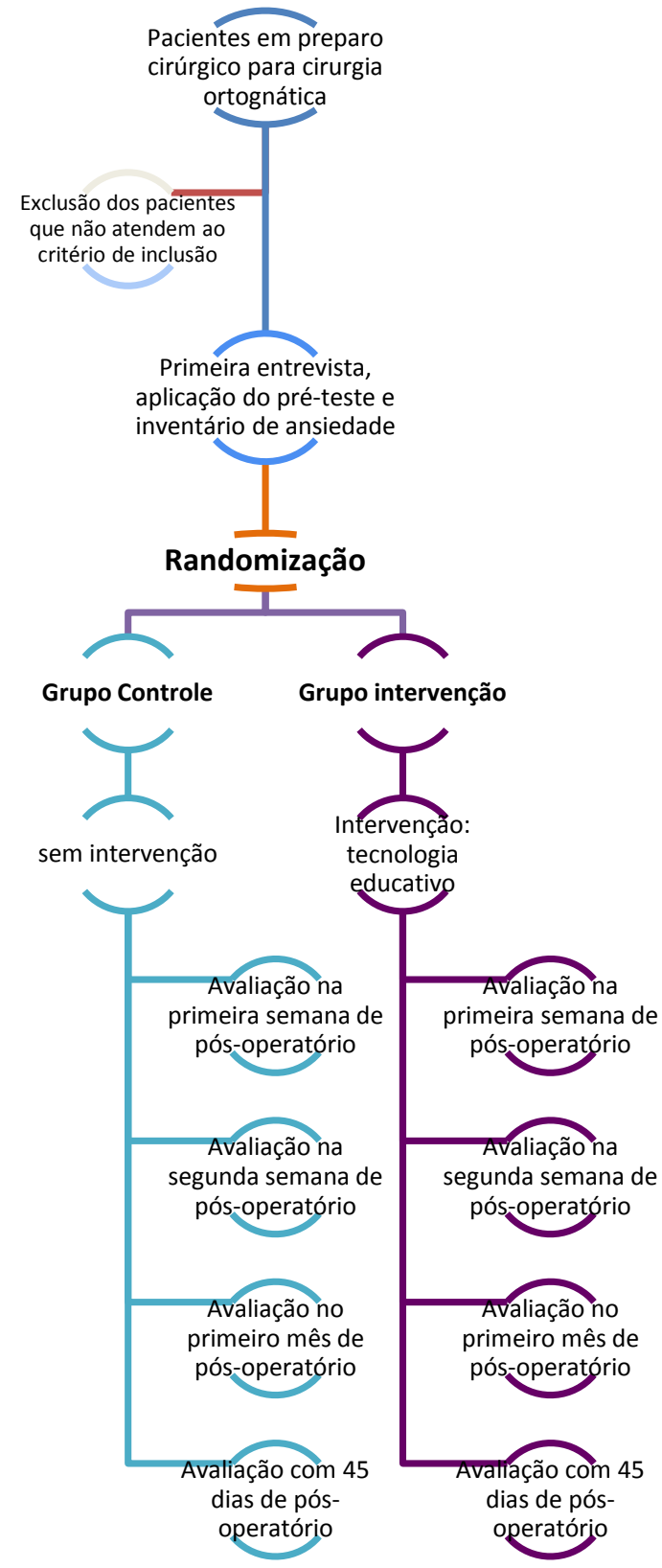

Figura 2 - Fluxograma do seguimento proposto neste estudo. São Paulo, 2013.

Para a execução do estudo, um segundo pesquisador foi inserido para coleta de dados. Esse profissional foi treinado pelo pesquisador1 para aplicação dos instrumentos de coleta de dados, não participava da intervenção com a tecnologia educativa e desconhecia as orientações fornecidas ao paciente. 


\subsection{ASPECTOS ÉTICOS}

Este estudo foi aprovado pela Comissão de Ética em Pesquisa da Escola de Enfermagem da USP sob parecer n. 193.454/13. Todos os participantes assinaram o Termo de Consentimento Livre e Esclarecido (TCLE) antes do início da coleta de dados, respeitando os preceitos éticos de pesquisa com seres humanos fundamentados na Resolução 466/12 do Conselho Nacional de Saúde ${ }^{56}$ (Apêndice III e IV).

Neste estudo, não foram evidenciados riscos durante a pesquisa em ambos os grupos. Em caso de recusa em participar da pesquisa, foi atendida a solicitação. Os dados pessoais e as informações clínicas e cirúrgicas do paciente foram preservadas e com confidencialidade.

Por se tratar de um ensaio clínico, foi realizado o registro no National Institutes of Health (NHS) - Clinical Trial, pelo site www.clinicaltrial.gov (identificador NCT01803204).

Dado que o estudo envolve duas fases, especificidades da metodologia, resultados e discussão serão feitas em capítulos independentes. 


\section{PRIMEIRA FASE - ESTUdO PILOTO}

\subsection{MÉTODO}

7.1.1 Tipo de estudo

$\mathrm{O}$ estudo piloto não randomizado foi proposto para avaliar a viabilidade da intervenção e dos instrumentos escolhidos para medir o efeito da intervenção nos pacientes submetidos a cirurgia ortognática.

Pode ser definido como um estudo experimental, exploratório, de teste, preliminar a um ensaio clínico ou de investigação. Um olhar aproximado desse método permite compreender que um estudo piloto é uma sondagem para guiar o planejamento de estudos maiores $^{57}$. Pode ser considerado um método de vanguarda para ensaios clínicos a fim de garantir a segurança do tratamento ou de uma intervenção; para avaliar o potencial do recrutamento, a possibilidade da colaboração internacional ou da coordenação para experimentações multicêntricas; para aumentar o conhecimento sobre o tratamento ou intervenção e identificar a dose necessária para o tratamento ou intervenção do ensaio clínico $^{57}$.

O período de coleta de dados dessa fase compreendeu os meses de fevereiro a julho de 2013. O cenário antes da intervenção consistia em orientações verbais gerais sobre o processo cirúrgico oferecidas pelo cirurgião bucomaxilofacial durante a consulta que antecedia a cirurgia.

\subsubsection{Amostra}

Foi aplicado a um pequeno número de pacientes $(n=8)$. $O$ tamanho amostral foi escolha aleatória do pesquisador, considerado adequado para avaliação, com intuito de promover maior segurança ao ensaio clínico randomizado realizado posteriormente.

\subsubsection{Procedimento de coleta}

No teste piloto, a intervenção propôs a orientação verbal individualizada dos cuidados pós-operatórios com apoio da tecnologia educativa por uma enfermeira especialista em assistência perioperatória.

O processo de coleta de dados envolveu a participação de dois enfermeiros 
especialistas em assistência perioperatória denominados pesquisador1 e pesquisador2.

O pesquisador1 foi responsável pela aplicação do teste de conhecimento do paciente sobre o processo cirúrgico (Apêndice I); avaliação dos níveis de ansiedade com o inventário de ansiedade traço-estado IDATE (Anexo I); e caracterização sociodemográfica do paciente e expectativa sobre a cirurgia (Apêndice II) no pré-operatório. Em seguida, aplicou a intervenção educativa com o livreto impresso Cirurgia ortognática para pacientes. O pesquisador2 foi responsável pela coleta de dados no pós-operatório.

O paciente foi abordado pelo pesquisador1 por ocasião da consulta de avaliação préoperatória com o cirurgião. Após aplicação dos instrumentos, o material educativo foi entregue ao paciente, que recebeu a orientação do pesquisador1 utilizando o material educativo como guia. Entre as informações, foram enfatizadas as orientações sobre os cuidados pós-operatórios (higiene oral, dieta, exercícios faciais, hidratação labial, exposição ao sol, abertura limitada da cavidade oral, controle da dor, repouso, banho e curativos). Esse processo de orientação teve a duração de cerca de quinze a vinte minutos e as questões feitas pelos pacientes eram esclarecidas. A compreensão da informação era confirmada com a concordância do paciente frente a orientação e repetida quantas vezes necessárias, caso o paciente referisse dúvidas sobre o assunto. Os pacientes foram encorajados a realizar a leitura no domicílio e não precisavam devolver o material ao final da pesquisa.

Após a cirurgia, na primeira consulta de pós-operatório, foram aplicados pelo pesquisador2 o teste de conhecimento (Apêndice I), o inventário de ansiedade traço-estado IDATE (Anexo I) e o instrumento de avaliação clínica, autocuidado e manejo dos sinais e sintomas no pós-operatório (Apêndice II). A avaliação da cavidade oral foi realizada em conjunto com o cirurgião. Na segunda e terceira consulta de retorno, foi aplicado apenas o instrumento de avaliação clínica. Na última consulta (cerca de quarenta a 45 dias de pósoperatório), além da avaliação clínica, foi aplicado novamente o inventário de ansiedade traço-estado IDATE (Anexo I).

\subsubsection{Análise dos dados}

Os dados descritivos foram apresentados em frequência relativa e absoluta, e quando possível por medidas de tendência central e de variabilidade. A análise dos dados do inventário IDATE foi feita pelo teste de Friedman; a comparação dos dados da avaliação clínica durante os retornos, pelo teste de Cochran's Q test; peso corporal, pelo teste de 
Kruskall-Wallis; e intensidade da dor por Friedman, com nível de significância de 5\%.

$\mathrm{Na}$ avaliação do primeiro e quarto retorno, foi aplicado o teste de $\mathrm{McNemar}$, que avalia as diferenças entre dois grupos relacionados, é tipicamente aplicado quando se procura por mudanças nos escores das pessoas e compara a proporção das pessoas que mudaram sua resposta em uma direção (aumento ou diminuição dos escores $)^{58}$.

Para a avaliação de conhecimento foi aplicado o teste de Wilcoxon. A propriedade psicométrica do teste de conhecimento foi analisada pelo modelo de Rasch, que utiliza o grau de dificuldade do item e a habilidade das pessoas para calibração, alinhados em uma linha contínua e com intervalos iguais. Os pressupostos do modelo de Rasch são a unidimensionalidade, ou medir somente um atributo, e a independência local, ou seja, os itens de um teste não podem apresentar pistas que permitam aos respondentes acertar outros itens do instrumento ${ }^{59}$.

Para o modelo de Rasch utilizou-se o software Winsteps $3.8^{60}$. A unidade básica dessa análise é o logito. Quanto maior o valor do logito de determinado item, maior a dificuldade relativa de um item comparado com os demais itens da escala. Da mesma forma, quanto maior a magnitude do logito do indivíduo, maior a habilidade apresentada pelo indivíduo, comparada com os demais integrantes do grupo amostral. O valor zero na escala arbitrária de logitos representa o centro; os itens mais fáceis apresentam valores negativos e os mais difíceis, positivos. A estatística do ajuste (fit) mostra o quanto os dados desviam do modelo, e essa informação é dada pela MNSQ (média quadrática) ou valor de $t$ do Infit e Outfit, considerando-se como valores adequados para indicar o ajuste dos itens ao modelo o MNSQ $=1,0 \pm 0,3$ e $\mathrm{t}= \pm 2,0$. A calibração das habilidades e dificuldades pode ser representada em um mapa que permite identificar se os itens estão distribuídos homogeneamente ou se estão concentrados nos extremos da reta, bem como se as pessoas estão distribuídas de acordo com suas habilidades. A análise de Rasch fornece a confiabilidade e, para as pessoas, também a confiabilidade pelo alfa de Cronbach. Nesse caso, a confiabilidade pelo alfa de Cronbach é sempre maior do que aquela dada pelo Winstep. Na análise dos itens do questionário, cada um foi identificado pelo número do item antecedido pela letra "P".

\subsection{RESULTADOS}


Os resultados do estudo piloto foram apresentados conforme o instrumento de coleta de dados aplicado.

\subsubsection{Característica dos participantes}

Os pacientes possuíam idade de 18 a 39 anos (média de 29,3 \pm 7,0); o grau de instrução variou de seis a dez anos de estudo (média 7,7 $\pm 2,8$ ); predomínio de pacientes do sexo feminino $(n=5 ; 62,5 \%) ; 50,0 \%(n=4)$ referiram motivação funcional para realizar a cirurgia, seguido de 37,5\% (n=3) por recomendação do cirurgião e 12,5\% (n=1) por estética. Todos os pacientes apresentavam expectativa de alteração física/estética no pré-operatório; no pós-operatório 87,5\% $(n=7)$ referiram melhora na alteração física facial e 12,5\% $(n=1)$ se sentiram mais confiantes. A satisfação com o procedimento ocorreu em $100 \%$ dos pacientes.

\subsubsection{Inventário de ansiedade}

Em todos os momentos de avaliação, os pacientes apresentaram ansiedade de médio grau $^{55}$, caracterizada por valores $\geq 30$ e $\leq 50$. As médias do IDATE-estado, apesar de não significativa estatisticamente, demonstraram uma redução de 3,7 pontos entre os momentos pré-operatório e 45 dias de pós-operatório (Tabela 1).

A média do IDATE-traço no pré-operatório foi superior à do IDATE-estado. Houve maior redução do IDATE-traço do pré-operatório para o pós-operatório (6,3 pontos) do que do pós-operatório para o seguimento de 45 dias ( $\mathrm{p}=0,016)$.

Tabela 1 - Valores médios e desvio padrão do inventário de ansiedade traço-estado (IDATE) em três momentos. São Paulo, 2013

\begin{tabular}{|c|c|c|c|c|c|}
\hline $\begin{array}{l}\text { Momento } \\
\text { de medida }\end{array}$ & $\begin{array}{c}\text { IDATE } \\
\text { estado, Média } \\
\text { (DP) }\end{array}$ & valor $\mathrm{p}^{\mathrm{a}}$ & $\begin{array}{l}\text { Momento } \\
\text { de medida }\end{array}$ & $\begin{array}{l}\text { IDATE-traço, } \\
\text { Média (DP) }\end{array}$ & valor $\mathrm{p}^{\mathrm{a}}$ \\
\hline Pré-op & $38,9(9,3)$ & & Pré-op & $41,6(8,4)$ & \\
\hline Pós-op & $39,3(9,5)$ & 0,882 & Pós-op & $35,3(9,1)$ & 0,016 \\
\hline 45 dias & $35,2(8,7)$ & & 45 dias & $35,1(6,5)$ & \\
\hline
\end{tabular}

${ }^{a}$ Friedman $* p<0,05$

Após a aplicação do teste de Wilcoxon-Nemeny-McDonald-Thompsoni (post-hoc) para avaliação do valor $\mathrm{p}$ significativo encontrado no IDATE-traço, foi percebida uma 
avaliação significativa entre as medidas no pré-operatório e na avaliação de 45 dias de pósoperatório $(\mathrm{p}<0,024)$.

\subsubsection{Avaliação clínica}

Foram avaliados os sinais e sintomas referentes aos cuidados pós-operatórios: higiene oral, nutrição (perda de peso corpóreo), mobilidade e sensibilidade facial, hidratação labial, característica do edema, mensuração de dor, dificuldade para dormir e respirar. Houve redução dos sinais e sintomas do primeiro retorno pós-operatório até aquele com 45 dias de pós-operatório (Tabela 2).

Tabela 2 - Dados da avaliação clínica $(\mathrm{n}=8)$ nos momentos de pós-operatório. São Paulo, 2013.

(continua)

Variáveis

Pós-operatório (\%)

$1^{\circ}$ retorno $2^{\circ}$ retorno $\quad 3^{\circ}$ retorno $4^{\circ}$ retorno

valor $\mathrm{p}^{\mathrm{a}}$

\section{Higiene Oral}

\begin{tabular}{|c|c|c|c|c|c|}
\hline Halitose & 37,5 & 12,5 & 25,0 & - & 0,172 \\
\hline Gengiva descorada & 12,5 & - & - & - & 0,392 \\
\hline Gengivite & 12,5 & - & - & - & 0,392 \\
\hline Língua saburrosa & 25,0 & - & 12,5 & - & 0,300 \\
\hline Sutura com resíduo alimentar & 50,0 & 12,5 & 25,0 & - & 0,103 \\
\hline Presença de placa bacteriana & 50,0 & - & 25,0 & - & 0,024 \\
\hline Dificuldade em realizar a & 100 & 37,5 & 12,5 & - & 0,066 \\
\hline
\end{tabular}

higiene oral 
(continuação)

$1^{\circ}$ retorno $2^{\circ}$ retorno $3^{\circ}$ retorno $4^{\circ}$ retorno

\section{Mobilidade e Sensibilidade}

Limitação da abertura da boca

12,5

0,392

acima do esperado

Estímulo tátil diminuído

50

37,5

25,0

0,125

Movimentos faciais alterados

12,5

$-$

0,392

\section{Hidratação labial}

Lábios ressecados

37,5

25,0

0,101

Lábios com lesão

12,5

0,392

\section{Evolução do Edema}

Edema acima do esperado

12,5

$-$

0,392

\section{Condição para dormir ou respirar}

$\begin{array}{lllllll}\text { Dificuldade para dormir ou } & 75 & 12,5 & 12,5 & 25,0 & 0,037 *\end{array}$

respirar 
(continuação)

\begin{tabular}{|c|c|c|c|c|c|}
\hline & \multicolumn{4}{|c|}{ Pós-operatório, Média (DP) } & \multirow[t]{2}{*}{ Valor $\mathrm{p}^{\mathrm{c}}$} \\
\hline \multicolumn{5}{|c|}{ Nutrição (alteração do peso corporal) } & \\
\hline Peso & $71,9(9,3)$ & $71,8(9,4)$ & $71,1(9,5)$ & $70,8(8,5)$ & $0,017 *$ \\
\hline \multicolumn{6}{|c|}{ Dor (escala analógica visual) } \\
\hline Intensidade & $4,8(2,9)$ & $3,4(3,4)$ & $1,6(1,9)$ & $0,8(1,7)$ & $0,003^{*}$ \\
\hline
\end{tabular}

${ }^{a}$ Cochran's Q test. ${ }^{\mathrm{b}}$ Kruskal-Wallis. ${ }^{\mathrm{c}}$ Friedman. $\quad * p<0,05$

O peso corporal médio no pré-operatório $(74,2 \mathrm{~kg})$ resultou em perdas médias progressivas a cada retorno pós-operatório, mais evidentes no terceiro $(3,1 \mathrm{~kg} \pm 2,9)$ e quarto retorno $(3,5 \mathrm{~kg} \pm 3,6)(\mathrm{p}<0,017)$. No comparativo pré-operatório e terceiro retorno, o valor estatístico foi significativo $(\mathrm{p}<0,008)$.

A dor foi significativa e mostrou redução gradual, conforme a evolução do pósoperatório; no post-hoc Wilcoxon-Nemexyi-McDonald-Thomposon, o ponto significativo entre os retornos foi a avaliação entre o primeiro e último retorno $(\mathrm{p}=0,017)$. Entretanto, a avaliação da halitose, gengiva descamada, gengivite, língua saburrosa, sutura com resíduo alimentar, presença de placa bacteriana, limitação da abertura da boca, estímulo tátil diminuído, movimentos faciais alterados, lábios ressecados, edema acima do esperado e dor intensa não foram significativos estatisticamente no comparativo entre os retornos.

Quanto aos cuidados com resultados significativos no pós-operatório, identificaramse a dificuldade de realizar a higiene oral, dormir e respirar, a perda de peso corpóreo e a presença de dor. No quarto retorno, o único problema evidenciado em dois dos pacientes foi a dificuldade para dormir e respirar. 
7.2.4 Teste de conhecimento

Os valores dos testes de conhecimento representam a média das notas alcançadas e são apresentados na Tabela 3 conforme o período de aplicação.

Tabela 3 - Dados do pré e pós-teste de conhecimento (n=8). São Paulo, 2013.

\begin{tabular}{ccc}
\hline Momento da aplicação & Média (DP) & Valor $\mathrm{p}^{\mathrm{a}}$ \\
\hline Pré-operatório & $7,3(1,5)$ & 1,000 \\
Pós-operatório & $7,3(1,3)$ & \\
\hline a'Wilcoxon $* p<0,05$ & &
\end{tabular}

A análise da propriedade psicométrica do instrumento utilizado para medir o conhecimento dos pacientes mostrou que este precisava de ajustes. O grau médio de dificuldade dos itens foi de 5,90 $( \pm 2,60)$ e o logito médio foi $-1,56$, indicando itens fáceis (Tabela 3). O ajuste médio verificado tanto pelo infit quanto pelo oufit foi de 1,0, dentro do padrão esperado. No entanto, ao se observar o resultado para cada item, notou-se que apenas o item P9 apresentou valores de infit e outfit adequados para o ajuste do modelo. Em relação às medidas de Rasch, os valores foram acima de três, tanto para os negativos (itens fáceis) quanto para os positivos (difíceis). O erro padrão foi elevado, pois a amostra é pequena. 
Tabela 4 - Resultados da análise de Rasch para os itens. São Paulo, 2013.

\begin{tabular}{|c|c|c|c|c|c|}
\hline Item & $\begin{array}{c}\text { Escore } \\
\text { total }\end{array}$ & $\begin{array}{l}\text { Medida } \\
\text { (logito) }\end{array}$ & $\begin{array}{l}\text { Erro padrão } \\
\text { (logito) }\end{array}$ & InfitMNSQ & OutfitMNSQ \\
\hline P5 & 0 & 3,11 & 1,85 & Medida & Máxima \\
\hline $\mathrm{P} 4$ & 4 & 0,00 & 0,87 & 0,5 & 0,5 \\
\hline P9 & 4 & 0,00 & 0,87 & 1,00 & 1,00 \\
\hline P10 & 4 & 0,00 & 0,87 & 1,50 & 1,50 \\
\hline $\mathrm{P} 1$ & 8 & $-3,11$ & 1,86 & Medida & Mínima \\
\hline $\mathrm{P} 2$ & 8 & $-3,11$ & 1,86 & Medida & Mínima \\
\hline P3 & 7 & $-3,11$ & 1,86 & Medida & Mínima \\
\hline P6 & 8 & $-3,11$ & 1,86 & Medida & Mínima \\
\hline P7 & 8 & $-3,11$ & 1,86 & Medida & Mínima \\
\hline P8 & 8 & $-3,11$ & 1,86 & Medida & Mínima \\
\hline Média & 5,90 & $-1,56$ & 1,56 & 1,00 & 1,00 \\
\hline DP & 2,60 & 2,09 & 0,45 & 0,41 & 0,41 \\
\hline
\end{tabular}

A habilidade média dos respondentes foi de 7,40 $( \pm 1,10)$ e o valor do logito foi zero (Tabela 4). A distribuição das medidas de Rasch mostra uniformidade entre os valores negativos e positivos, ou seja metade da amostra apresenta uma distribuição igual à outra metade. Excluindo-se as medidas máxima e mínima do infit e outfit, os valores indicam um bom ajuste da habilidade das pessoas. 
Tabela 5 - Resultados da análise de Rasch para as pessoas (respondentes). São Paulo, 2013.

\begin{tabular}{|c|c|c|c|c|c|}
\hline Pessoa & $\begin{array}{l}\text { Escore } \\
\text { total }\end{array}$ & $\begin{array}{l}\text { Medida } \\
\text { (logito) }\end{array}$ & $\begin{array}{c}\text { Erro padrão } \\
\text { (logito) }\end{array}$ & InfitMNSQ & OutfitMNSQ \\
\hline 3 & 9 & 2,15 & 1,89 & Medida & Máxima \\
\hline 4 & 8 & 0,69 & 1,22 & 1,00 & 1,00 \\
\hline 5 & 8 & 0,69 & 1,22 & 1,00 & 1,00 \\
\hline 6 & 8 & 0,69 & 1,22 & 1,00 & 1,00 \\
\hline 2 & 7 & $-0,69$ & 1,22 & 1,00 & 1,00 \\
\hline 7 & 7 & $-0,69$ & 1,22 & 1,00 & 1,00 \\
\hline 8 & 7 & $-0,69$ & 1,22 & 1,00 & 1,00 \\
\hline 1 & 5 & $-2,15$ & 1,89 & Medida & Mínima \\
\hline Média & 7,4 & 0,00 & 1,39 & 1,00 & 1,00 \\
\hline DP & 1,1 & 1,23 & 0,29 & 0,00 & 0,00 \\
\hline
\end{tabular}

A Figura 3 mostra, à esquerda, as pessoas distribuídas de acordo com seu conhecimento e à direita a distribuição dos itens de acordo com sua dificuldade. Quando a pessoa está alinhada ao item, significa que para esses itens a pessoa tem 50\% de chance de responder corretamente. As pessoas $(n=6 ; 75 \%)$ que não se alinham a qualquer item indicam um desajuste do modelo. Observou-se também que os itens não cobrem todo o constructo, há um empilhamento dos itens mais fáceis e de média dificuldade. 


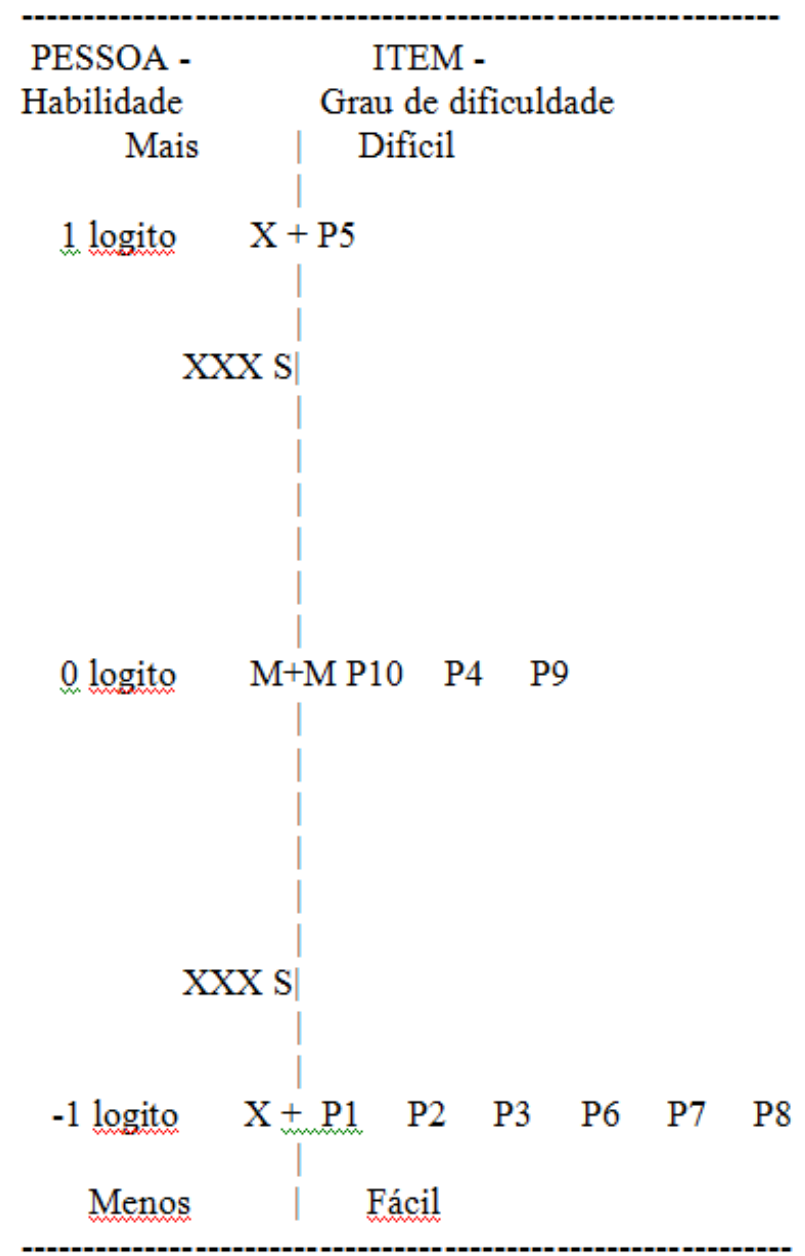

Figura 3 - Mapa da distribuição dos itens de acordo com o grau de dificuldade e das pessoas de acordo com a habilidade. São Paulo, 2013.

A confiabilidade do modelo para o grau de dificuldade dos itens foi de 0,39 e para a habilidade das pessoas foi de zero.

\subsection{DISCUSSÃO}

Frente aos dados da avaliação clínica, observou-se a necessidade de alterar a forma de avaliação de alguns sinais e sintomas. Foram retirados do instrumento os itens de normalidade, permanecendo apenas para checklist itens de anormalidade com questão sim/não para cada item. Nas perguntas abertas, foram inseridos o porquê ou qual método foi aplicado. Na sessão mobilidade e sensibilidade, foi inserida a questão "se o paciente faz uso 
de elástico ortodôntico" e as regiões de parestesia foram elaboradas em forma de checklist. Na sessão edema, em vez de induzir o paciente com a questão "fez uso de bolsa de gelo ou exercícios propostos", foi utilizada a questão "utilizou algum método para reduzir edema, e quais métodos foram realizados". A sessão dormir e respirar foi desmembrada, pois o paciente pode ter uma dificuldade e não outra.

Em relação ao teste de conhecimento, as pessoas apresentaram bom ajuste ao modelo com relação a habilidade para responde-lo. No entanto, a análise de Rasch para os itens mostrou que o modelo não se ajusta, com empilhamento de questões fáceis no limite inferior do mapa. Além disso, os itens ficaram centrados em determinados pontos, o que mostra uma lacuna na elaboração do constructo. O ideal seria que os participantes se dividissem uniformemente em três níveis de habilidade: baixa, média e alta ${ }^{61}$.

Um valor de MNSQ menor que 0,7 indica pouca variância do escore dos itens ou um padrão de resposta previsível $^{62}$. No presente estudo, $70 \%$ dos itens apresentaram valor inferior ou igual a 0,5. Geralmente, assume-se que quando mais de 5\% dos itens não se ajustam ao modelo, os itens da escala não medem um constructo unidimensional ${ }^{63}$ e precisam ser revistos.

A questão P4, por exemplo, foi muito genérica; as alternativas focavam diversos cuidados e havia uma alternativa de "todas estão corretas". O grau de dificuldade do item P4 foi zero. O item P3 sobre uso de aparelho ortodôntico após a cirurgia era fácil demais e poderia ser acertado por dedução.

A confiabilidade tanto para o grau de dificuldade quanto para a habilidade das pessoas foi baixa. Os resultados indicam que para melhorar a confiabilidade dos itens é preciso aumentar o tamanho da amostra e para melhorar a confiabilidade da habilidade das pessoas é preciso aumentar o número de itens ${ }^{60}$.

A partir dos resultados obtidos para a realização do futuro ensaio clínico randomizado e controlado algumas modificações foram feitas nos instrumentos para o teste de conhecimento (Apêndice II) e avaliação clínica (Apêndice I). As questões do teste de conhecimento foram reavaliadas e verificou-se que alguns enunciados poderiam medir mais de um constructo e havia respostas capazes de induzir respostas de outros testes. 


\section{SEGUNDA FASE - ENSAIO CLÍNICO RANDOMIZADO}

Posteriormente ao estudo piloto e após adequação dos instrumentos de coleta de dados, foi dado início ao ensaio clínico. O período de coleta compreendeu agosto de 2013 a agosto de 2015.

\subsection{MATERIAL E MÉTODO}

\subsubsection{Casuística}

Ensaio clínico randomizado, com tamanho amostral determinado por conveniência $(n=40)$. Esse tamanho amostral foi determinado com base na condição de um número restrito de cirurgias realizadas por mês (duas a três), que, ao longo de dois anos, período para conclusão da coleta de dados, proporcionaria 48 pacientes. Levando em consideração a possibilidade de perda de alguns pacientes, optou-se pela amostra de quarenta pacientes. $\mathrm{O}$ poder do teste calculado após a coleta foi de teste de 99,9\%.

Baseado no CONSORT (Consolidated Standards of Reporting Trials) checklist, o pesquisador deve estipular o número de participantes na pesquisa para que seus propósitos sejam alcançados de maneira satisfatória. Um ensaio clínico com tamanho amostral superior ao necessário para alcançar seus propósitos pode infligir questões éticas, pois é possível que um número desnecessário de indivíduos seja exposto a riscos, desconfortos e inconvenientes trazidos pelo tratamento ou intervenção em estudo. Além disso, implica em desperdício de tempo e recursos financeiros, materiais e humanos ${ }^{64}$.

8.1.2 Randomização

O processo de inclusão dos pacientes para o grupo de intervenção ocorreu por randomização por blocos.

Na distribuição aleatória por blocos (blocked randomization), cada bloco contém um número predeterminado de participantes. Por exemplo, cada bloco possui o mesmo número de As e $\mathrm{Bs}$ ( $\mathrm{A}=$ =intervenção e $\mathrm{B}=$ controle) e a ordem dos tratamentos é permutada aleatoriamente dentro de cada bloco. Um bloco contendo quatro sujeitos possui seis possibilidades diferentes de combinações de dois As e dois Bs (AABB, ABAB, ABBA, BABA, BAAB e BBAA). Assim, as intervenções são alocadas para os próximos quatro 
pacientes na ordem pré-especificada pelo próximo bloco aleatório. A permuta aleatória dos segmentos assegura o equilíbrio no número de sujeitos alocados em cada braço do estudo ${ }^{65}$.

Dessa forma, para esta pesquisa, aplicou-se a alocação com blocos de quatro sujeitos, como descrito na literatura, constituído de dez blocos de quatro sujeitos para atender de forma regular todos os pacientes e garantir que os grupos controle e intervenção tenham distribuição equilibrada (20/20).

Os blocos foram criados e distribuídos pelo pesquisador principal, sendo nominados como "A" grupo intervenção, e "B" grupo controle. Com a criação do primeiro bloco, os pacientes eram distribuídos conforme iniciam o preparo para cirurgia e alocados como controle ou experimental seguindo a ordem de distribuição do bloco. Ao final desse bloco, foi criado o segundo bloco e realizada a distribuição dos pacientes conforme a determinação do bloco, e assim sucessivamente até a conclusão do décimo bloco para esta intervenção.

\subsubsection{Grupos de estudo}

Grupo experimental: orientação perioperatória individualizada com apoio de material educativo impresso dada pela enfermeira e orientação perioperatória rotineira dada pelo cirurgião.

Grupo controle: orientações fornecidas pelo cirurgião como ocorre habitualmente, apenas com realização do seguimento.

Os instrumentos de ansiedade, teste de conhecimento e avaliação clínica propostos para o grupo intervenção também foram aplicados ao grupo controle em momentos iguais aos propostos para o grupo intervenção.

\subsubsection{Recrutamento}

No período de $1^{\mathrm{o}}$ de agosto de 2013 a 31 de agosto de 2015, 49 pacientes potencialmente elegíveis foram avaliados no ambulatório de cirurgia e traumatologia bucomaxilofacial referência ao estudo. Destes, quatro perderam o plano de saúde e interromperam o tratamento, dois optaram por prosseguir com outra equipe bucomaxilo, dois 
fizeram o acompanhamento pós-operatório em outro ambulatório e um se recusou a participar da pesquisa. Foram randomizados quarenta pacientes para o estudo e, conforme proposto, alocados vinte em cada grupo. Não houve perdas até o final da pesquisa dentro de 45 dias de seguimento pós-operatório (Figura 4).

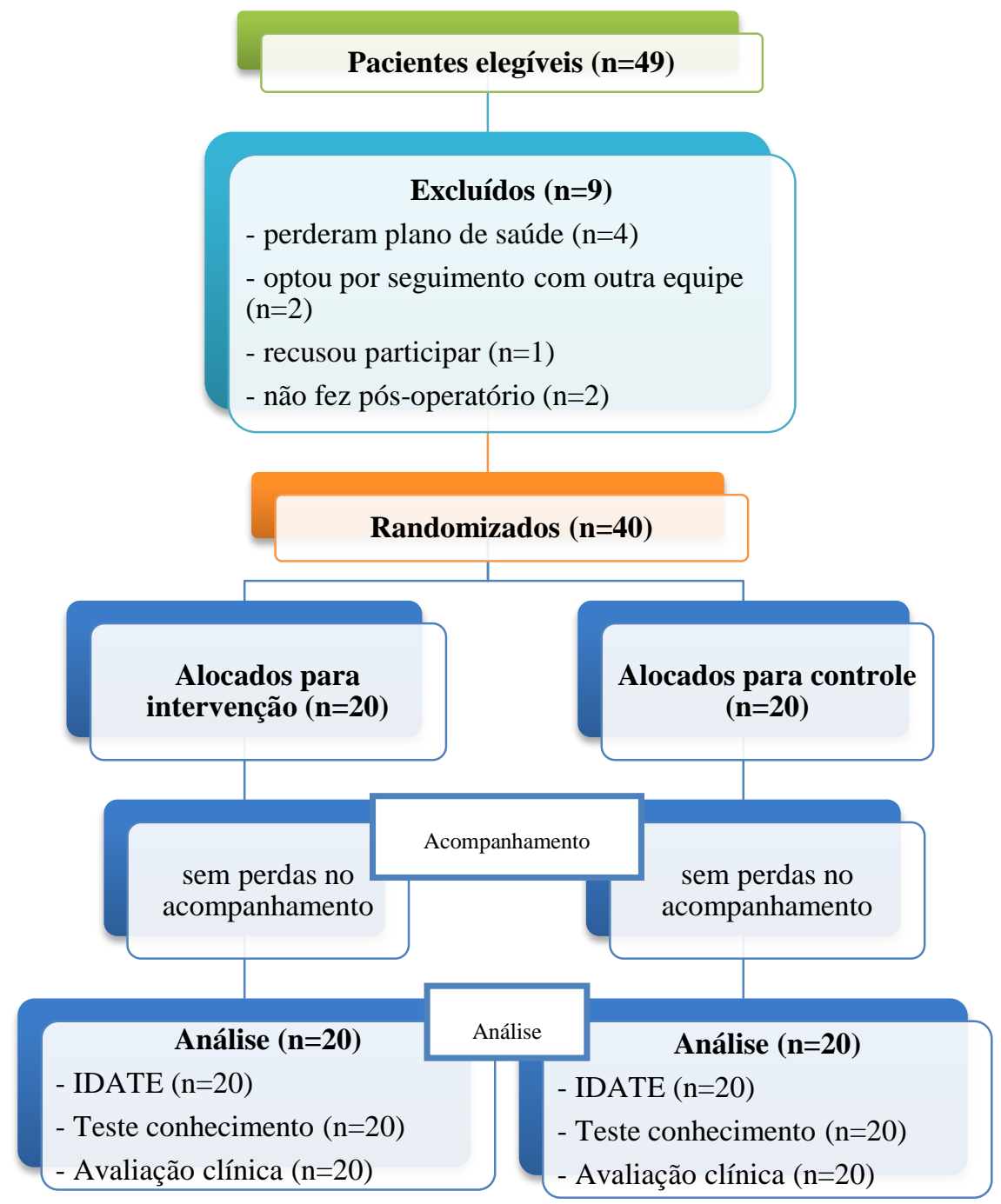

Figura 4 - Diagrama Consort. São Paulo, 2015.

\subsubsection{Desfecho}

O desfecho primário foi o conhecimento sobre os cuidados pós-operatórios, avaliado pelo teste de conhecimento. Os desfechos secundários foram os sinais e sintomas do pós-operatório, medidos pela avaliação clínica e pela ansiedade medida pelo inventário IDATE. 
Apesar dos itens serem avaliados a cada encontro, o desfecho foi mensurado na conclusão da coleta de dados para evitar inferência na condução do processo.

\subsubsection{Seguimento}

Após a randomização para o grupo intervenção, houve um segundo contato para realizar a intervenção com uso da tecnologia educativa, proposto no pré-operatório na consulta em que antecede a cirurgia.

No pós-operatório, houve quatro momentos de contato com o paciente, com intervalos regulares para avaliação clínica: três a sete dias (corresponde ao primeiro retorno); dez a quinze dias (segundo retorno); 25 a trinta dias (terceiro retorno) e 45 dias de pósoperatório (quarto retorno) para ambos os grupos (controle e intervenção). O inventário de ansiedade e o teste de conhecimento foram aplicados nos primeiro, terceiro e quarto retornos para ambos os grupos (controle e intervenção).

Assim como no estudo piloto, o acompanhamento no pós-operatório foi realizado pelo pesquisador2, que não participava da intervenção com a tecnologia educativa e desconhecia as orientações fornecidas ao grupo experimental. $O$ pesquisador 2 estava cegado quanto à randomização e ao processo de intervenção, com atuação apenas na coleta de dados dos instrumentos propostos.

Por sua vez, o pesquisador1, que fez a randomização por blocos e aplicou a intervenção no grupo experimental, não acompanhou a evolução e a coleta de dados do pósoperatório, portanto desconhecia os resultados coletados durante o processo e não interviu nos retornos pós-operatórios.

8.1.5 Instrumentos de mensuração

O instrumento de avaliação clínica foi readequado após o estudo piloto para melhorar a avaliação e foi aplicado aos pacientes por profissional sem conhecimento do grupo intervenção e controle (Apêndice V). Nas avaliações posteriores, foi aplicado o 
mesmo instrumento, assim, ao final das avaliações, obtiveram-se quatro vias do instrumento (uma para cada momento de avaliação).

Os níveis de ansiedade foram mensurados com inventário de ansiedade traço-estado IDATE (Anexo I) no pré e pós-operatório.

O instrumento para o teste do conhecimento do paciente sobre a cirurgia pré e pósprocedimento foi readequado para questões de maior complexidade. Mantiveram-se dez questões de múltipla escolha sobre a cirurgia e os cuidados necessário no pós-operatório e aplicação ao paciente no pré e pós-operatório (Apêndice VI).

\subsubsection{Grupo intervenção}

O grupo de intervenção seguiu o modelo proposto e aplicado no teste piloto com orientação verbal individualizada e apoio da tecnologia educativa impressa Cirurgia ortognática para pacientes. Também receberam a orientação habitual do cirurgião, que compreende, na consulta pré-operatória, informações sobre a marcação da cirurgia, jejum, exames pré-operatórios, edema pós-operatório, presença de parestesia, abertura da boca limitada, possível hematoma, alteração da estética facial e auto aceitação sobre nova face. No pós-operatório, são reforçados a necessidade de higiene oral, a abertura da cavidade oral limitada, o reforço do manuseio de elásticos ortodônticos, controle da dor pós-operatória e respondidas as questões do paciente que costumam ser mais frequentes sobre parestesia, abertura da boca, dieta e quando retorna as atividades.

\subsubsection{Grupo controle}

Para o grupo controle as orientações foram fornecidas pelo cirurgião como ocorre atualmente e foi realizado apenas o seguimento. Os instrumentos de ansiedade, teste de conhecimento e avaliação clínica propostos para o grupo intervenção também foram aplicados a estes pacientes em momentos iguais aos propostos para o grupo intervenção. 
Neste estudo, as observações repetidas do paciente tendem a ser correlacionadas entre si e, na análise de medidas repetidas, os modelos estatísticos empregados correspondem aos modelos lineares longitudinais. Os dados foram inseridos em planilha Excell® for Mac 2011 e posteriormente analisados no Statistical Package for the Social Sciences Software - SPSS 20.0.

Utilizaram-se na análise Equações de Estimação Generalizadas (Generalized Estimating Equations - GEE) e os Modelos de Efeitos Mistos. O método GEE tem por objetivo estimar parâmetros de regressão especialmente quando os dados estão correlacionados e é capaz de avaliar a relação entre a variável resposta e as variáveis preditores em um contexto populacional e não individual. Por sua vez, o Modelo de Efeitos Mistos está composto por dois componentes: um intraindivíduo (uma alteração longitudinal intraindivíduo é descrita pelo modelo de regressão com um intercepto e inclinação populacional) e outro entre indivíduos (variação no intercepto e inclinação individual), ou seja, o foco é o indivíduo ${ }^{66}$.

Assim, aplicou-se para análise dos dados no inventário de ansiedade IDATE teste de conhecimento. Para a variável dor e peso corporal da avaliação clínica, o modelo de efeitos mistos; e para os demais itens da avaliação clínica, foi aplicado o teste GEE com distribuição binomial

\subsection{RESULTADOS}

Os resultados das variáveis deste estudo são apresentados por categorias, conforme o instrumento de coleta de dados aplicado.

\subsubsection{Característica dos pacientes}

Os pacientes do grupo experimental apresentaram idade média de $26,8 \pm 8,2$ anos, 100\% sem os principais antecedentes clínicos (tabagismo, obesidade e diabetes mellitus), $55 \%(n=11)$ eram do sexo masculino, $50 \%(n=10)$ solteiros, $60 \%(n=12)$ com ensino médio completo (seis a dez anos de estudo), 85\% ( $\mathrm{n}=17)$ apresentavam motivação funcional para realizar a cirurgia e os outros $15 \%(n=3)$ apresentavam motivação estética. Durante o 
acompanhamento, não houve complicações cirúrgicas para este grupo. Após o procedimento cirúrgico, $70 \%(\mathrm{n}=14)$ referiram como alteração significativa a alteração da aparência física, seguidos de $20 \%(n=4)$ que se sentiram mais confiantes, $5 \%(n=1)$ que notaram uma alteração da voz e 5\%(n=1), outra (relacionada a mastigação). Cem por cento $(100 \%)$ disseram sentir-se satisfeitos com os resultados do procedimento.

Os pacientes do grupo controle apresentaram idade média de $27,4 \pm 6,9$ anos, $100 \%$ sem os principais antecedentes clínicos (tabagismo, obesidade e diabetes mellitus), 55\% $(n=11)$ eram do sexo feminino, $80 \%(n=16)$ solteiros, $40 \%(n=8)$ com ensino superior completo (dez a catorze anos de estudo), 55\% ( $\mathrm{n}=11)$ apresentavam motivação funcional para realizar cirurgia, seguidos de 35\% ( $n=7)$ movidos pela indicação médica e $10 \%(n=2)$, por motivação estética. Durante o acompanhamento, dois pacientes submetidos a Osteotomia Segmentar de Maxila apresentaram complicação cirúrgica, um com sinupatia pós-operatória e outro com sangramento arterial no 15ำ dia pós-operatório. Após o procedimento cirúrgico, $65 \%(n=13)$ referiram como alteração significativa a alteração da aparência física, seguidos de 30\% (n=6), outra alteração (relacionada a mordida e melhora na mastigação). Cinco por cento (5\%) $(\mathrm{n}=1)$ sentiram-se mais confiantes e 100\% disseram sentir-se satisfeitos com os resultados do procedimento.

A técnica cirúrgica utilizada nos procedimentos é apresentada na Tabela 6 e não houve diferença significativa entre os grupos.

Tabela 6 - Pacientes do ensaio clínico quanto a técnica cirúrgica. São Paulo, 2015. 


\begin{tabular}{|c|c|c|c|c|c|}
\hline & \multicolumn{2}{|c|}{ Experimental } & \multicolumn{2}{|c|}{ Controle } & \multirow{2}{*}{ Valor $\mathrm{p}$} \\
\hline & $\mathrm{N}$ & $\%$ & $\mathrm{~N}$ & $\%$ & \\
\hline Lefort I & 5 & 25 & 5 & 25 & 1,000 \\
\hline Lefort I com mentoplastia & - & - & 1 & 5 & 1,000 \\
\hline $\begin{array}{l}\text { Lefort I com Osteotomia } \\
\text { mandíbula }\end{array}$ & 6 & 30 & 2 & 10 & 0,235 \\
\hline Osteotomia segmentar de maxila & 3 & 15 & 8 & 40 & 0,155 \\
\hline $\begin{array}{l}\text { Osteotomia de ramo bilateral de } \\
\text { mandíbula }\end{array}$ & 6 & 30 & 4 & 20 & 0,716 \\
\hline
\end{tabular}

\subsubsection{Teste de conhecimento}

A aplicação do teste de conhecimento foi realizada no pré-operatório e nos três retornos subsequentes. Os valores de medida, desvio padrão e variação com a representação estatística para ambos os grupos são apresentados na Tabela 7. 
Tabela 7 - Resultados do pré e pós-teste de conhecimento nos momentos propostos, segundo grupo. São Paulo. 2015.

\begin{tabular}{|c|c|c|c|c|c|}
\hline \multirow{3}{*}{ Momento de aplicação } & \multicolumn{4}{|c|}{ Grupo } & \multirow{3}{*}{ Valor $\mathrm{p}^{\mathrm{a}}$} \\
\hline & \multicolumn{2}{|c|}{ Experimental } & \multicolumn{2}{|c|}{ Controle } & \\
\hline & Média(DP) & Variação & Média(DP) & Variação & \\
\hline Pré-operatório & $4,2(1,7)$ & $1-8$ & $4,3(2,2)$ & $1-9$ & \\
\hline $1^{\circ}$ retorno & $6,5(1,5)$ & $4-10$ & $4,3(1,9)$ & $1-8$ & \\
\hline $3^{\circ}$ retorno & $6,8(1,6)$ & $4-10$ & $5,0(2,2)$ & $1-9$ & $<0,001^{*}$ \\
\hline $4^{\circ}$ retorno & $7,0(1,5)$ & $3-10$ & $5,2(2,3)$ & $1-9$ & \\
\hline
\end{tabular}

Observa-se que o grupo experimental apresentou melhora da média principalmente do pré-operatório para o primeiro retorno pós-operatório, enquanto no grupo controle a média pouco se modificou. Ambos os grupos iniciaram com média semelhante, em torno de quatro pontos, porém no segundo retorno pós-operatório observa-se aumento de 2,3 pontos na nota média, com alcance de 2,9 pontos até o último retorno, que corresponde a 45 dias de pós-operatório.

Os valores foram representativos, com significância estatística $(p=0,000)$, demonstrando que os grupos evoluíram de forma diferente durante o acompanhamento. $\mathrm{O}$ grupo experimental teve melhor desempenho em relação ao conhecimento, demonstrando a eficácia da aplicação da orientação verbal apoiada pelo material educativo, conforme demonstra a Figura 5. 


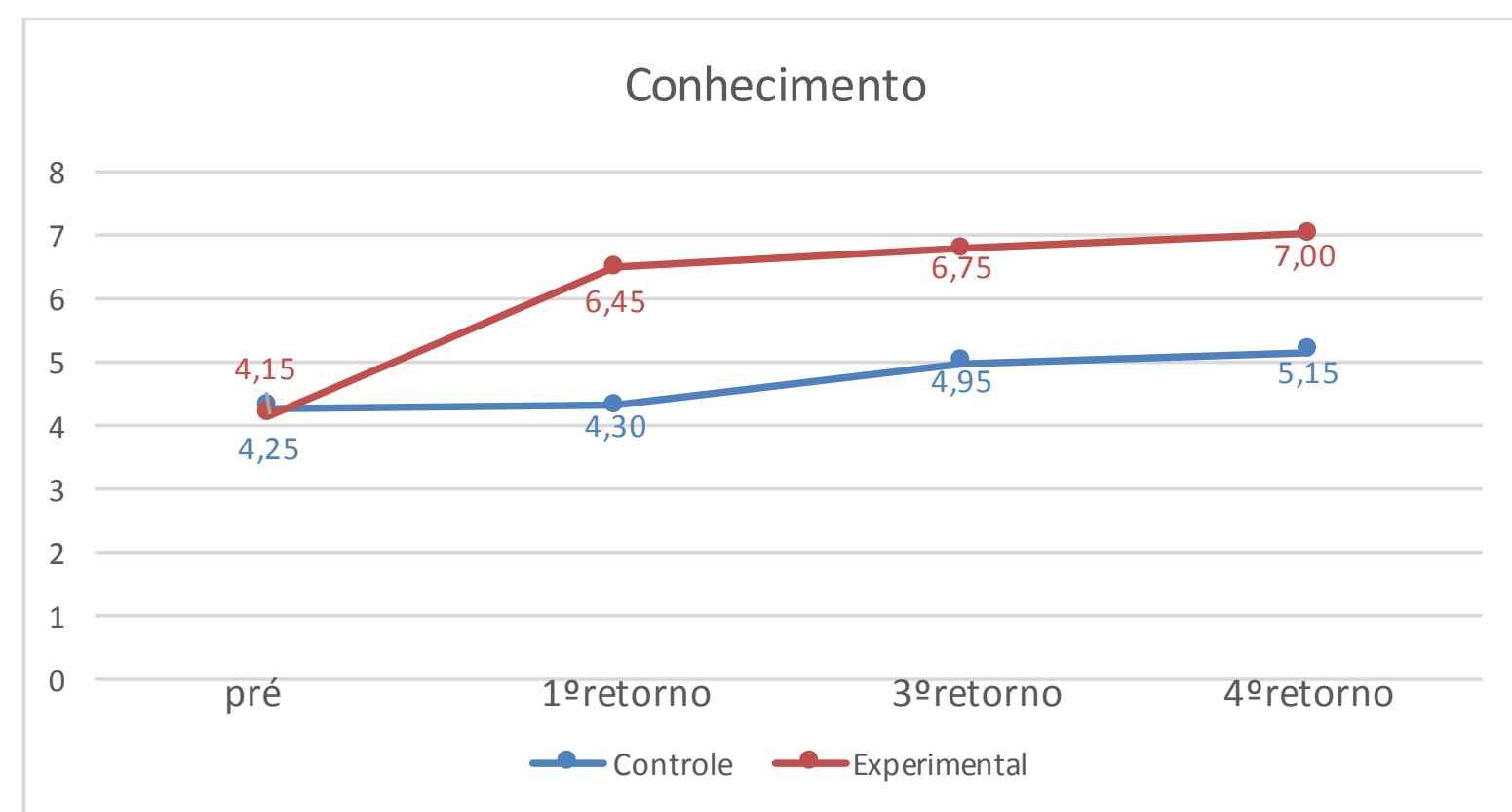

Figura 5 - Evolução dos grupos na mensuração de conhecimento sobre o procedimento cirúrgico. São Paulo, 2015.

Ao se analisar os temas abordados nas questões de conhecimento, observa-se que o diferencial no manejo de sinais e sintomas no pós-operatório esteve relacionado à higiene oral $(\mathrm{p}=0,014)$.

Em uma avaliação do conhecimento basal com os dados colhidos no pré-operatório entre o grupo experimental e controle, observou-se que o conhecimento prévio sobre o procedimento cirúrgico era semelhante nesse período, e não houve diferença estatística entre os dois grupos $(\mathrm{p}=0,873)$. 
Tabela 8 - Respostas corretas por questão para os grupos experimental e controle no pré-operatório. São Paulo, 2015.

\begin{tabular}{|c|c|c|c|c|c|}
\hline \multirow{3}{*}{ Questões } & \multicolumn{4}{|c|}{ Grupo } & \multirow{3}{*}{ Valor $\mathrm{p}^{\mathrm{a}}$} \\
\hline & \multicolumn{2}{|c|}{ Experimental } & \multicolumn{2}{|c|}{ Controle } & \\
\hline & $\mathrm{N}$ & $\%$ & $\mathrm{~N}$ & $\%$ & \\
\hline 1.cirurgia & 18 & 90 & 14 & 70 & 0.235 \\
\hline 2.pós-operatório & 16 & 80 & 13 & 65 & 0.480 \\
\hline 3.sangramento oral & 2 & 10 & 4 & 20 & 0.661 \\
\hline 4.mobilidade & 7 & 35 & 6 & 30 & 1.000 \\
\hline 5.edema & 4 & 20 & 5 & 25 & 1.000 \\
\hline 6.hidratação labial & 2 & 10 & 5 & 25 & 0.407 \\
\hline 7.higiene oral & 8 & 40 & 9 & 45 & 1.000 \\
\hline 8.alimentação & 12 & 60 & 10 & 50 & 0.751 \\
\hline 9.higiene corporal & 13 & 65 & 13 & 65 & 1.000 \\
\hline 10.atividades pós-procedimento & 5 & 25 & 6 & 30 & 1.000 \\
\hline
\end{tabular}

${ }^{a}$ Modelo de Efeitos Mistos $* p<0,05$

Os acertos em porcentagem sã 6 para grupo experimental e na figura esta parte...o apresentados na Figura 6 para grupo experimental e na Figura 7 para grupo controle. 


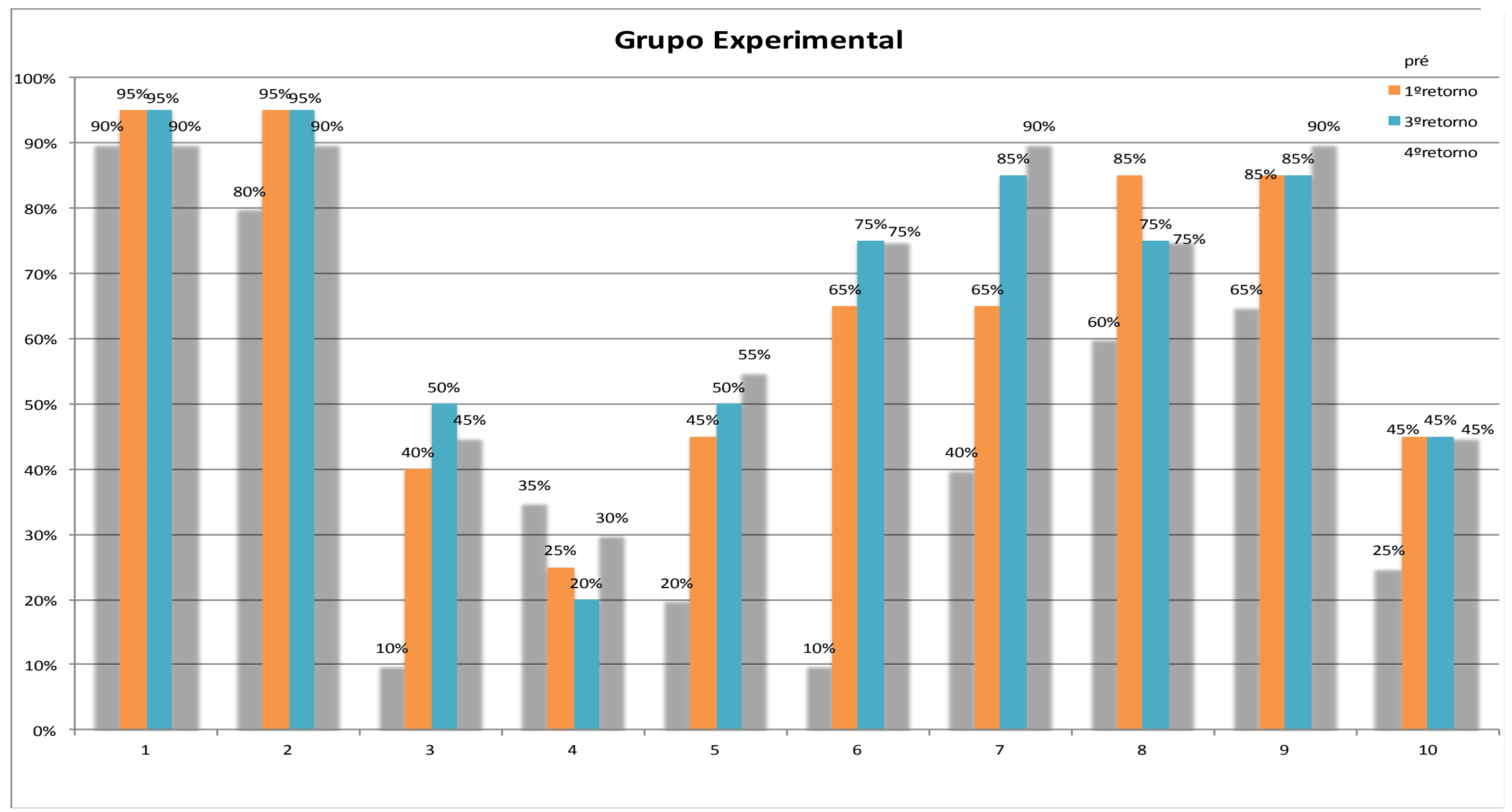


Figura 6 - Porcentagem de acertos por questão do pré e pós-teste de conhecimento do grupo experimental nos momentos propostos . São Paulo, 2015. 


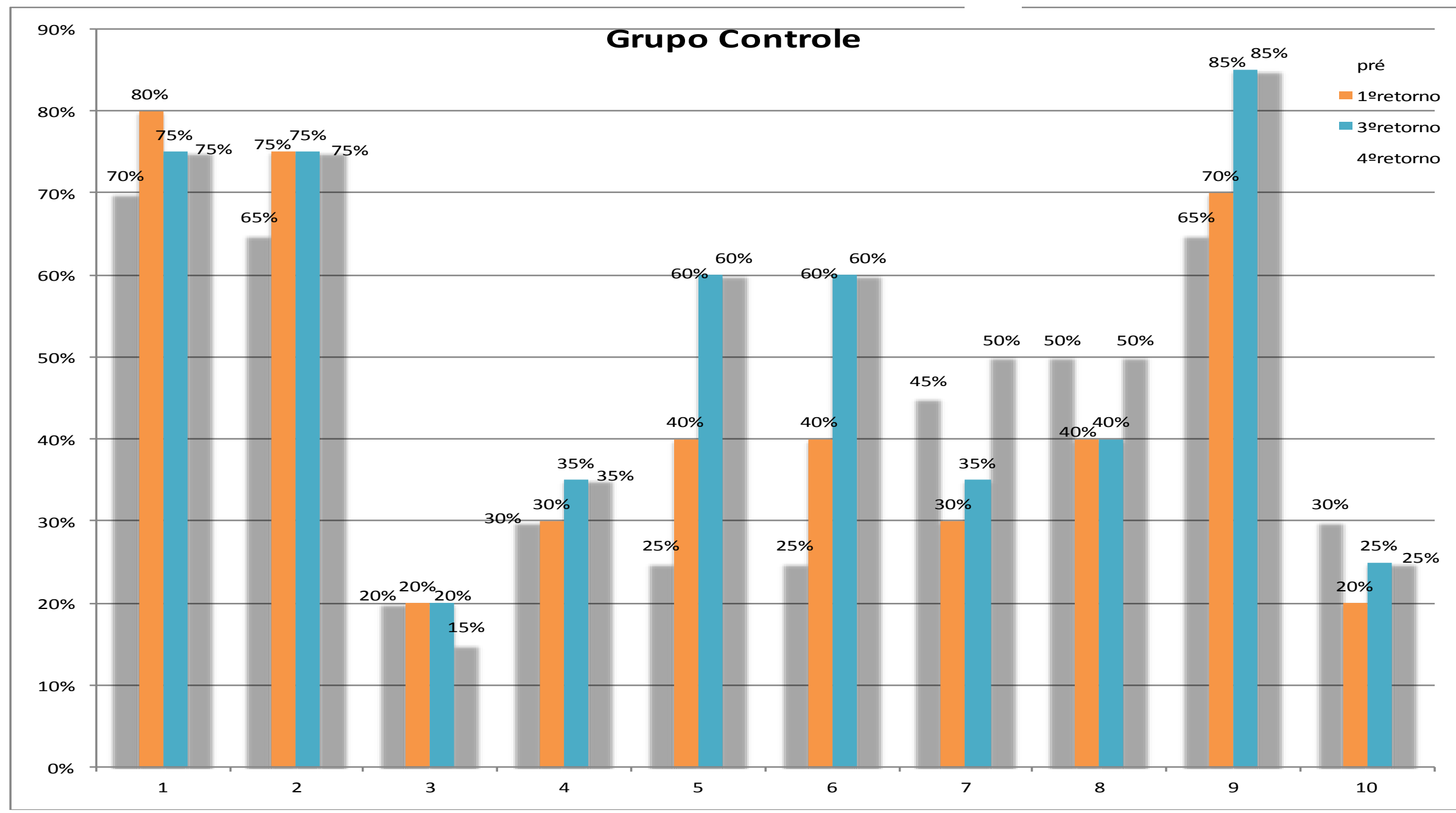


Figura 7 - Porcentagem de acertos por questão do pré e pós-teste de conhecimento do grupo controle nos momentos propostos. São Paulo, 2015. 
8.2.3 Inventário de ansiedade

O grau de ansiedade mensurado nos pacientes do grupo experimental é considerado nível médio ${ }^{55}$, com valores entre $\geq 30$ e $\leq 50$. O grupo controle apresentou valores médios superiores, porém caracterizam o nível médio de ansiedade (Tabela 9).

Tabela 9 - Resultados da análise do inventário de ansiedade IDATE. São Paulo, 2015.

\begin{tabular}{|c|c|c|c|c|c|c|}
\hline \multirow{2}{*}{ Momento de medida } & \multicolumn{2}{|c|}{ IDATE-estado, Média(DP) } & \multicolumn{3}{|c|}{ IDATE-traço, Média(DP) } & \multirow{2}{*}{ valor $\mathrm{p}^{\mathrm{a}}$} \\
\hline & Experimental & Controle & & Experimental & Controle & \\
\hline Pré-operatório & $39,3(12,1)$ & $45,2(10,4)$ & & $35,4(7,4)$ & $40,2(10,6)$ & \\
\hline \multirow[t]{2}{*}{$1^{\circ}$ retorno } & $35,8(11,3)$ & $40,1(11,2)$ & & $35,0(8,1)$ & $38,9(9,6)$ & \\
\hline & & & 0,818 & & & 0,906 \\
\hline $3^{\circ}$ retorno & $33,9(9,4)$ & $36,7(10,3)$ & & $33,3(8,0)$ & $37,0(8,5)$ & \\
\hline $4^{\circ}$ retorno & $34,4(10,2)$ & $37,2(10,4)$ & & $33,9(8,6)$ & $37,0(9,2)$ & \\
\hline
\end{tabular}

${ }^{\mathrm{a}}$ Modelo de Efeitos Mistos $* p<0,05$

Em ambos os grupos, os valores médios do IDATE-estado foram superiores aos mensurados pelo IDATE-traço nos momentos de pré-operatório e retornos do pósoperatório.

$\mathrm{Na}$ avaliação dos níveis de ansiedade IDATE-traço, os valores não apresentam redução expressiva para pacientes do grupo experimental e controle. A redução dos níveis de ansiedade é evidenciada com maior valor entre o pré-operatório e o quarto retorno. Nesta avaliação, os pacientes do grupo experimental apresentam redução de 1,5 pontos e o grupo controle 3,25 pontos. 
8.2.4 Avaliação clínica

Os sinais e sintomas e manejo dos cuidados pós-operatórios são apresentados conforme avaliação na Tabela 10.

Apresentaram resultados significativos a presença de halitose e perda de peso corpóreo, demonstrando evolução diferente entre o grupo experimental e controle.

Para manter a hidratação labial, $85 \%$ dos pacientes do grupo experimental utilizaram a manteiga de cacau nos três primeiros retornos, seguido de $65 \%$ no quarto retorno. No grupo controle, $55 \%$ dos pacientes utilizaram a manteiga de cacau nos três primeiros retornos, seguidos de $10 \%$ que utilizaram bepantol e $5 \%$ que passaram batom. Observa-se que nesse grupo $20 \%$ dos pacientes não realizou a hidratação labial.

O recurso utilizado para a auxiliar na redução do edema pelos pacientes do grupo experimental foi o gelo, em $80 \%$ no primeiro retorno, seguidos de $50 \%$ no segundo, $25 \%$ no terceiro e $15 \%$ no quarto. O grupo controle também usou gelo, $75 \%$ dos pacientes fez uso no primeiro retorno, seguidos de $60 \%$ no segundo, $25 \%$ no terceiro e quarto retornos. Nesse grupo, um dos pacientes referiu o uso de creme hidrante para controle do edema.

Dentre os exercícios faciais, $75 \%$ dos pacientes não executou nenhum exercício facial até o primeiro retorno, seguidos de $45 \%$ no segundo, $40 \%$ no terceiro e $50 \%$ no quarto. No grupo controle, foram observados índices maiores: $80 \%$ no primeiro retorno, seguidos de $50 \%$ no primeiro e segundo retornos e $55 \%$ no quarto.

Quando executaram o exercício facial, o exercício de fazer bico foi o predominante, com $15 \%$ dos pacientes do grupo experimental no primeiro retorno, seguidos de $25 \%$ no segundo e terceiro retornos e $15 \%$ no quarto. No grupo controle, foram observados $5 \%$ no primeiro retorno, $30 \%$ no segundo retorno, $25 \%$ no terceiro e $5 \%$ no quarto retorno. 
Tabela 10 - Resultados dos itens de avaliação clínica $(n=40)$ a cada retorno segundo o grupo de estudo. São Paulo. 2015.

(continua)

\begin{tabular}{|c|c|c|c|c|c|c|c|c|}
\hline \multirow{4}{*}{ Variáveis } & \multicolumn{7}{|c|}{ Pós-operatório (\%) } & \multirow{4}{*}{ Valor $\mathrm{p}^{\mathrm{a}}$} \\
\hline & $1^{\circ}$ retorno & $2^{\circ}$ reto & & $3^{\circ}$ retor & & $4^{\circ}$ retor & no & \\
\hline & \multicolumn{7}{|c|}{ Grupo } & \\
\hline & Experimental & Experimental & Controle & Experimental & Controle & Experimental & Controle & \\
\hline
\end{tabular}

Higiene Oral

Halitose

Gengiva descorada

Gengivite

Língua saburrosa

Sutura com resíduo alimentar
40

25

25

60

35

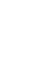

10

60

20
5

50

20
5

5

$-$

- $\quad 0,003^{*}$
55

15

-
55
15

20

20

15

5

5

$\begin{array}{ccc}- & - & 0,003^{*} \\ - & - & - \\ - & - & 0,241 \\ 5 & 15 & 0,444 \\ - & - & 1,000\end{array}$


ป̀(continuação)

\begin{tabular}{|c|c|c|c|c|c|c|c|c|c|}
\hline \multirow{4}{*}{ Variáveis } & \multicolumn{8}{|c|}{ Pós-operatório (\%) } & \multirow{4}{*}{$\begin{array}{c}\text { Valor } \\
\mathrm{p}^{\mathrm{a}}\end{array}$} \\
\hline & \multicolumn{2}{|c|}{$1^{\circ}$ retorno } & \multicolumn{2}{|c|}{$2^{\circ}$ retorno } & \multicolumn{2}{|c|}{$3^{\circ}$ retorno } & \multicolumn{2}{|c|}{$4^{\mathrm{o}}$ retorno } & \\
\hline & \multicolumn{8}{|c|}{ Grupo } & \\
\hline & Experimental & Controle & Experimental & Controle & Experimental & Controle & Experimental & Controle & \\
\hline Presença de placa bacteriana & 15 & 15 & 15 & - & 15 & - & 5 & 10 & 0,174 \\
\hline Dificuldade em realizar higiene oral & 70 & 60 & 45 & 30 & 25 & 5 & 5 & 5 & 0,602 \\
\hline \multicolumn{10}{|l|}{ Mobilidade e Sensibilidade } \\
\hline $\begin{array}{l}\text { Limitação de abertura de boca acima do } \\
\text { esperado }\end{array}$ & 5 & - & - & 5 & - & - & - & - & 1,000 \\
\hline Desvio de mordida & - & - & - & - & - & - & - & - & - \\
\hline Resposta ao estímulo tátil & 50 & 50 & 65 & 65 & 70 & 75 & 70 & 80 & 0,653 \\
\hline
\end{tabular}




\begin{tabular}{|c|c|c|c|c|c|c|c|c|c|}
\hline \multirow{4}{*}{ Variáveis } & \multicolumn{8}{|c|}{ Pós-operatório (\%) } & \multirow{4}{*}{ Valor $\mathrm{p}^{\mathrm{a}}$} \\
\hline & \multicolumn{2}{|c|}{$1^{\circ}$ retorno } & \multicolumn{2}{|c|}{$2^{\circ}$ retorno } & \multicolumn{2}{|c|}{$3^{\circ}$ retorno } & \multicolumn{2}{|c|}{$4{ }^{\circ}$ retorno } & \\
\hline & \multicolumn{8}{|c|}{ Grupo } & \\
\hline & Experimental & Controle & Experimental & Controle & Experimental & Controle & Experimental & Controle & \\
\hline Movimentos faciais alterados & 5 & 15 & - & - & - & - & - & - & 1,000 \\
\hline Parestesia & 100 & 90 & 90 & 90 & 85 & 85 & 85 & 85 & 0,205 \\
\hline \multicolumn{10}{|l|}{ Hidratação labial } \\
\hline Ressecamento labial & 70 & 55 & 55 & 45 & 40 & 15 & 30 & 10 & 0,543 \\
\hline Lesão labial & 15 & 15 & 10 & 10 & 10 & 5 & - & 5 & 0,412 \\
\hline \multicolumn{10}{|l|}{ Evolução edema } \\
\hline Edema acima do esperado & - & - & - & - & - & - & - & - & - \\
\hline Exercício facial & 20 & 15 & 50 & 50 & 55 & 55 & 50 & 35 & 0,730 \\
\hline
\end{tabular}


(continuação) 
(continuação)

Pós-operatório (\%)

\begin{tabular}{ccccc}
\hline \multicolumn{1}{c}{$1^{\circ}$ retorno } & $2^{\circ}$ retorno & $3^{\circ}$ retorno & $4^{\circ}$ retorno & Valor \\
& & Grupo & $\mathrm{p}^{\mathrm{a}}$ \\
\hline Experimental & Controle & Experimental $\quad$ Controle Experimental Controle Experimental Controle
\end{tabular}

\section{Condições para dormir ou respirar}

Dificuldade para dormir

20

20

15

10

10

$-$

5

0,738

Dificuldade para respirar

15

10

10

$-$

10

Utilizou algum método para dormir ou

10

10

10

5

10

5

1,000

respirar melhor

\section{Nutrição (condições para alimentação)}

Auxílio para refeições

95

95

85

85

85

75

80

65

0,520

Dificuldade para fazer as refeições

55

15
30
15

5

0,382 
Pós-operatório (\%)

\begin{tabular}{|c|c|c|c|c|c|c|c|c|}
\hline \multirow{3}{*}{ Variáveis } & \multicolumn{2}{|c|}{$1^{\circ}$ retorno } & \multicolumn{2}{|c|}{$2^{\circ}$ retorno } & \multicolumn{2}{|c|}{$3^{\circ}$ retorno } & \multicolumn{2}{|c|}{$4^{\circ}$ retorno } \\
\hline & \multicolumn{8}{|c|}{ Grupo } \\
\hline & Experimental & Controle & Experimental & Controle & Experimental & Controle & Experimental & Controle \\
\hline
\end{tabular}

\section{Dor (tratamento)}

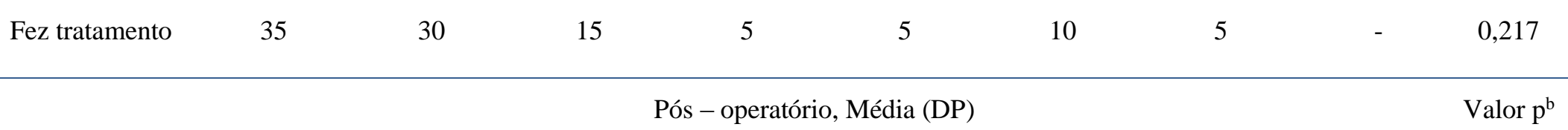

\section{Nutrição (alteração peso corporal)}

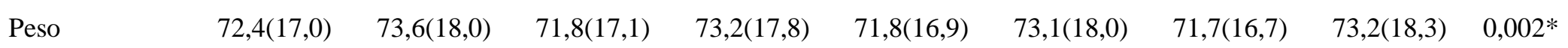

\section{Dor (escala analógica visual)}

$\begin{array}{lllllllll}\text { Intensidade } \quad 2,1(2,7) & 0,7(1,3) & 0,8(1,6) & 0,5(1,5) & 0,6(1,3) & 0,6(1,5) & 0,0(0,2) & 0,0(0,2) & 0,063\end{array}$

${ }^{a}$ GEE $\quad{ }^{b}$ Modelo de Efeitos Mistos $\quad *_{p}<0,05$ 
Em relação ao tratamento da dor, quando presente, os pacientes do grupo experimental utilizaram como analgésico a dipirona, com frequência de apenas $30 \%$ no primeiro retorno, seguidos de $15 \%$ no segundo, $5 \%$ no terceiro e $5 \%$ no quarto retorno. $\mathrm{O}$ grupo controle fez uso de dipirona, lisador ${ }^{\circledR}$ e anti-inflamatórios no primeiro retorno, com $15 \%, 10 \%$ e $5 \%$, respectivamente; no segundo retorno, $15 \%$ fez uso de dipirona, no terceiro, $10 \%$, e no quarto retorno não houve medicamento.

Além da inspeção da cavidade oral, algumas questões abertas foram feitas ao paciente para compreender sua dificuldade durante o pós-operatório (Tabela 11).

Em relação a higiene oral, no grupo experimental no primeiro retorno apenas $30 \%$ não apresentaram dificuldade em realizar a escovação após as refeições. Esse percentual evoluiu a cada retorno: $55 \%$ no segundo, $80 \%$ no terceiro e $95 \%$ no quarto retorno. Para o grupo controle, $50 \%$ referiram não ter dificuldade no primeiro retorno, seguido de $65 \%$ no segundo, $95 \%$ no terceiro e $100 \%$ no quarto.

Quanto ao manuseio do elástico ortodôntico, no grupo experimental 50\% dos pacientes não apresentaram dificuldade em manusear os elásticos no primeiro retorno. Esse índice melhorou conforme a evolução pós-operatória, com $60 \%$ no segundo retorno, $70 \%$ no terceiro e $80 \%$ no quarto. Para o grupo controle, $15 \%$ dos pacientes não apresentaram dificuldade de manuseio do elástico no primeiro e segundo retornos, seguidos de $25 \%$ no terceiro e quarto retornos.

Percebem-se pontos relevantes na evolução dos pacientes do grupo experimental, como no caso da orientação para realizar as refeições no domicílio.

Em um dos itens de avaliação clínica, era questionado ao paciente se havia dificuldade em fazer as refeições. Para os pacientes que receberam orientação pré-operatória com adjunto da tecnologia educativa, observa-se menor dificuldade em realizar as refeições, o que indica uma eficácia na aplicação da tecnologia educativa, embora essa diferença não tenha sido estatisticamente significativa nos seguimentos. 
Tabela 11 - Questões realizadas nos momentos de retorno pós-operatório. São Paulo, 2015.

\begin{tabular}{|c|c|c|c|c|c|c|c|c|}
\hline \multirow[b]{2}{*}{ Variável } & \multicolumn{8}{|c|}{ Pós-operatório (\%) } \\
\hline & \multicolumn{2}{|c|}{$1^{\circ}$ retorno } & \multicolumn{2}{|c|}{$2^{\circ}$ retorno } & \multicolumn{2}{|c|}{$3^{\circ}$ retorno } & \multicolumn{2}{|c|}{$4^{\circ}$ retorno } \\
\hline \multicolumn{9}{|c|}{ Higiene oral (Por que a dificuldade de fazer a higiene oral?) } \\
\hline Não conseguiu abrir a boca & 50 & 25 & 40 & 15 & 10 & 5 & 5 & - \\
\hline Teve medo & 5 & - & - & - & - & - & - & - \\
\hline Devido aos elásticos & 5 & 15 & - & 15 & 5 & - & - & - \\
\hline \multicolumn{9}{|l|}{ Elásticos ortodônticos (manuseio) } \\
\hline Sentiu dificuldade em manusear & 10 & 45 & 20 & 50 & 15 & 40 & 5 & 40 \\
\hline Não manuseou & 25 & 5 & 5 & - & - & - & - & - \\
\hline Não usou & 15 & 35 & 15 & 35 & 15 & 35 & 15 & 35 \\
\hline
\end{tabular}




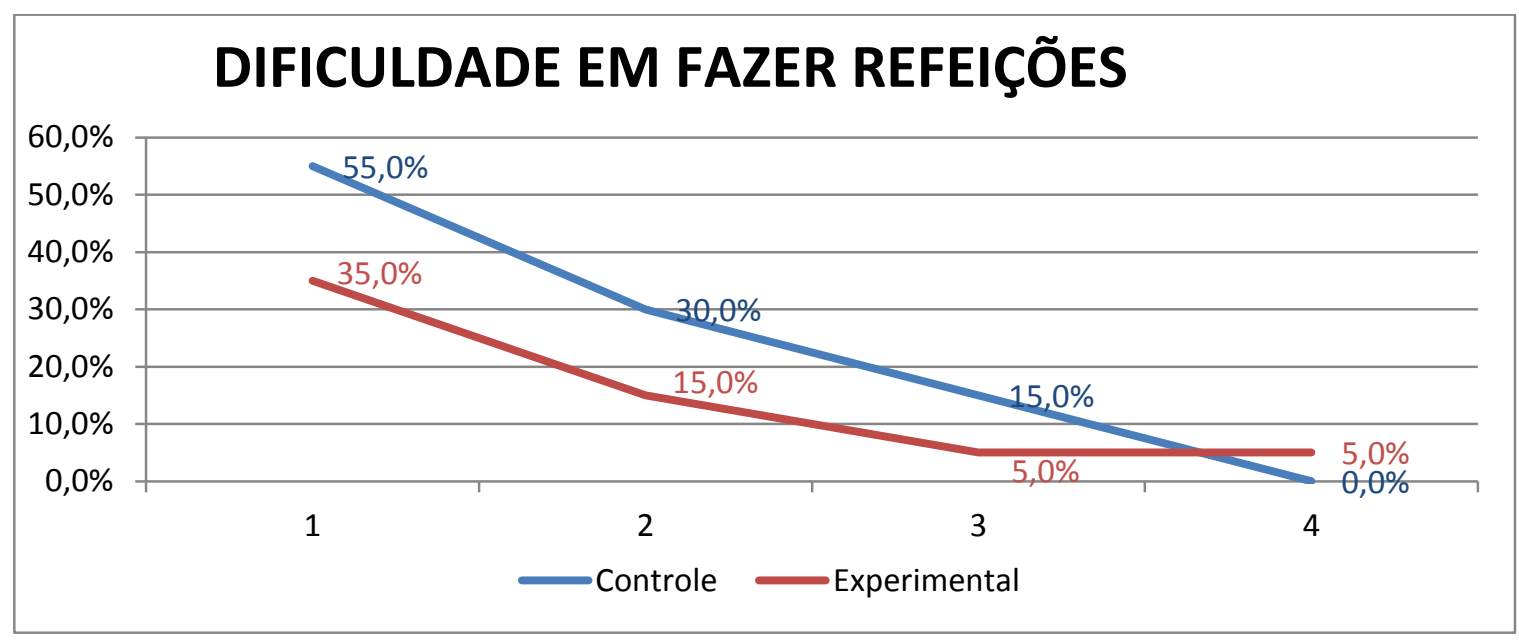

Figura 8 - Evolução dos grupos quanto à dificuldade em fazer as refeições. São Paulo, 2015.

Em relação à orientação para realizar o exercício facial e auxiliar na redução do edema e melhora da sensação temporária de parestesia, percebe-se que os pacientes do grupo experimental iniciaram a execução de exercícios antes dos pacientes do grupo controle. Entretanto, os pacientes do grupo controle que receberam uma orientação da equipe no retorno alcançaram níveis semelhantes na execução da orientação.

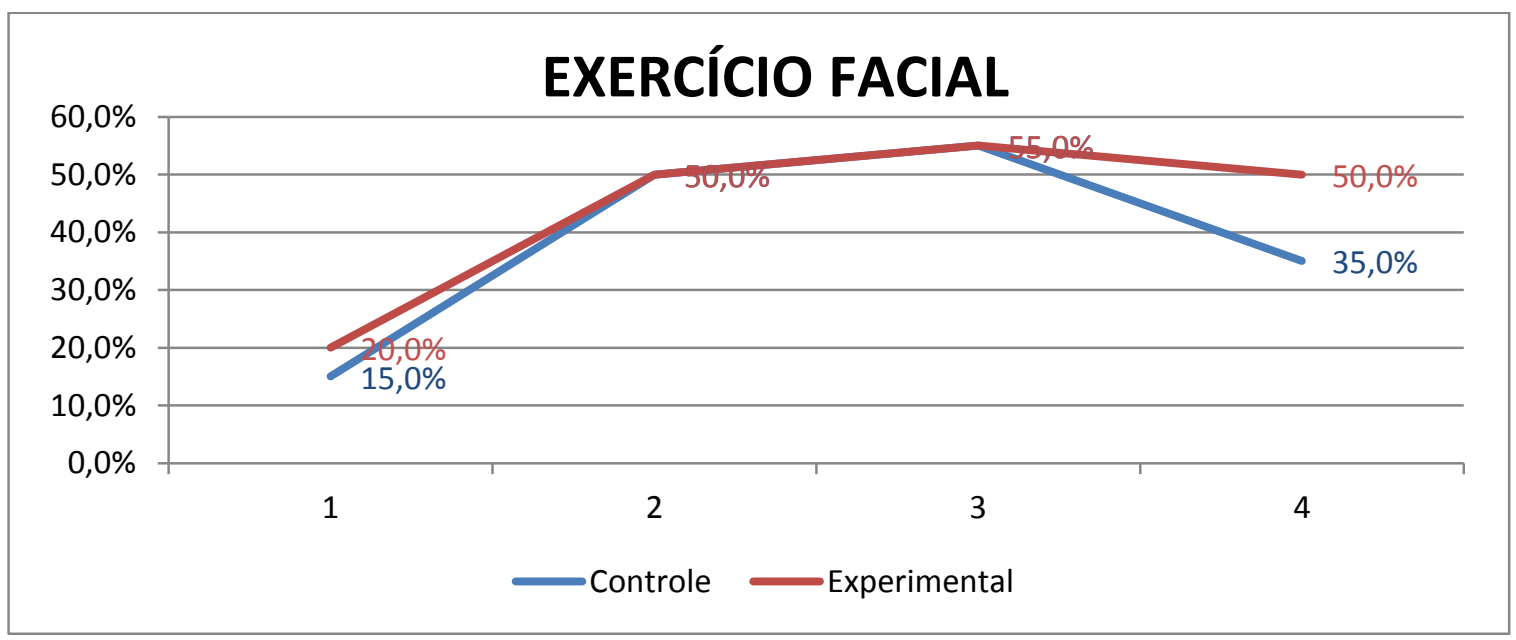

Figura 9 - Evolução dos grupos quanto a orientação de execução do exercício facial. São Paulo, 2015.

Outra orientação relevante é aplicação de métodos para dormir ou respirar melhor. Durante a orientação com aplicação da tecnologia educativa, era sugerido aos pacientes o uso 
de dois travesseiros para manter a cabeceira elevada e manter-se a maior parte do dia com a cabeça mais elevada para melhor respiração. Nota-se que para o grupo experimental houve um maior uso de estratégias para melhorar padrão de sono e de respiração durante o pós-operatório.

O uso dos elásticos ortodônticos no pós-operatório foi menos frequente no grupo controle, consequentemente, o fato diminui a dificuldade de realizar a higiene oral, resultado averiguado nesse grupo. Entretanto, nos pacientes com uso de elástico nesse grupo, percebe-se maior dificuldade de manuseio quando comparados ao grupo controle.

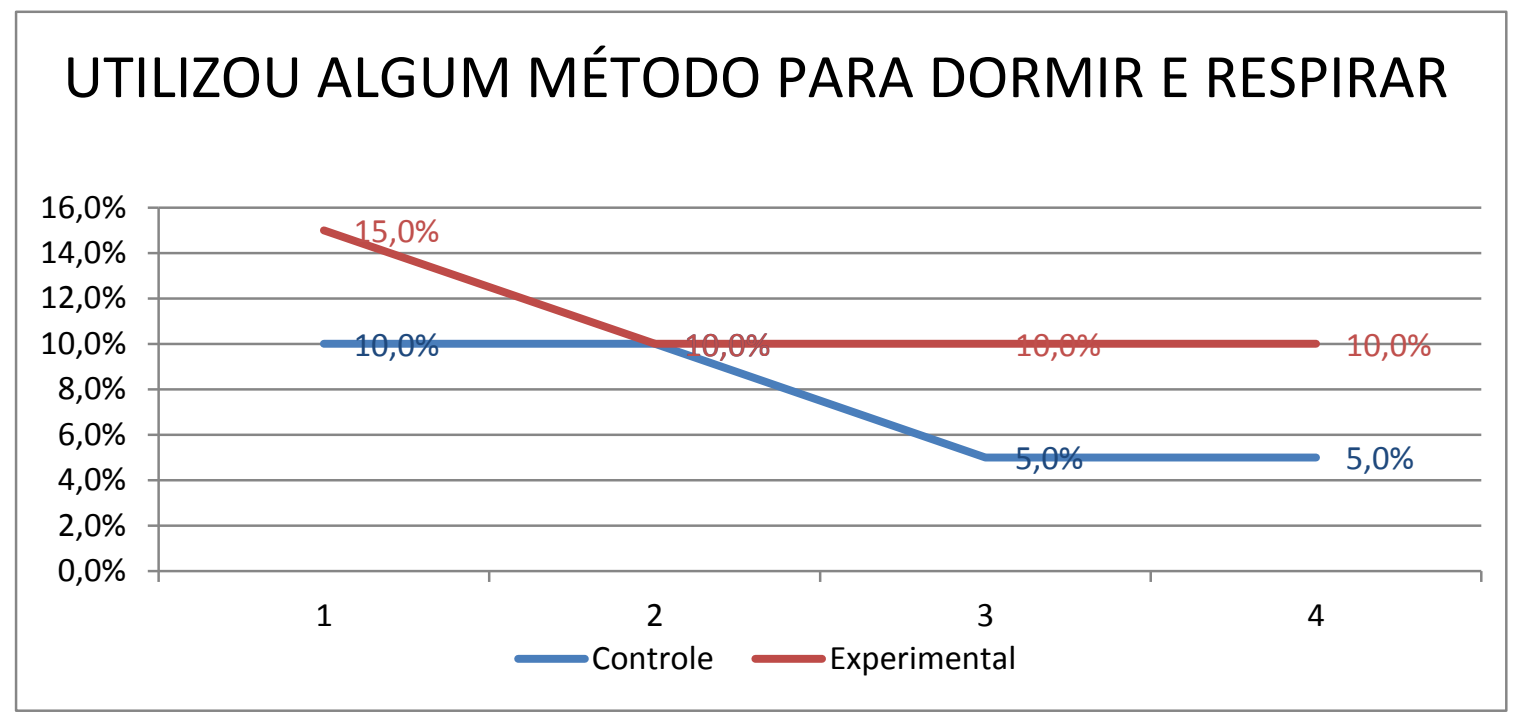

Figura 10 - Evolução dos pacientes quanto ao uso de métodos para melhora do padrão de sono e respiratório. São Paulo, 2015.

\subsection{DISCUSSÃO}

Os pacientes deste estudo, em média, são jovens, na faixa etária de 20 a 30 anos, como encontrados em outros estudos ${ }^{15,18,67}$. É comum o paciente com deformidade dentofacial buscar auxílio ainda jovem, iniciando com a correção ortodôntica na adolescência e, após a completa formação óssea aos 18 anos, inicia o preparo para um procedimento cirúrgico. A predominância do sexo feminino também foi observada em alguns estudos ${ }^{18,22,24}$, o que pode ser justificado pelo fato do sexo feminino possuir maior preocupação com a atratividade e a harmonia facial.

Houve uma predominância de pacientes solteiros, resultado semelhante a outro estudo brasileiro sobre a análise quantitativa da motivação para cirurgia ortognática ${ }^{68}$. Em relação a 
formação e alfabetização, os pacientes desta pesquisa não possuem baixa literacia, pois apresentaram em média nove anos de estudo. Esse perfil é semelhante ao encontrado na literatura ${ }^{68}$.

Dentre os motivos que levaram a buscar o procedimento cirúrgico, encontramos no grupo experimental uma maioria de pacientes com motivação funcional, seguido por motivação estética. Esse perfil também foi encontrado em outros estudos ${ }^{11,68}$. No grupo controle, houve uma diferença na motivação, apesar da maioria buscar motivação funcional, também foram citadas indicação médica e estética.

Um estudo da Noruega ${ }^{69}$ com 35 pacientes sobre a percepção após a cirurgia ortognática relatou impactos relacionados a sorrir $(22,9 \%)$, sono $(20 \%)$, comer e apreciar a comida $(17,1 \%)$, higiene oral, fala e contato social (14,3\%). A dificuldade com a higiene oral foi relatada por $23 \%$ dos indivíduos que estavam satisfeitos com seu tratamento.

A satisfação com o resultado da cirurgia ocorreu para todos os pacientes desta pesquisa, resultados semelhantes são descritos em literatura ${ }^{11}$ e podem estar diretamente relacionados ao objetivo alcançado, ou seja, a alteração do perfil facial.

Quanto ao teste de conhecimento relacionado a intervenção para o grupo experimental, a aquisição do conhecimento do paciente quando avaliado no primeiro retorno em comparação com o pré-operatório alcançou $23 \%$, percentual que difere de outro estudo com intervenção com material educativo para mulheres mastectomizadas, que nesse período alcançou apenas $11 \%$ de percentual de $\operatorname{acertos}^{40}$. O grupo controle da presente investigação apresentou apenas $1 \%$ de percentual de acertos no mesmo período.

Estudos realizados no Brasil ${ }^{9,14}$ sobre a percepção/conhecimento dos pacientes após a cirurgia ortognática relatam a dificuldade dos pacientes em realizar a higiene oral e de alimentar-se corretamente, consequentemente a precária higiene oral pode predispor a presença de resíduo alimentar na cavidade oral, halitose, gengivite e infecção. Pressupõe-se que os pacientes tenham medo de movimentar os lábios e bochechas e visualizar ou manter contato com a sutura

Com o olhar no conhecimento prévio do paciente, e uma perspectiva de acerto acima de $70 \%$, os resultados desta pesquisa evidenciaram que os pacientes portadores de deformidade dentofacial somente possuem conhecimento sobre a cirurgia e a sensação do pós-operatório 
(alteração da mordida, sensibilidade). Esse fato se deve ao acesso à internet e às informações generalizadas que esses pacientes têm acesso. Em um estudo sobre avaliação da informação que os pacientes submetidos a ortognática trocam com colegas fora do ambiente clínico, que avaliou 1912 posts em fóruns sobre o assunto, observou-se que pacientes buscam informações na internet para complementar aquelas relativas ao seu tratamento, ao apoio e às similaridades com o tratamento de seus pares ${ }^{70}$.

Entretanto, essa informação generalizada não produz qualidade na informação e não transmite ao paciente o suficiente para que ele conduza seus cuidados domiciliares no pósoperatório. Um estudo do Reino Unido ${ }^{71}$ avaliou a qualidade das informações em sites sobre a cirurgia ortognática. Dos 25 sites avaliados, o escore máximo foi entre 64-80 pontos, abaixo do escore mínimo de 80 para ser considerado excelente em informação. Para essa avaliação, foi utilizado um instrumento validado denominado DISCERN ${ }^{\mathrm{b}}$, que consiste em dezesseis questões sobre a qualidade e a confiabilidade da informação ao consumidor sobre problemas de saúde.

Um estudo da Jordânia ${ }^{72}$ sobre a percepção dos pacientes submetidos a cirurgia ortognática afirma que os pacientes acreditavam que a informação pré-operatória era adequada, porém sugeriram uso de materiais adicionais, incluindo folhetos ou vídeos, para assimilar os dados recebidos. Neste estudo, também foi sugerido conhecer a enfermeira do centro cirúrgico antes da cirurgia.

Na aplicação do IDATE traço-estado, os pacientes do grupo experimental apresentavam numericamente uma ansiedade traço-estado inferior ao grupo controle no pré-operatório e nos retornos de pós-operatório, apesar de não haver significância estatística na evolução dos grupos (controle e experimental).

Os sentimentos de ansiedade podem ser desenvolvidos no período pré-operatório, com alteração emocional que pode contribuir para vulnerabilidade e dependência ${ }^{23}$. Uma ausência de alteração na ansiedade durante o pós-operatório pode ser explicada pelo fato de que, durante a recuperação do trauma cirúrgico, há uma consequente melhora da autoimagem, os pacientes experimentam uma melhora no estado psicológico, com a alteração facial ganham autoconfiança e melhor relação interpessoal. Essas mudanças positivas levam a satisfação notável com o resultado cirúrgico por meio do reforço de ajustamento social e autoconfiança ${ }^{73}$.

\footnotetext{
${ }^{\mathrm{b}}$ DISCERN disponível em: www.discern.org.uk/discern_instrument.php
} 
A ansiedade-traço refere-se a diferenças individuais relativamente estáveis na tendência à ansiedade, isto é, as diferentes maneiras de reagir a situações percebidas como ameaçadoras, podendo intensificar no estado de ansiedade. Neste estudo, a orientação com material educativo parece ter sido capaz de reduzir o traço de ansiedade dos pacientes do grupo experimental no pós-operatório, embora não se saiba explicar o fenômeno, pois deveria se manter constante teoricamente, as intervenções deveriam influir sobre a ansiedade-estado e não na ansiedadetraço.

Uma investigação da Itália sobre a evolução do estado psicológico e sua correlação com o nível de deformidade dentofacial antes do procedimento cirúrgico mostrou que pacientes com maior deformidade dentofacial possuem maiores níveis de introversão, ansiedade-traço, dependência, insociabilidade, liderança e neuroticismo ${ }^{22}$.

Outro estudo reforça a questão social da deformidade dentofacial em pacientes que buscaram pelo procedimento cirúrgico; foi questionado quanto ao fato de seu relacionamento afetivo ser prejudicado pela sua estética facial: $45 \%$ dos pacientes disseram que sim, destes, a maioria pacientes do sexo masculino. E quando questionados se, devido a sua simetria facial, sentiam-se diferentes das outras pessoas, $60 \%$ referiu que $\operatorname{sim}^{68}$.

Outro transtorno observado na literatura é a ansiedade social. No Reino Unido ${ }^{24}$, um estudo sobre a ansiedade social, mensurada em pacientes ortognatas e comparados à população local, resultou em maiores níveis de ansiedade social nesses pacientes.

As variáveis psicológicas na cirurgia ortognática têm sido estudadas e apresentam resultados significativos quanto ao estado emocional desses pacientes, o que leva ao profissional de saúde estar atento a percepção de possíveis alterações e encaminhamento para avaliação com profissional adequado (psicólogos, psiquiatras).

É percebido que o tratamento para deformidade facial prove melhora nas alterações psicológicas e na interação social desse paciente, e a ansiedade parece ser o fator de menor impacto no tratamento. Pressupõe-se que a ausência de alteração significativa seja decorrente de uma expectativa pela modificação de sua deformidade. Essa nova face promove autoconfiança e melhora nas relações interpessoais.

$\mathrm{Na}$ avaliação dos sinais e sintomas, a halitose e a perda corporal foram significativas. Em relação ao percentual de sinais e sintomas com maior incidência, considerado superior a 
$60 \%$, foram observados: língua saburrosa, dificuldade de realizar a higiene oral, parestesia e ressecamento labial.

A halitose é um termo comum para descrever odor desagradável ou ofensivo da cavidade oral, as causas podem ser fisiológicas e patológicas, algumas causas fisiopatológicas decorrem da má higiene oral. Entre as causas fisiopatológicas que podem estar relacionadas a cirurgia ortognática, além da má higiene oral no pós-operatório, estão a saburra lingual, impactação de alimentos nos espaços interproximais e ferida cirúrgica ${ }^{74}$.

A língua saburrosa é característica de ausência de higiene oral, a dificuldade de realizar a higiene oral leva a consequência do aumento da placa bacteriana e presença de resíduos alimentares na incisão cirúrgica, fatores predisponentes para a infecção de sítio cirúrgico.

Essa dificuldade pode estar relacionada ao medo de manipular a área recém-operada, ao edema e à limitação da abertura da boca, o que dificulta o acesso da cavidade oral, bem como à falta de informação do paciente. No presente estudo, houve maior proporção de pacientes do grupo experimental com halitose no primeiro retorno pós-operatório, mas também foi nesse grupo que houve maior dificuldade de abertura da boca e de uso de elásticos ortodônticos.

A parestesia é um sintoma inevitável, ocorre pela manipulação das estruturas e a possível injuria em nervos faciais. Em um estudo italiano sobre as complicações da cirurgia ortognática em um centro de atendimento, dos 3236 pacientes atendidos, 19\% apresentou parestesia temporária e $2 \%$ permanente ${ }^{75}$. Quando temporárias, possuem duração de seis a doze meses, mas alguns pacientes podem experimentar lesões permanentes.

Nos resultados deste estudo, não houve diferença entre os grupos (controle e experimental) em relação a parestesia, e esse sintoma foi relatado até o último seguimento. Fato esperado e condizente com a literatura ${ }^{7,75}$.

Nessa manipulação de estruturas, os lábios também sofrem alterações, que resultam em ressecamento labial e podem chegar a lesões. No pós-operatório, alguns pacientes apresentam a respiração bucal, que contribui para o ressecamento labial.

A orientação de uso de hidratação labial estava presente no material educativo e, apesar de haver ressecamento labial em incidência semelhante entre os grupos controle e experimental, e sem diferença significativa no seguimento, o grupo experimental obteve maior aplicação de medidas para melhora do ressecamento: $85 \%$ fez uso de manteiga de cacau até o primeiro 
retorno, no grupo controle foram apenas $55 \%$ dos pacientes fizeram uso desse recurso.

Para auxiliar na redução dessas lesões durante o intraoperatório, alguns estudos ${ }^{52,76}$ têm buscado alternativas para melhorar a manipulação das estruturas e preservar os lábios, como o uso de protetores para o lábio que não interferem no uso dos afastadores.

A perda de peso corporal foi significativa estatisticamente, achado é visto em outros estudos $^{77,78}$. Recomenda-se que o paciente compreenda a necessidade de uma dieta de alta caloria suave e nutritiva após a cirurgia para a manutenção de seu peso corporal, acelerando sua recuperação ${ }^{3,77,79}$.

No material educativo, era enfatizado a importância de alimentar-se de forma nutritiva e com consistência adequada para o período pós-operatório. Para reforço da informação, um quadro em destaque apresentava a evolução do pós-operatório e a consistência permitida dos alimentos.

Limitações do estudo: Dentre as limitações da intervenção, estão a possível falta de adesão do paciente a intervenção educativa, o que levaria a baixos índices de resposta a intervenção e o possível uso de outras tecnologias durante o processo, que podem resultar em informações incorretas e inferir no resultado pós-operatório. As orientações do cirurgião são semelhantes às orientações da intervenção contidas no livreto, o que pode ter interferido na tentativa de evidenciar que o folheto educativo poderia refletir em melhor manejo no autocuidado pós-operatório. . Para evitar a perda de participantes durante o seguimento, as avaliações foram realizadas por ocasião dos retornos com o cirurgião e, assim, não houve uma data fixa para avaliação, mas um intervalo de cerca cinco dias.

\section{CONCLUSÃO}

Este estudo apresentou resultados significativos para o desfecho primário, como aumento do conhecimento do paciente com uso de uma tecnologia educativa. Para os desfechos secundários, mostrou que ansiedade e manejo dos sinais e sintomas, com exceção de halitose e peso corporal, não apresentaram significância estatística. A perda de peso e a halitose foi mais observada no grupo experimental do que no grupo controle, mas os pacientes do grupo experimental tiveram maior dificuldade na abertura da boca do que os do grupo controle. 
Apesar de não significativo, foi possível observar menores níveis de ansiedade em pacientes do grupo experimental durante o perioperatório. A orientação com material educativo parece ter sido capaz de reduzir o traço de ansiedade dos pacientes do grupo experimental no pós-operatório, embora não se saiba explicar o fenômeno. A expectativa e a recuperação psicológica do indivíduo com deformidade facial por meio do procedimento cirúrgico e alteração facial podem ser os fatores que mantêm níveis de ansiedade sem alteração significativa.

$\mathrm{Na}$ avaliação clínica, o seguimento do pós-operatório em inúmeras variáveis, apesar de não significativo na evolução dos grupos para a maioria dos itens de avaliação, não exclui a aplicação do material como estratégia de melhoria e auxílio ao paciente. Foi observado em alguns itens de manejo do pós-operatório: dificuldade para fazer refeições, início de exercícios faciais para controle do edema, uso de estratégias para melhora do padrão de sono e respiratório e hidratação labial, melhor evolução do paciente do grupo experimental que recebeu o material educativo. Também se observou que os pacientes do grupo experimental tiveram menor dificuldade no manuseio dos elásticos ortodônticos que o grupo controle. Observação importante foi o fato dos pacientes do grupo experimental terem utilizado menor variedade de analgésicos e antinflamatórios do que o grupo controle.

Por fim, recomendamos a aplicação dessa tecnologia educativa para auxiliar o paciente submetido a cirurgia ortognática de forma a melhorar seu conhecimento sobre o procedimento e os cuidados pós-operatórios.

Outras investigações se fazem necessárias para avaliar a adesão dos pacientes aos materiais educativos em seu autocuidado.

\section{REFERÊNCIAS}

1. Barros EJ, Santos SS, Gomes GC, Erdmann AL. [Educational geronto-technology for ostomized seniors from a complexity perspective]. Rev Gaucha Enferm. 2012;33(2):95-101.

2. Sousa CS. Educação pós-operatória: construção e validação de uma tecnologia educativa para pacientes submetidos a cirurgia ortognática [dissertação]. São Paulo: Escola de Enfermagem da Universidade de São Paulo; 2011.

3. Robinson RC, Holm RL. Orthognathic surgery for patients with maxillofacial deformities. AORN J. 2010;92(1):28-49; quiz 50-2. 
4. Bauer RE, Ochs MW. Maxillary orthognathic surgery. Oral Maxillofac Surg Clin North Am. 2014;26(4):523-37.

5. Sar C, Soydan SS, Ozcirpici AA, Uckan S. Psychosocial and functional outcomes of orthognathic surgery: Comparison with untreated controls. J Oral Maxillofac Surg Med Pathol. 2015;27(4):451-7.

6. Pacheco-Pereira C, Abreu LG, Dick BD, De Luca Canto G, Paiva SM, Flores-Mir C. Patient satisfaction after orthodontic treatment combined with orthognathic surgery: A systematic review. Angle Orthod. 2015; [Epub ahead of print].

7. Sousa CS, Turrini RNT. Complications in orthognathic surgery: A comprehensive review. J Oral Maxillofac Surg Med Pathol. 2012;24:67-74.

8. Carvalho SC, Martins EJ, Barbosa MR. Variáveis Psicossociais Associadas à Cirurgia Ortognática: Uma Revisão Sistemática da Literatura. Psicologia: Reflexão e Crítica. 2012;25(3):477-90.

9. Santos MR, Sousa CS, Turrini RN. [Perception of orthognathic surgery patients on postoperative care]. Rev Esc Enferm USP. 2012;46(Spe):78-85.

10. Millione Dutra CL, Amando J, Cruz RL, Mendes Miguel JA. Análise crítica do planejamento digital em caso complexo de deformidade dentofacial. (Portuguese). Rev Clín Ortod Dental Press. 2014;13(4):30-8.

11. Costa KLD, Martins LD, Gonçalves RCG, Zardo M, Sá ACD. Avaliação da qualidade de vida de pacientes submetidos à cirurgia ortognática. Rev Cir Traumatol Buco-maxilo-fac. 2012;12(2):81-92.

12. Perin C, Perilla-Rodríguez LM, Fukusima SS. Diferenças Individuais em Mulheres na Avaliação da Atratividade Facial: Uma Revisão. Psicologia: Reflexão e Crítica. 2014;27(3):531-8.

13. Sadat-Marashi Z, Scolozzi P, Antonarakis GS. Perceptions of young adults having undergone combined orthodontic and orthognathic surgical treatment: A grounded theory approach. J Oral Maxil Surg. 2015;[Epub ahead of print].

14. Barros BR, Sousa CS, Turrini RNT. Knowledge of Internet-using patients about the perioperative period of orthognathic surgery. J Nurs Educ Pract. 2013;3(12):93-102.

15. Cadogan J, Bennun I. Face value: an exploration of the psychological impact of orthognathic surgery. Br J Oral Maxillofac Surg. 2011;49(5):376-80.

16. van der Vlis M, Dentino KM, Vervloet B, Padwa BL. Postoperative swelling after orthognathic surgery: a prospective volumetric analysis. J Oral Maxillofac Surg. 2014;72(11):2241-7.

17. Ryan FS, Barnard M, Cunningham SJ. What Are Orthognathic Patients' Expectations of Treatment Outcome-A Qualitative Study. J Oral Maxil Surg. 2012;70(11):2648-55.

18. Shinagawa A, Melhem FE, de Campos AC, Cicarelli DD, Frerichs E. Predictors of pain and prolonged length of stay after orthognathic surgery: A retrospective cohort study. Rev Colom Anesthesiol. 2015;43(2):129-35. 
19. Chen CM, Lai SS, Chen HS, Hsu KR, Lai YH. Effects of patient- and operation-related factors on postoperative pain after orthognathic surgery. J Craniofac Surg. 2012;23(3):724-7.

20. Kim YK, Kim SG, Kim JH. Altered sensation after orthognathic surgery. J Oral Maxillofac Surg. 2011;69(3):893-8.

21. Johnston C, Hunt O, Burden D, Stevenson M, Hepper P. Self-Perception of Dentofacial Attractiveness among Patients Requiring Orthognathic Surgery. Angle Orthod. 2010;80(2):361-6.

22. Kovalenko A, Slabkovskaya A, Drobysheva N, Persin L, Drobyshev A, Maddalone M. The association between the psychological status and the severity of facial deformity in orthognathic patients. Angle Orthod. 2011;82(3):396-402.

23. Costa TMN, Sampaio CEP. As orientações de enfermagem e sua influência nos níveis de ansiedade dos pacientes cirúrgicos hospitalares. Revista Enfermagem UERJ. 2015;23(2):260-5.

24. Ryan FS, Moles DR, Shute JT, Clarke A, Cunningham SJ. Social anxiety in orthognathic patients. Int J Oral Maxillofac Surg. 2015;[Epub ahead of print].

25. Collins B, Gonzalez D, Gaudilliere DK, Shrestha P, Girod S. Body dysmorphic disorder and psychological distress in orthognathic surgery patients. J Oral Maxillofac Surg. 2014;72(8):1553-8.

26. Alves GG, Aerts D. As práticas educativas em saúde e a Estratégia Saúde da Família. Cien Saude Colet. 2011;16(1):319-25.

27. Dissen CM, Freitas NQ, Sangoi TP, Beck CLC, Prestes FC, de Moraes Blois J. Educação em saúde no pré-operatório: uma vivência de acadêmicas de enfermagem. Revista Contexto \& Saúde. 2013;11(20):919-24.

28. Amthauer C, Falk JW. O enfermeiro no cuidado ao paciente cirúrgico no período préoperatório. Revista de Enfermagem. 2014;10(10):54-9.

29. Ronco M, Iona L, Fabbro C, Bulfone G, Palese A. Patient education outcomes in surgery: a systematic review from 2004 to 2010. Int J Evid Based Healthc. 2012;10(4):309-23.

30. Amthauer C, Dalla Nora TT, Souza TP, Fernandes CR, Nogueira QDS, Martins LB. Atividades de educação em saúde com pacientes cirúrgicos em um hospital universitário: relato de experiência. Revista Contexto \& Saúde. 2013;11(20):705-10.

31. Fredericks S, Guruge S, Sidani S, Wan T. Postoperative patient education: a systematic review. Clin Nurs Res. 2010;19(2):144-64.

32. Friberg F, Granum V, Bergh AL. Nurses' patient-education work: conditional factors an integrative review. J Nurs Manag. 2012;20(2):170-86.

33. Avsar G, Kasikci M. Evaluation of patient education provided by clinical nurses in Turkey. Int J Nurs Pract. 2011;17(1):67-71.

34. Ghorbani R, Soleimani M, Zeinali MR, Davaji M. Iranian nurses and nursing students' attitudes on barriers and facilitators to patient education: a survey study. Nurse Educ Pract. 2014;14(5):551-6. 
35. Pedrosa M, Pimenta C, Cruz D. Effects of educational programs in the post-operative pain. Cienc Cuid Saude. 2007;6(1):21-32.

36. Áfio ACE, Balbino AC, Alves MDS, Carvalho LVd, Santos MCL, Oliveira NR. Análise do conceito de tecnologia educacional em enfermagem aplicada ao paciente. Rev Rene. 2014;15(1):158-65.

37. Oliveira SC, Oliveira Lopes MV, Fernandes AFC. Construção e validação de cartilha educativa para alimentação saudável durante a gravidez. Rev Lat Am Enfermagem. 2014;22(4):611-20.

38. Fonseca LMM, Leite AM, Mello DFd, Silva MAI, Lima RAGd, Scochi CGS. Tecnologia educacional em saúde: contribuições para a enfermagem pediátrica e neonatal. Esc Anna Nery Rev Enferm. 2011;15(1):190-6.

39. Shieh C, Hosei B. Printed health information materials: evaluation of readability and suitability. J Community Health Nurs. 2008;25(2):73-90.

40. Oliveira MS, Santos MCL, Almeida PC, Panobianco MS, Fernandes AFC. Avaliação de manual educativo como estratégia de conhecimento para mulheres mastectomizadas. Rev Lat Am Enfermagem. 2012;20(4):668-76.

41. Achaval S, Fraenkel L, Volk RJ, Cox V, Suarez-Almazor ME. Impact of educational and patient decision aids on decisional conflict associated with total knee arthroplasty. Arthritis Care Res (Hoboken). 2012;64(2):229-37.

42. Guo P, East L, Arthur A. A preoperative education intervention to reduce anxiety and improve recovery among Chinese cardiac patients: A randomized controlled trial. Int $\mathbf{J}$ Nurs Stud. 2011.

43. Dankner R, Geulayov G, Ziv A, Novikov I, Goldbourt U, Drory Y. The effect of an educational intervention on coronary artery bypass graft surgery patients' participation rate in cardiac rehabilitation programs: a controlled health care trial. BMC Cardiovasc Disord. 2011;11(1):60.

44. Cinar FI, Tosun N, Akbayrak N, Simsek I, Cinar M, Erdem H, et al. Comparison of the efficacy of written information vs. verbal plus written information in rheumatic patients who receive colchicine treatment. Gulhane Med J. 2013;55:94-100.

45. Eames S, Hoffmann T, Worrall L, Read S, Wong A. Randomised controlled trial of an education and support package for stroke patients and their carers. Bmj Open. 2013;3(5):e002538.

46. Doak CC, Doak LG, Root JH. Writing the message. In: Doak CC, Doak LG, Root JH, editors. Teaching patients with low literacy skills. Philadelphia (PA): J.B.Lippincott; 1996. p. 73-90.

47. Sousa CS, Turrini RNT. Construct validation of educational technology for patients through the application of the Delphi technique. Acta Paul Enferm. 2012;25(6):990-96.

48. Figueiredo LMG, Carvalho MC, Sarmento VA, Brandão GRR, Oliveira TFLd, Carneiro Junior B, et al. Evaluation the nutritional status of subjects before and after orthognathic surgery: pilot study. Rev cir traum buco-maxilo-facial. 2013;13(4):89-93. 
49. Politis C, Kunz S, Schepers S, Vrielinck L, Lambrichts I. Obstructive airway compromise in the early postoperative period after orthognathic surgery. J Craniofac Surg. 2012;23(6):1717-22.

50. Leventhal LC, Bianchi RC, Oliveira SMJV. Ensaio clínico comparando três modalidades de crioterapia em mulheres não grávidas. Rev Esc Enferm USP. 2010;44(2):33945 .

51. Denegri MA. Fonoaudiología en relación a la Cirugía Buco Maxilofacial, revisión bibliográfica. Revista Facultad de Odontología. 2015;9(1):27-31.

52. Zhao J, Jin X, Teng L, Gui L. Strategy to minimize oral mucosal tear and lip injury in facial contouring and orthognathic surgery. J Craniofac Surg. 2013;24(5):e485-6.

53. Oncul AM, Cimen E, Kucukyavuz Z, Cambazoglu M. Postoperative analgesia in orthognathic surgery patients: diclofenac sodium or paracetamol? Br J Oral Maxillofac Surg. 2011;49(2):138-41.

54. Julian LJ. Measures of anxiety: State-Trait Anxiety Inventory (STAI), Beck Anxiety Inventory (BAI), and Hospital Anxiety and Depression Scale-Anxiety (HADS-A). Arthritis Care Res (Hoboken). 2011;63(S11):S467-72.

55. Cevada T, Cerqueira LS, de Moraes HS, dos Santos TM, Pompeu FAMS, Deslandes AC. Relationship between sport, resilience, quality of life, and anxiety. Rev Psiq Clin-Brazil. 2012;39(3):85-9.

56. Brasil Ministério da Saúde. Conselho Nacional de Saúde. Resolução 466, de 12 de dezembro de 2012. Dispõe sobre diretrizes e normas regulamentadoras de pesquisas envolvendo seres humanos [Internet]. Brasília; 2012[citado 2015 maio 18]. Disponível em: http:// conselho.saude.gov.br/resolucoes/2012/Reso466.pdf.

57. Thabane L, Ma J, Chu R, Cheng J, Ismaila A, Rios LP, et al. A tutorial on pilot studies: the what, why and how. BMC medical research methodology. 2010;10:1.

58. Field A. Descobrindo a estatistica usando o SPSS. $2^{\text {a }}$ ed. Porto Alegre: Artmed; 2009. $688 \mathrm{p}$.

59. Andriola WB. Psicometria moderna: características e tendências. Estudos em Avaliação Educacional. 2009;20(43):319-40.

60. Linacre JM. Winstep-Rasch model computer program. Version 3.69. 1.16. Chicago: Mesa Press; 2013.

61. Velozo CA, Magalhaes LC, Pan AY, Leiter P. Functional Scale Discrimination at Admission and Discharge - Rasch Analysis of the Level of Rehabilitation Scale-Iii. Archives of Physical Medicine and Rehabilitation. 1995;76(8):705-12.

62. Linacre JM. What do infit and outfit, mean-square and standardized mean. Rasch Measurement Transactions. 2002;16(2):878.

63. Lai JS, Fisher AG, Magalhaes LC, Bundy AC. Construct validity of the sensory integration and praxis tests. Occupational Therapy Journal of Research. 1996;16(2):75-97. 
64. Martinez EZ. Constribuições do estatístico para atendimento ao CONSORT Checklist. Medicina (Ribeirão Preto). 2009;42(1):22-30.

65. Pannuti CM, Rosa EF, Guglielmetti MR, Moreira RTB. Avaliação crítica de ensaios clínicos. Rev Odontol Bras Central. 2011;20(52):2-6.

66. Guimarães LSP, Hirakata VN, Camey SA, Nunes LN, Mancuso ACB. ENSAIOS CLÍNICOS (PARTE II). Revista HCPA. 2013;33(3/4):295-302.

67. Brunault P, Battini J, Potard C, Jonas C, Zagala-Bouquillon B, Chabut A, et al. Orthognathic surgery improves quality of life and depression, but not anxiety, and patients with higher preoperative depression scores improve less. Int J Oral Maxillofac Surg. 2015;[Epub ahead of print].

68. Abitante C, Schneider LE, Vargas IA, Bridi AdO, Crusius KC, Krause RGdS. Análise quantitativa da motivação estética do paciente de cirurgia ortognática da ULBRA-Canoas. Revista de Ciências Médicas e Biológicas. 2011;9(3):185-8.

69. Trovik TA, Wisth PJ, Tornes K, Boe OE, Moen K. Patients' perceptions of improvements after bilateral sagittal split osteotomy advancement surgery: 10 to 14 years of follow-up. Am J Orthod Dentofacial Orthop. 2012;141(2):204-12.

70. Bhamrah G, Ahmad S, NiMhurchadha S. Internet discussion forums, an information and support resource for orthognathic patients. Am J Orthod Dentofacial Orthop. 2015;147(1):89-96.

71. Aldairy T, Laverick S, McIntyre GT. Orthognathic surgery: is patient information on the Internet valid? Eur J Orthod. 2012;34(4):466-9.

72. Ghannam SA, Malkawi ZA, Sawair FA, Baqain ZH. Perception of Outcome After Orthognathic Surgery at Jordan University Hospital. Jordan Medical Journal. 2010;42(4):1-8.

73. Moon W, Kim J. Psychological Considerations in Orthognathic Surgery and Orthodontics. Semin Orthod. 2015; [Epub ahead of print].

74. Mantovani AC, Grigoleto ARL. Halitose: uma questão de saúde pública/Halitosis: a matter of public health. Braz J Health. 2012;1(3):186-92.

75. Iannetti G, Fadda TM, Riccardi E, Mitro V, Filiaci F. Our experience in complications of orthognathic surgery: a retrospective study on 3236 patients. European Review for Medical and Pharmacological Sciences. 2013;17(3):379-84.

76. Sun R, Jin J. Strategy to minimize oral mucosal tear and lip injury in facial contouring and orthognathic surgery. J Craniofac Surg. 2015;26(2):599-600.

77. Khattak ZG, Benington PC, Khambay BS, Green L, Walker F, Ayoub AF. An assessment of the quality of care provided to orthognathic surgery patients through a multidisciplinary clinic. J Craniomaxillofac Surg. 2012;40(3):243-7.

78. Giacobbo J, Mendel MIL, Borges WD, El-Kik RM, Oliveira RB, Silva DN. Assessment of nutritional anthropometric parameters in adult patients undergoing orthognathic surgery. Revista Odonto Ciência. 2009;24:92-6. 
79. Sousa CS, Turrini RN. Creating and validating educational material for patients undergoing orthognathic surgery. Asian Nurs Res (Korean Soc Nurs Sci). 2012;6(4):166-72. 
INSTRUMENTO DE COLETA DE DADOS PARA PACIENTES SUBMETIDOS A CIRURGIA ORTOGNÁTICA

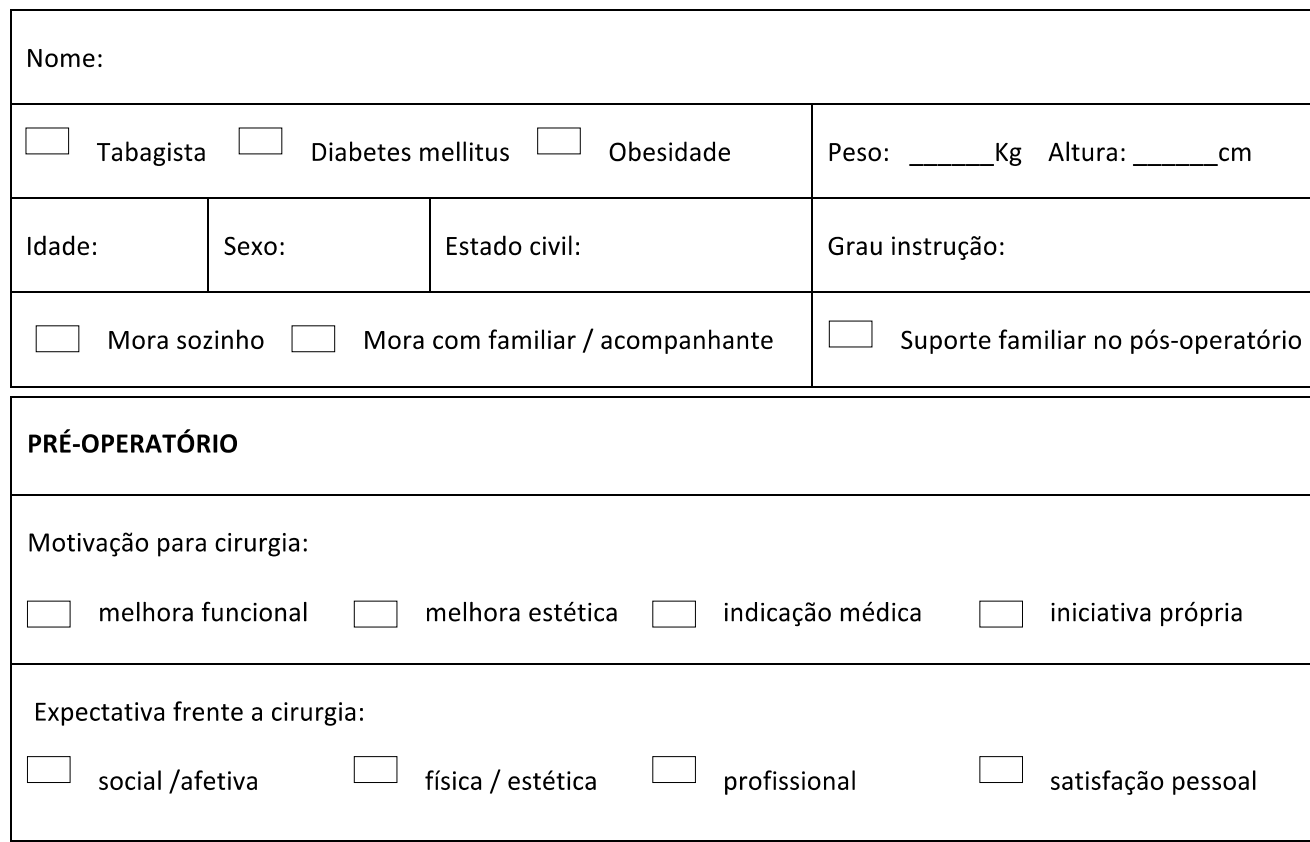

\section{PÓS-OPERATÓRIO}

Técnica cirurgica utilizada:

Complicações cirúrgicas:

Dificuldades vivenciadas:

Mudanças após a cirurgia

$\square$ aparência física $\square$ alteração na voz $\square$ mais confiante $\square$ não observou $\quad \square$ outras

Satisfação com o resultado $\quad \square$ Satisfeito $\quad \square$ Insatisfeito


Avaliação dos cuidados no pós-operatório

Primeira semana - retorno 3 a 7 dias

Higiene oral

halitose $\square$ gengiva descorada $\square$ gengivite $\square$ língua saburrosa

sutura com resíduo alimentar presença de placa

gengiva rosada $\quad \square$ cavidade oral limpa $\quad \square$ sutura sem resíduo alimentar

Sentiu dificuldade para realizar a higiene oral?

Nutrição Peso corporal___ Kg

Possui auxilio para preparo das refeições?

Teve dificuldade em fazer refeições equilibradas?

Teve dificuldades para deglutir ou mastigar os alimentos?

Mobilidade e Sensibilidade

Alteração na abertura de boca

limitação esperada para o pós-operatório

limitação acima do esperado

desvio $\square$ para direita $\square$ para esquerda

Resposta ao Estimulo tátil e térmico

ausente $\square$ diminuida $\square$ preservada

Movimentos faciais (sorrir, levantar a sobrancelha, franzir a testa, depressão do ângulo da mandibula e fazer bico)

Teve dificuldade em manipular os elásticos do aparelho ortodontico?

Apresenta parestesia em quais regiöes faciais? 


\section{Aspecto dos lábios}

ressecamento $\square$ fissura $\square$ lesão $\square$ cianose

hidratado

com integridade cutanea

roseo

Como tem feito para manter a hidratação dos lábios?

Edema

adequado para o período pós-operatório $\square$ acima do esperado

Fez uso de bolsa de gelo?

Tem realizado os exercicios propostos?

Conseguiu realizar o repouso adequadamente?

Utilizou outros métodos para auxiliar a reduzir o edema?

Dor

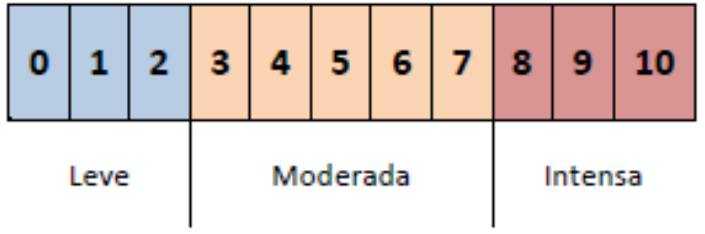

Fez uso de medicação analgesica?

Usou outras formas de tratamento para dor?

Dormir e respirar

Teve dificuldades para dormir ou respirar?

Utilizou algum método para desobstrução? 


\section{APÊNDICE II}

\section{TESTE DE CONHECIMENTO SOBRE O PROCEDIMENTO CIRÚRGICO}

Leia atentamente cada questão, somente há uma resposta certa para cada uma. Assinale a alternativa que julgar correta.

1. Como é a cirurgia?

a) A cirurgia mexe com os ossos da minha face e o cirurgião irá colocar placas e parafusos

b) A cirurgia pode ser feita no consultório

c) A cirurgia é para a arrumar a mordida e o cirurgião não mexe com os ossos da face

d) A cirurgia é rápida

2. Após a cirurgia vou ficar com:

a) Inchaço na face, dificuldade de abrir a boca e pouca sensibilidade

b) Nenhuma alteração

c) Apenas dificuldade de abrir a boca

d) Vermelhidão na face

3. Após a cirurgia ainda vou usar o aparelho ortodôntico?
a) $\operatorname{Sim}$
b) Não

4. Os cuidados com a cirurgia são:

a) Escovar os dentes e manter a boca sem restos de alimentos

b) Fazer uma dieta equilibrada

c) Manter repouso nos primeiros dias

d) Todas as alternativas estão corretas

5. Vou sentir o rosto inchado por:
a) 30 dias
b) 60 dias
c) 120 dias
d) 180 dias

6. Como devo me preparar para a cirurgia?
a) Não precisa de preparo
b) Devo realizar alguns exames para avaliar minha saúde
c) Posso fazer a cirurgia enquanto estiver fazendo tratamento para uma infecção
d) Devo fazer uma dieta especial

7. Em relação a escovação dos dentes:

a) Após a cirurgia não preciso escovar os dentes

b) Só poderei escovar os dentes após 30 dias da cirurgia

c) Devo escovar os dentes com escova pequena e macia logo após a cirurgia

d) Posso usar a escova de dentes que uso habitualmente

8. Em relação a alimentação após a cirurgia: 
a) Devo fazer uma dieta especial

b) Devo comer normalmente

c) Não preciso de dieta específica

d) Vou me alimentar com líquidos nos primeiros dias e depois de alguns dias alimentos batidos

9. Devo retornar ao trabalho em:
a) 7 dias
b) 14 dias
c) 30 dias
d) 45 dias

10. Após a cirurgia:

a) posso fazer todas as atividades normalmente

b) não posso tomar sol

c) posso fazer atividades leves

d) não poderei tomar banho nos primeiros dias 


\section{APÊNDICE III}

\section{Termo de Consentimento Livre e Esclarecido}

\section{- Estudo Piloto -}

NOME DA PESQUISA: "Avaliação do uso de uma tecnologia educativa na educação perioperatória de cirurgia ortognática: ensaio clínico randomizado”, o objetivo é usar um folheto educativo para pacientes submetidos à cirurgia ortognática e reforçar as orientações, avaliar a ansiedade e auxiliar nos cuidados pós-operatórios.

\section{Prezado (a) Senhor (a),}

Eu, Cristina Silva Sousa, aluna do doutorado do programa de pós-graduação na saúde do adulto da Escola de Enfermagem da USP (EEUSP) em São Paulo, venho convidá-lo a participar desta pesquisa na qual você receberá um material educativo e irá responder um teste de conhecimento sobre a cirurgia, um teste de ansiedade e permitindo-me acompanhá-lo nos retornos ao consultório do cirurgião para avaliação clínica. As informações obtidas nestes questionários auxiliarão na análise das orientações oferecidas a você sobre a cirurgia ortognática.

Você receberá um material educativo e as informações sobre os cuidados pós-operatório com uma enfermeira, e contará com as informações médicas como de costume.

A sua participação no estudo é livre, podendo desistir a qualquer momento sem nenhum prejuízo. Os resultados obtidos nesta pesquisa serão organizados e apresentados em eventos científicos nacionais e internacionais e publicados em revistas científicas. Seu nome não será revelado em nenhum momento da pesquisa, será mantido segredo, bem como a privacidade dos seus dados pessoais.

Qualquer dúvida com relação aos aspectos éticos do projeto entrar em contato com o Comitê de Ética em Pesquisa EEUSP pelo e-mail: edipesq@usp.br, ou telefone: 3061-7548. Em caso de dúvida você poderá entrar em contato com a pesquisadora Cristina Silva Sousa pelos telefones: 996017972 / 50833007

Este termo será preenchido em duas vias, sendo uma entregue ao participante da pesquisa.

Nome:

RG: data de nascimento 
Endereço:

Telefone:

Declaro que, após ser esclarecido pelo pesquisador e ter entendido o que me foi explicado, consinto em participar desta pesquisa

São Paulo, de de

Assinatura do colaborador

Cristina Silva Sousa

Enfermeira e aluna do Doutorado da Escola de Enfermagem da USP (EEUSP) 


\section{APÊNDICE IV}

\section{Termo de Consentimento Livre e Esclarecido \\ - Ensaio Clínico Randomizado -}

NOME DA PESQUISA: "Avaliação do uso de uma tecnologia educativa na educação perioperatória de cirurgia ortognática: ensaio clínico randomizado", o objetivo é as orientações no pós-operatório.

\section{Prezado (a) Senhor (a),}

Eu, Cristina Silva Sousa, aluna do doutorado do programa de pós-graduação na saúde do adulto da Escola de Enfermagem da USP (EEUSP) em São Paulo, venho convidá-lo a participar desta pesquisa na qual você receberá orientações sobre a cirurgia e cuidados pós-operatórios, irá responder um teste de conhecimento sobre a cirurgia, um teste de ansiedade e permitindo-me acompanhá-lo nos retornos ao consultório do cirurgião para avaliação clínica. As informações obtidas nestes questionários auxiliarão na análise das orientações oferecidas aos pacientes sobre a cirurgia ortognática.

A sua participação no estudo é livre, podendo desistir a qualquer momento sem nenhum prejuízo. Os resultados obtidos nesta pesquisa serão organizados e apresentados em eventos científicos nacionais e internacionais e publicados em revistas científicas. Seu nome não será revelado em nenhum momento da pesquisa, será mantido segredo, bem como a privacidade dos seus dados pessoais.

Qualquer dúvida com relação aos aspectos éticos do projeto entrar em contato com o Comitê de Ética em Pesquisa EEUSP pelo e-mail: edipesq@usp.br, ou telefone: 3061-7548. Em caso de dúvida você poderá entrar em contato com a pesquisadora Cristina Silva Sousa pelos telefones: 996017972 / 50833007

Este termo será preenchido em duas vias, sendo uma entregue ao participante da pesquisa.

Nome:

RG: data de nascimento

Endereço:

Telefone: 
Declaro que, após ser esclarecido pelo pesquisador e ter entendido o que me foi explicado, consinto em participar desta pesquisa

São Paulo, de de

Assinatura do colaborador

Cristina Silva Sousa

Enfermeira e aluna do Doutorado da Escola de Enfermagem da USP (EEUSP) 


\section{APÊNDICE V}

\section{TESTE DE CONHECIMENTO SOBRE O PROCEDIMENTO CIRÚRGICO}

Leia atentamente cada questão, somente há uma resposta certa para cada uma. Assinale a alternativa que julgar correta.

1. Como é a cirurgia?

a) A cirurgia mexe com os ossos da minha face e o cirurgião irá colocar placas e parafusos

b) A cirurgia mexe somente na arcada dentária e não precisa de placas e parafusos

c) A cirurgia é para melhorar a estética da mordida e o cirurgião não mexe com os ossos da face

d) A cirurgia é rápida, feita no hospital e com anestesia local

2. Após a cirurgia é possível:

a) Manter a abertura total da boca

b) Apresentar dor cervical e nas costas

c) Diminuir a sensibilidade da face

d) Apresentar vermelhidão na face

3. Em caso de sangramento pequeno na boca após a cirurgia devo:
a) Fazer compressa de gelo
b) Fazer bochecho com água gelada
c) Entrar em contato com o cirurgião
d) Observar e aguardar a consulta de retorno

4. Para ajudar na recuperação da cirurgia e da mobilidade da face posso fazer:
a) Exercícios faciais
b) Compressa quente
c) Repouso na cama
d) Todas as alternativas estão corretas

5. Vou sentir o rosto inchado por:
a) Uma semana
b) Quinze dias
c) Um mês
d) Por mais de 30 dias

6. Em relação aos cuidados com os lábios devo:
a) Beber mais líquidos
b) Usar algum hidratante ou protetor
c) Esperar diminuir o inchaço
d) Todas as alternativas anteriores

7. Em relação a escovação dos dentes devo: 
a) Ficar dois dias sem escovar os dentes após a cirurgia

b) Fazer somente bochecho com antisséptico após a cirurgia

c) Escovar os dentes com escova macia logo após a cirurgia

d) Usar a mesma escova de dente, que utilizava antes

8. Em relação à alimentação após a cirurgia devo:
a) Ingerir somente líquidos
b) Ingerir somente alimentos pastosos
c) Ingerir qualquer alimento
d) Iniciar com líquidos nos primeiros dias

9. Em relação ao banho após a cirurgia:
a) Evitar lavar o rosto por dois dias
b) Tomar banho normalmente
c) Evitar lavar o cabelo por cinco dias
d) Tomar banho somente após liberação do cirurgião

10. Em relação as minhas atividades, logo após a cirurgia devo:
a) Fazer repouso na cama por dois dias
b) Fazer atividades simples
c) Realizar atividade física
d) Fazer repouso na cama por cinco dias 


\section{APÊNDICE VI}

\section{INSTRUMENTO DE COLETA DE DADOS PARA PACIENTES SUBMETIDOS A CIRURGIA ORTOGNÁTICA}

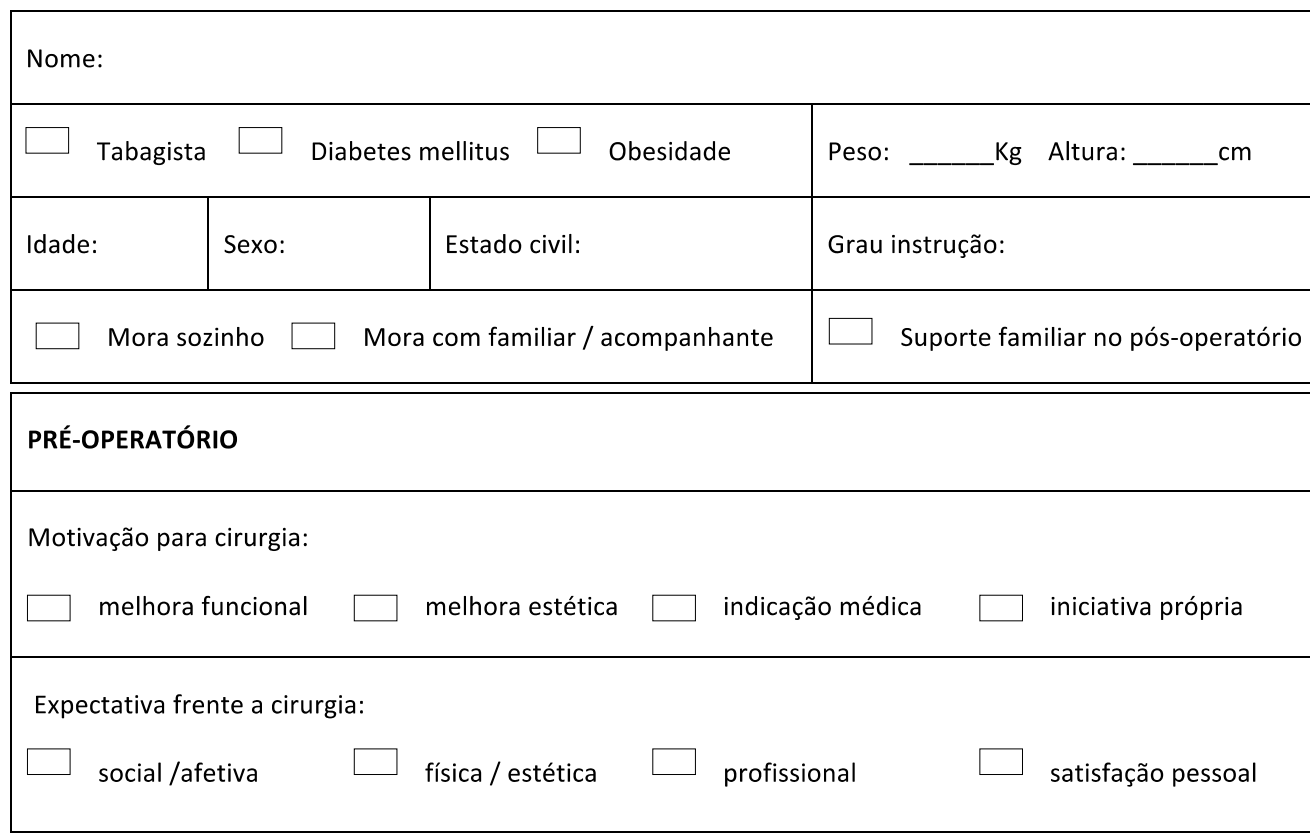

\section{PÓS-OPERATÓRIO}

Técnica cirurgica utilizada:

Complicações cirúrgicas:

Dificuldades vivenciadas:

Mudanças após a cirurgia

$\square$ aparência física $\square$ alteração na voz $\square$ mais confiante $\square$ não observou $\square$ outras

Satisfação com o resultado $\quad \square$ Satisfeito $\quad \square$ Insatisfeito

Observações 


\section{Avaliação dos cuidados no pós-oper atório}

Primeiro, Segundo, Terceiro e Quarto retorno

Higiene oral

Halitose ( ) sim ( ) não Gengiva descorada ( ) sim ( ) não Presença de placa ( ) sim ( ) não

Gengivite ( ) sim ( ) não Língua saburrosa ( )sim ( ) não Sutura com resíduo ( ) sim ( )não

Sentiu dificuldade para realizar higiene oral ( ) sim ( ) não. Se sim, porque?

Nutrição

Peso corporal

$\mathrm{Kg}$

Possui auxilio para preparo das refeições ( ) sim ( ) não

Teve dificuldade em fazer as refeições ( ) sim ( ) não. Se sim, qual?

\section{M obilidade e sensibilidade}

Possui limitação acima do esperado para abertura da boca （ ) sim （ ) não

Apresenta desvio da mordida ( ) sim ( ) não. Se sim, tende lateralidade?

Apresenta resposta ao estimulo tátil ( )sim ( ) não

Consegue realizar movimentos faciais (ex. sorrir, fazer bico) ( ) sim ( ) não

Usa elástico no aparelho ortodôntico ( ) sim ( ) não. Teve dificuldade na manipulação?

Apresenta parestesia ( ) sim ( ) não. Se sim, em quais regiões:

( ) queixo ( ) lábio superior ( ) lábio inferior ( )asa do nariz ( ) bochecha ( )

Aspectos dos lábios

Apresenta ressecamento ( ) $\operatorname{sim}$ ( ) não Apresenta lesão labial ( ) sim ( ) não

Como tem feito hidratação dos lábios?

\section{Edema}

Apresenta edema acima do esperado para o período ( ) sim ( ) não

O que tem feito para reduzir o edema:

( ) gelo ( ) camomila ( ) arnica ( ) creme hidratante ( ) massagem facial ( )outro

Tem realizado algum exercício facial ( ) sim ( ) não. Se sim, qual a frequência e exercício

\section{Dor}

Escala dor ]

Fez algum tratamento para dor ( ) sim ( ) não. Se sim, qual?

\section{Dormir e respirar}

Teve dificuldade para dormir ( ) sim ( ) não. Se sim, porque?

Teve dificuldade para respirar ( ) sim ( ) não. Se sim, porque?

Utilizou algum método para dormir ou respirar melhor ( ) sim ( ) não. Se sim, qual? 


\section{ANEXO I}

\section{Inventário de Ansiedade traço-estado (IDATE)}

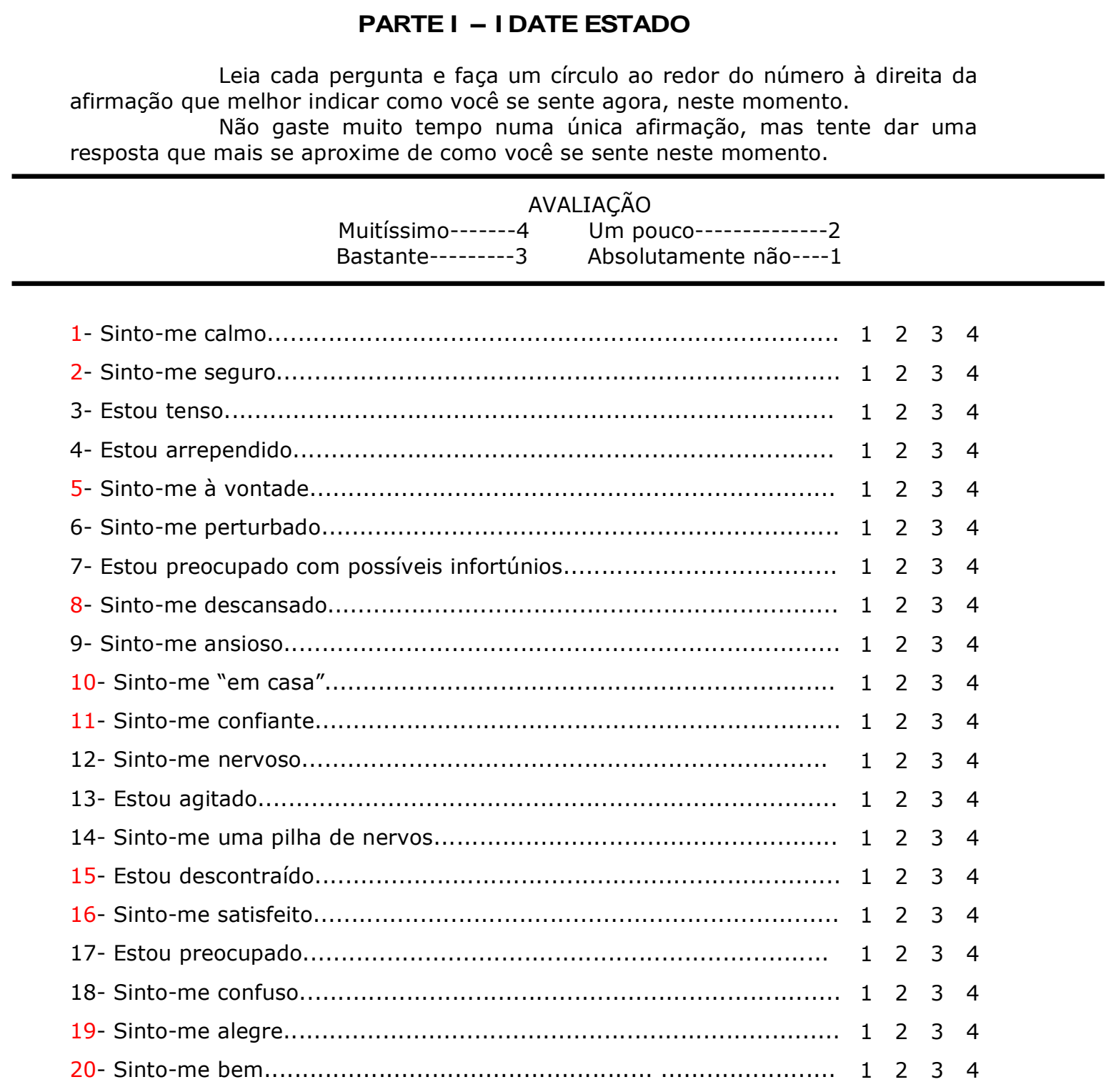




\section{PARTE I I - I DATE TRAÇO}

Leia cada pergunta e faça um círculo em redor do número à direita que melhor indicar como você geralmente se sente.

Não gaste muito tempo numa única afirmação, mas tente dar a resposta que mais se aproximar de como você se sente geralmente.

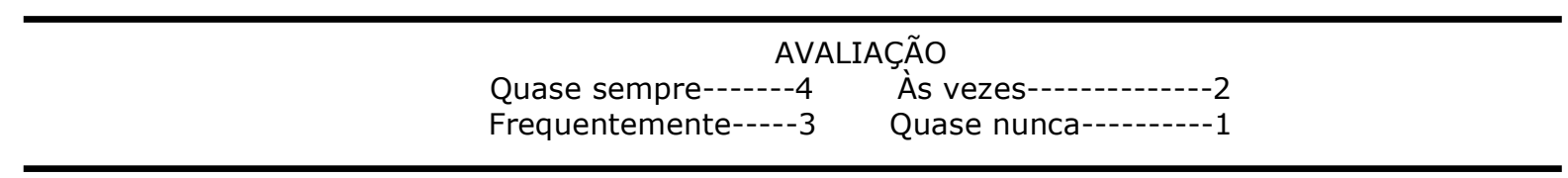

1. Sinto-me bem. $\begin{array}{llll}1 & 2 & 3 & 4\end{array}$

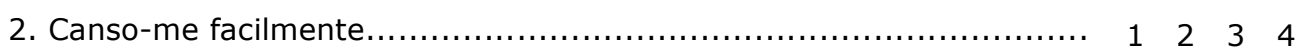

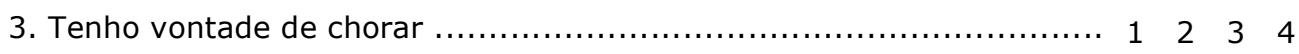

4. Gostaria de poder ser tão feliz quanto os outros parecem ser........... $12 \begin{array}{llll}2 & 3 & 4\end{array}$

5. Perco oportunidades porque não consigo tomar decisões rapidamente............................................................ 1434

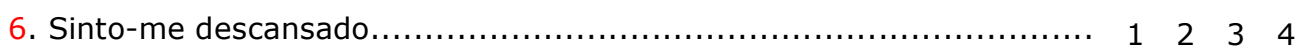

7. Sou calmo, ponderado e senhor de mim mesmo...................... $124 \quad 3 \quad 4$

8. Sinto que as dificuldades estão se acumulando de tal forma

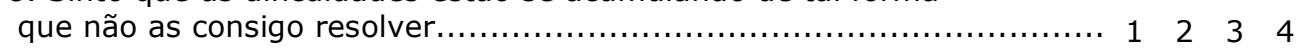

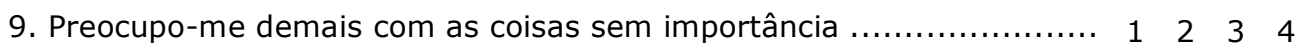

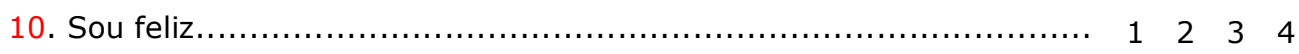

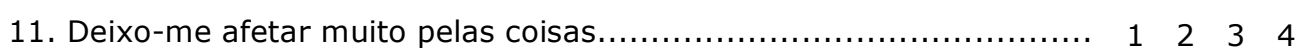

12. Não tenho muita confiança em mim mesmo........................... $123 \quad 34$

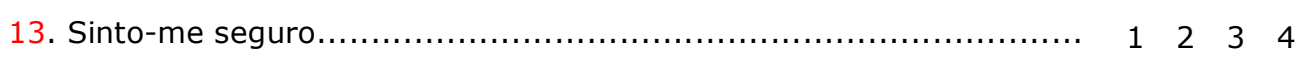

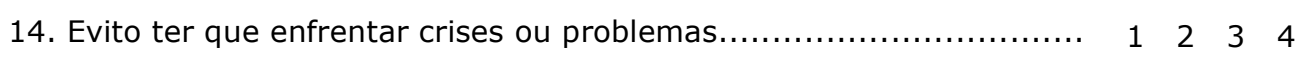

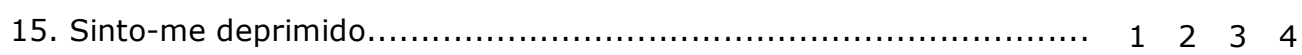

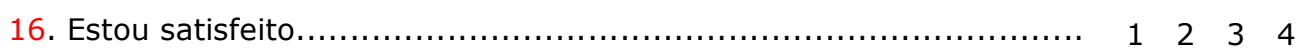

17. Idéias sem importância me entram na cabeça e ficam me preocupando............................................................. $124 \quad 34$

18. Levo os desapontamentos tão a sério que não consigo tirá-los da cabeça.

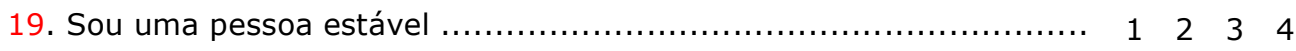

20. Fico tenso e perturbado quando penso em meus problemas do momento. 


\section{ANEXO II}

\section{Cirurgia Ortognática} para pacientes

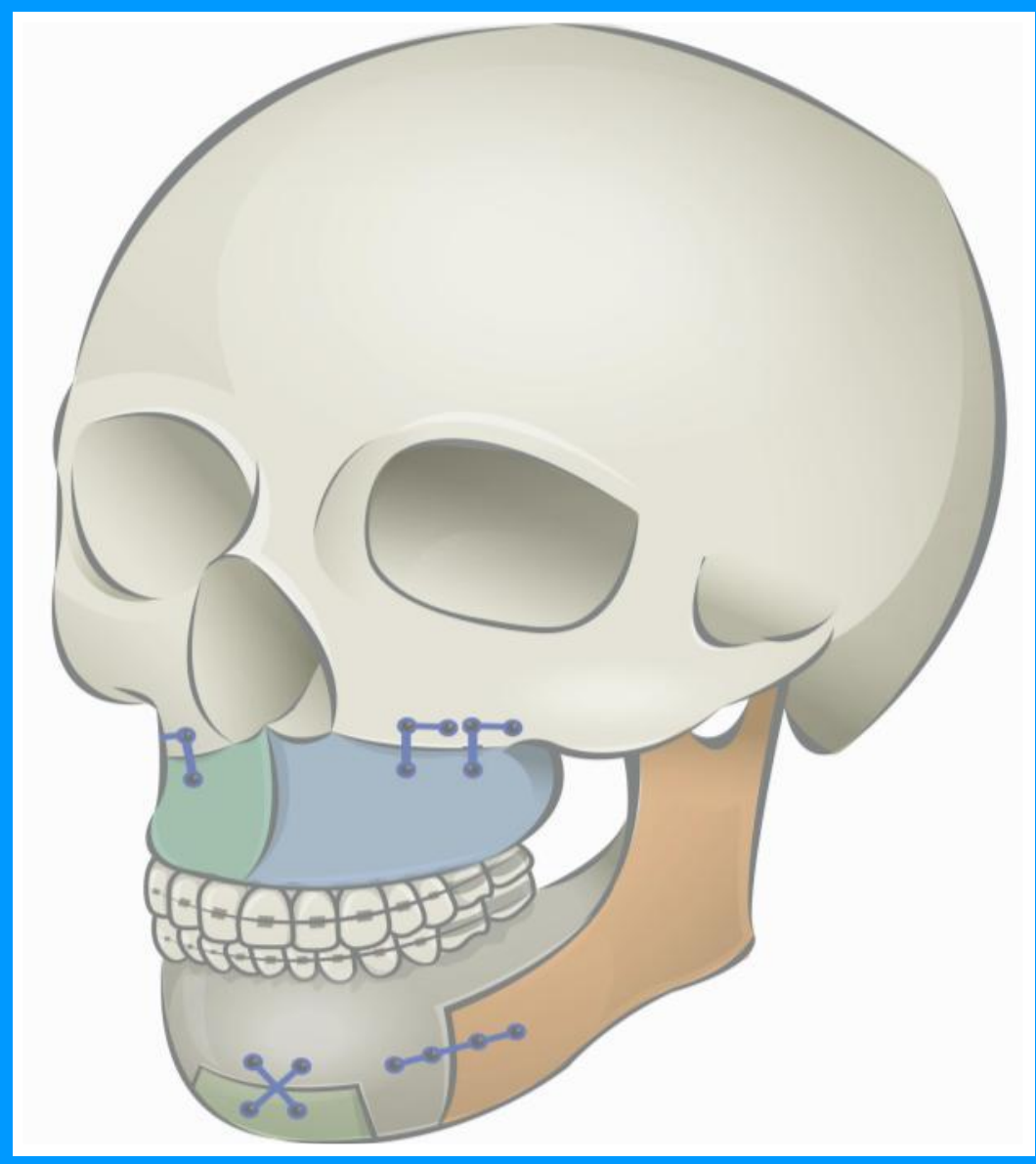




\section{Apresentação}

Este material educativo foi elaborado com a finalidade de orientar você e seus familiares sobre a cirurgia ortognática, preparo e cuidados no pós-operatório da cirurgia.

Toda a cirurgia necessita de alguns cuidados para sua melhor recuperação, sendo assim, procure aproveitar ao máximo as informações deste material e se persistirem as dúvidas procure seu cirurgião.

\section{Elaboração}

Cristina Silva Sousa. Enfermeira. Aluna do Mestrado da Pós-graduação em Enfermagem na Saúde do Adulto da Escola de Enfermagem da USP.

Ruth Natalia Teresa Turrini. Enfermeira. Profa. Dra. do Departamento de Enfermagem Médico-Cirúrgica da Escola de Enfermagem da USP.

Agradecimento a $\operatorname{Prof}^{\mathrm{a}} \operatorname{Dr}^{\mathrm{a}}$ Maria Cecília Focesi Pelicioni pelo auxilio no desenvolvimento deste trabalho.

Produto originado da Dissertação de Mestrado: "Educação pós-operatória: construção e validação de uma tecnologia educativa para pacientes submetidos a cirurgia ortognática"

\section{Validação}

Dr. Sergio Eduardo Migliorini- Cirurgião Bucomaxilofacial

Dr. Fabio Augusto Cozzolino - Cirurgião Bucomaxilofacial

Dr. Igor Thiago Bragatto de Mendonça - Cirurgião Bucomaxilofacial

Dra Taisa Maria Mendes Matuiama - Cirurgiã Bucomaxilofacial

Dolores Milaré Pereira - Nutricionista

Tatiani de Oliveira-Nutricionista

Maria Valberlene da Silva - Enfermeira

Suzi Leida Fontes-Enfermeira

Trixy Cristina Neimeyer Vilela Alves - Fonoaudióloga

Giédre Berretin Felix-Fonoaudióloga

\section{Ilustração}

Marcio dos Santos Batista

São Paulo, 2011

Copyright @Todos os direitos reservados 


\section{Neste material educativo você irá encontrar}

Tópicos

O que é a cirurgia ortognática?

Quem precisa fazer a cirurgia?

Como é feita esta cirurgia?

Como ficará a colocação de placas e parafusos no meu rosto?

Chegou o dia da cirurgia

Preparo da cirurgia

No dia da cirurgia

Durante a cirurgia

Termino da cirurgia

A Alta Hospitalar

Como é a recuperação da cirurgia?

O que pode ocorrer após a cirurgia

Retorno no consultório após a cirurgia

Cuidados de pós-operatório em casa

Higiene oral

Dieta

Abertura da boca

Aplicação de gelo

Exercícios

Umidificação dos lábios

Exposição ao sol

Banho e curativos

Dor

Como dormir e respirar

Repouso

Perguntas frequentes
Página

04

04

05

07

08

08

08

09

10

10

11

12

13

14

14

14

16

16

17

19

19

19

20

20

21

22 


\section{O que é a Cirurgia Ortognática?}

Cirurgia realizada para corrigir as deformidades dentofaciais e estabelecer a harmonia dos maxilares e arcada dentária. É um tratamento combinado de aparelho ortodôntico e cirurgia, que poderá levar até dois anos para um resultado final.

\section{Quem precisa fazer esta cirurgia?}

Pacientes com deformidades dentofaciais que não podem ser corrigidas apenas com aparelho ortodôntico. Geralmente, excesso ou falta de desenvolvimento de mandíbula ou maxila, ou os dois juntos.

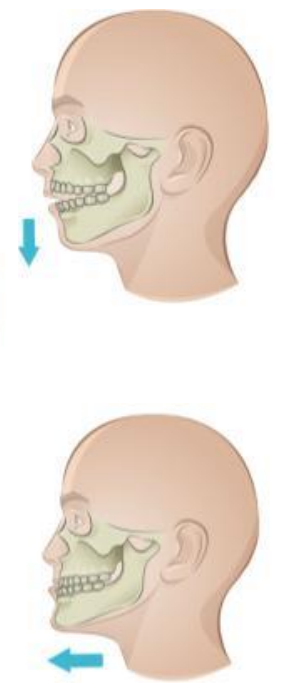

Uma equipe de ortodontistas e cirurgião bucomaxilofacial trabalham em conjunto para o melhor resultado cirúrgico. No pós-operatório enfermeiros, nutricionistas, fonoaudiólogos e outros profissionais podem estar presentes.

Os benefícios deste procedimento são melhora na função de mastigar, falar e respirar e, em muitos casos, uma melhor equilíbrio e harmonia facial. 


\section{Como é feita a cirurgia?}

A estrutura óssea da face é fraturada e reposicionada, com placas e parafusos, veja alguns exemplos.
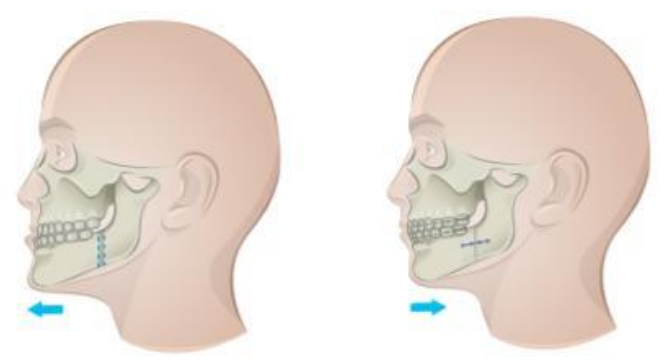

A mandíbula é fraturada e um fragmento ósseo é retirado para diminuir o tamanho da mandíbula. Depois a estrutura é fixada com placas e parafusos
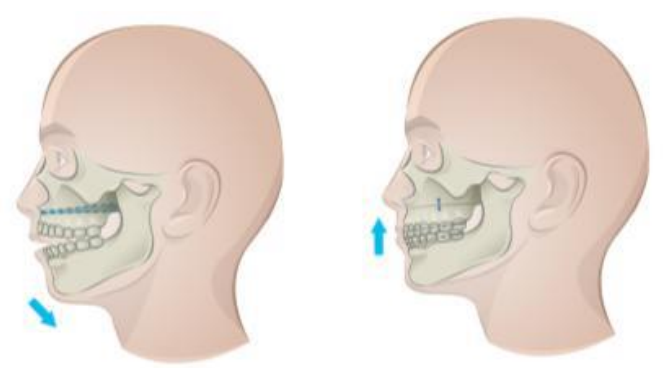

A maxila é fraturada , a estrutura óssea é reorganizada e fixada.
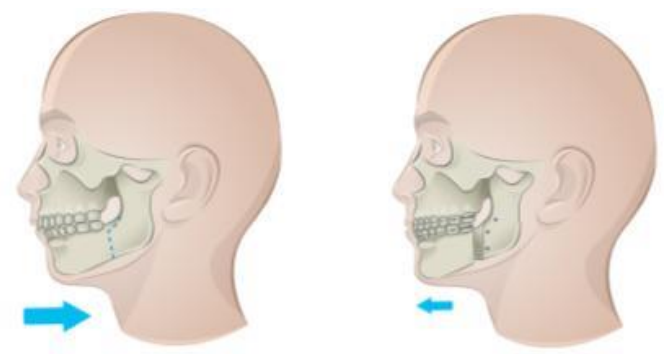

A mandíbula é fraturada e reposicionada para frente para corrigir o posicionamento das estruturas.
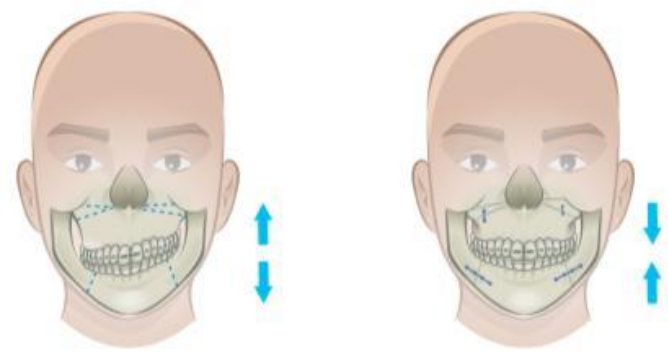

A maxila e a mandíbula são fraturadas e reorganizadas para harmonia da face e fixa com placa e parafuso. 


\section{Como é feita a cirurgia?}
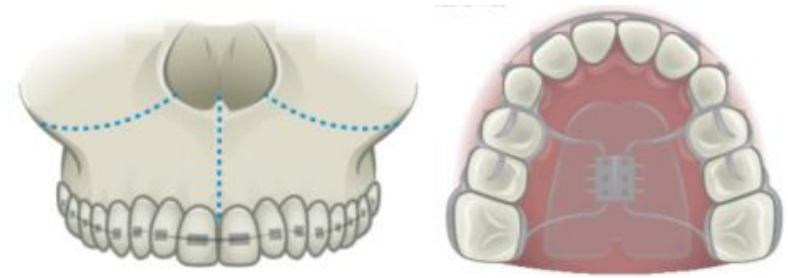

A maxila é fraturada em três partes e a colocação do aparelho Hass vai auxiliar na expansão da maxila

Nomes das técnicas cirúrgicas e seus resultados

Mentoplastia: altera o tamanho e a forma do queixo.

Osteotomia Lefort I: correção de deformidades da maxila, permitindo movimentar a maxila para frente, para trás, para cima e para baixo, com ou sem enxerto ósseo.

Osteotomia sagital oblíqua: correção de deformidades da mandíbula, permitindo movimentar a mandíbula para frente ou para trás e também medidas da parte inferior da face.

Osteotomia segmentar: permite movimentar uma ou mais partes dentro da estrutura óssea dentaria.

Disjunção: abertura da maxila e descruzamento da mordida.

Osteotomia vertical de ramo mandibular: procedimento realizado na parte posterior da mandíbula, para recuar o osso. 


\section{Como é feita a cirurgia?}

Como ficará a colocação de placas e parafusos no meu rosto?

As fixações podem ser diferentes e dependem da cirurgia e da técnica que será aplicada para sua deformidade. Observe um exemplo de como podem ser colocadas as fixações nas figuras abaixo.
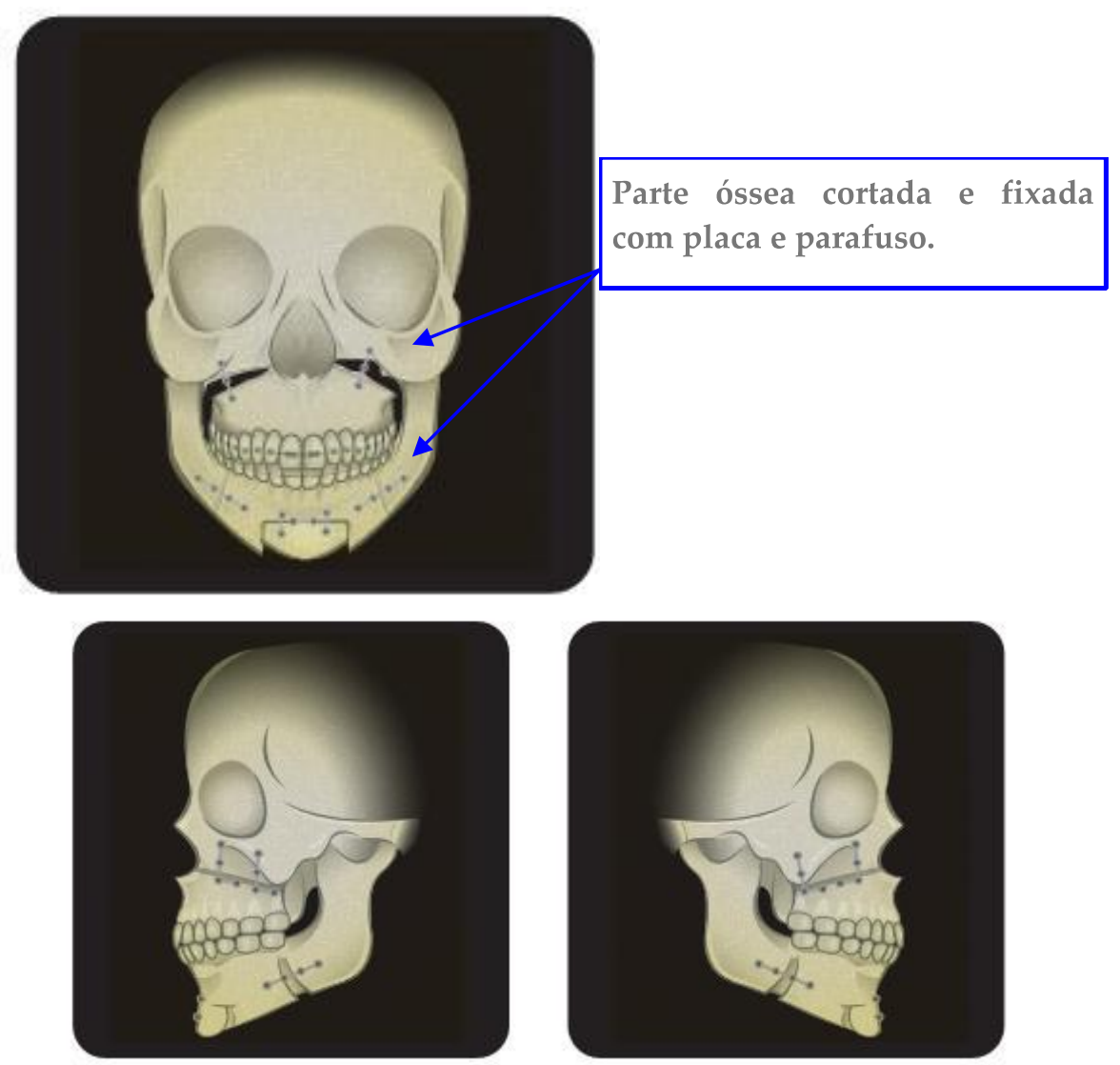

Pós-operatório da cirurgia ortognática combinada (feita tanto na maxila quanto na mandíbula). 


\section{Chegou o dia da cirurgia}

\section{Preparo para a Cirurgia}

Não é uma cirurgia de emergência e por isso você só poderá operar com boa saúde e sem infecção.

Antes da cirurgia você irá realizar exames pré-operatórios para avaliar sua saúde. Lembre-se de avisar o cirurgião sobre as medicações que você faz uso e problemas de saúde que possui.

\section{No dia da Cirurgia}

- Jejum de 8h (nem água pode ser ingerida);

- Cabelos devem estar secos e sem cremes;

- Unhas dos pés e mãos sem esmalte;

- Deixe em casa brincos, pulseiras, piercing, anéis e correntes;

- Leve para o hospital:

- seus exames;

- objetos pessoais (higiene e roupas confortáveis);

- documentação para internação (RG, CPF, e se for o caso o cartão do plano de saúde, guia de liberação do convenio e a carta para internação do cirurgião). 


\section{Durante a Cirurgia}

A cirurgia é realizada sob anestesia geral, isso quer dizer que você vai receber algumas medicações para dormir profundamente e será necessário colocar um pequeno tubo pelo nariz até o pulmão que será ligado a um aparelho para manter sua respiração.

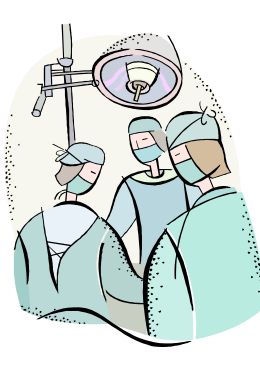

A duração da cirurgia pode ser de 1,5 a $6 \mathrm{~h}$ dependendo do tipo de correção que será feita. Os cortes geralmente são realizados dentro de sua boca e, neste caso, não haverá cicatrizes em sua face. Se for preciso algum corte externo, podem haver cicatrizes.

O "splint" ou goteira de sua mordida que servirá de guia cirúrgico é feita pelo cirurgião com articulador, mesas ou programas de computador e será utilizado na cirurgia para colocar sua arcada dentária na posição correta (veja a imagem abaixo).

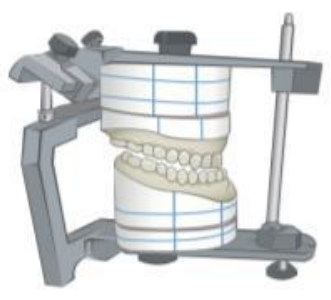

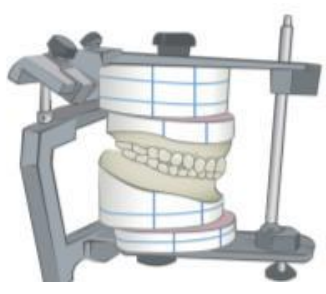

9

Articulador com molde da mordida antes da cirurgia e com planejamento da nova mordida 


\section{Termino da Cirurgia}

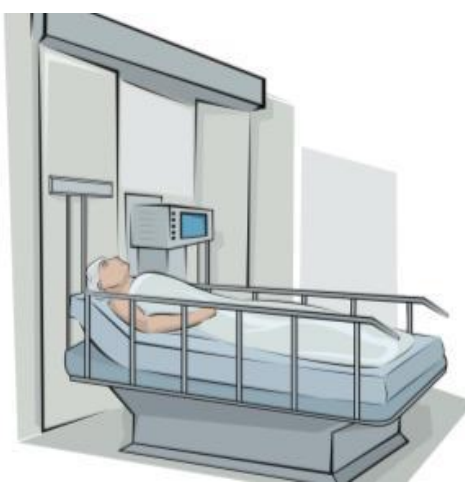

Ao término da cirurgia você ficará na Recuperação Anestésica (uma sala com vários leitos $\mathrm{e}$ aparelhos, no centro cirúrgico) até que esteja recuperado da anestesia e após retornará ao seu quarto.

No quarto você ficará com a cabeceira da cama levantada, poderá sentir muito sono (efeito da anestesia), poderá falar e ingerir líquidos, receberá medicamentos para dor e para diminuir o inchaço.

Você pode levantar para ir ao banheiro, mas para sua segurança peça a enfermagem para te acompanhar.

\section{A Alta Hospitalar}

Pode ser no dia seguinte da cirurgia, mas é o cirurgião que determina sua alta hospitalar de acordo com sua recuperação.

Você pode ficar afastado de suas atividades por até 14 dias ou conforme determinação do seu cirurgião. 


\section{Como é a recuperação da cirurgia?}

- Você vai sentir sua cabeça pesada, seu rosto ficará inchado ( 2 a 3 vezes o tamanho normal) e isto é previsto, então não se assuste;

- O inchaço vai diminuir com medicamentos e com o passar do tempo (cerca de 10 dias para melhorar o aspecto e até 6 a 12 meses para diminuição do inchaço na bochecha), logo será possível ver seu novo perfil facial;

- Poderá haver pouca sensibilidade na face, então você pode "babar" e não perceber. Mas será apenas por um período;

- Seus lábios podem ter rachaduras;

- Você vai ter dificuldade para abrir a boca e a musculatura da face estará dolorida. Após um período, as funções da boca (sorriso, mastigação) estarão normais;

- Poderá perder peso pela dificuldade de se alimentar;

Os primeiros dias são delicados e podem levar a desânimo, mas com o passar dos dias e a percepção do resultado surge a satisfação.

Lembre-se, esta é apenas uma fase do pós-operatório. 


\section{O que poderá ocorrer após a cirurgia}

Dor: é mais intensa durante dois a três dias após a cirurgia, mas pode ser controlada com medicação.

Ausência de união óssea ou quebra da placa de fixação: isso pode ocorrer se você começar a mastigar o alimento sólido mais cedo do que é permitido. É mais comum em fumantes e em pacientes que rangem os dentes a noite.

Alteração da sensibilidade: você pode notar formigamento na região da mandíbula, palato, nariz, lábio e queixo, mas o movimento e a mímica labial está inalterada. Esta sensibilidade deve retornar em até 18 meses.

Hematoma (coágulo de sangue): um sangramento na região da cirurgia pode formar um hematoma, quando grande pode até necessitar de uma cirurgia para retira-lo. O hematoma pode comprimir estruturas e sem tratamento causar infecção.

Náuseas e vômitos: pode ocorrer pelo efeito da anestesia, e logo após a cirurgia pode conter sangue. Comunique a enfermagem para receber medicamentos e aliviar estes sintomas.

Infecção: é rara nesta cirurgia, mas pode ocorrer quando a cavidade (boca) é contaminada. $\mathrm{O}$ tratamento será antibiótico e seu cirurgião irá acompanhar de perto. 


\section{Retorno no consultório após a cirurgia}

O retorno ao consultório do cirurgião ocorre dentro de 3 a 5 dias do pós-operatório.

A cicatrização da gengiva ocorre em média em 10 dias. Os maxilares podem levar até 4 meses para consolidação óssea.

Você usará os elásticos no aparelho ortodôntico, necessários no pós-operatório para assegurar esta fixação, guiar a abertura da boca e garantir a cicatrização óssea na nova posição.

Você continuará com o aparelho ortodôntico para organização dos dentes na nova posição dos maxilares por mais algum tempo de acordo com o ortodontista

(cerca de 8 meses a 1 ano). 


\section{Cuidados do Pós-operatório em Casa}

Higiene Oral

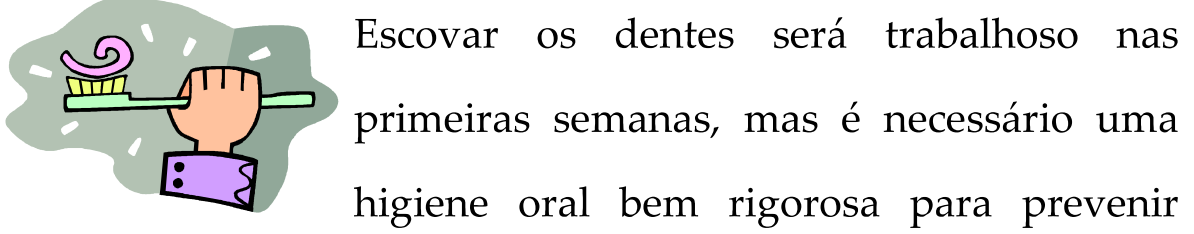
infecções.

Você vai sentir dificuldade para usar sua escova de dente, então use uma escova menor com cerdas muito macias.

Por causa do inchaço, você pode sentir dificuldade de colocar a escova dentro da boca, então, com o dedo afaste a bochecha e coloque a escova dentro da boca; durante o vai e vem da escova faça o movimento bem devagar, sem força, mas é importante que alcance os dentes do fundo.

Enxague bem com água e após faça bochechos com antisséptico bucal várias vezes ao dia.

Faça sempre uma higiene oral depois de comer.

\section{Dieta}

Nos primeiros dias:

- Dieta liquida fria (sopa batida de legumes, verduras, cereais e carne pelo menos 2 vezes ao dia); 


\section{Cuidados do Pós-operatório em Casa}

- Procure beber bastante liquido (água, sucos, água de coco) cerca de 1,5 1/dia;

- Preparações com leite (achocolatado, leite com frutas, mingau ralo) ou suplementos de 2 a 3 vezes por dia.

Se você sentir dificuldade em utilizar o canudo, pode usar um copinho de café, uma colher ou uma seringa para auxiliar a colocar os líquidos dentro da boca para engolir.

Procure respeitar a aceitação do seu corpo com a quantidade de comida e lembre-se de comer de 3 em 3 horas.

Depois do período de dieta liquida, você deve passar para pastosa liquida (como a papinha de bebê) por 2 a 3 semanas; depois pastosa com mais

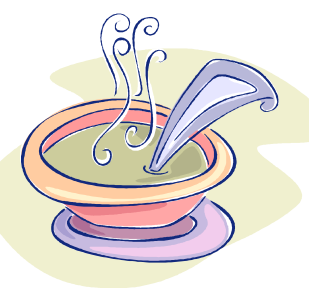
consistência (alimentos amassados) por 2 a 3 semanas; e dieta com alimentos sólidos macios (que não exigem força para morder) por 2 a 3 semanas; e em 90 dias você estará comendo alimentos com a mesma consistência de antes da cirurgia.

\begin{tabular}{|l|l|l|l|l|}
\hline Até 15 dias & 16 a 25 dias & 26 a 45 dias & 46 a 60 dias & 61 a 90 dias \\
\hline Liquida & $\begin{array}{l}\text { Pastosa } \\
\text { liquida }\end{array}$ & $\begin{array}{l}\text { Pastosa com } \\
\text { consistência }\end{array}$ & $\begin{array}{l}\text { Alimentos } \\
\text { macios }\end{array}$ & $\begin{array}{l}\text { Alimentos } \\
\text { sólidos }\end{array}$ \\
\hline
\end{tabular}




\section{Cuidados do Pós-operatório em Casa}

\section{Abertura de boca}

Siga as orientações do cirurgião e do ortodontista para uso e troca dos elásticos conforme sua evolução no pósoperatório e para realizar os exercícios para retornar a abrir a boca normalmente em 6 semanas

O excesso de força para a abertura da boca e a mastigação, pode prejudicar a estabilidade da nova posição das estruturas de sua face.

\section{Aplicação de gelo}

Você poderá aplicar uma bolsa térmica de gelo no rosto para ajudar a diminuir o inchaço, por um período de 20 minutos com intervalo de 10 a 15 minutos entre cada aplicação de gelo.

Ou então, coloque vários cubos de gelo em uma toalha e quando for colocar sobre o rosto cubra primeiro a pele do rosto com um tecido.

Tempo superior a 20 minutos pode machucar a pele, esteja a atento ao tempo de permanência do gelo. 


\section{Cuidados do Pós-operatório em Casa}

\section{Exercícios}

Para auxiliar a recuperação da cirurgia e da mobilidade e sensibilidade da região, você pode realizar alguns exercícios em casa após liberação do cirurgião.

\section{Com a bochecha}

Coloque um pouco de ar dentro da boca e empurre o ar para lado direito e esquerdo dentro da boca, como se você fizesse uma bola na bochecha. Repita algumas vezes durante o dia.

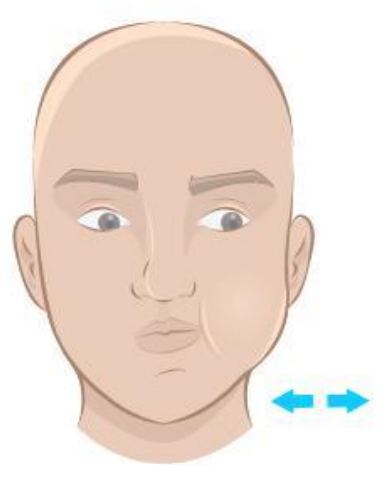

\section{Com a língua}

Tente passar a ponta da língua nos lábios superior e inferior, sem forçar a abertura da boca, se não estiver com a sensibilidade da região você pode fazer em frente do espelho para visualizar. Repita algumas vezes durante o dia.

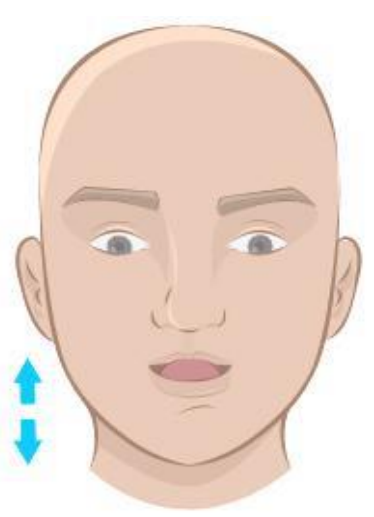




\section{Cuidados do Pós-operatório em Casa}

Se estiver conseguindo respirar pelo nariz, procure manter os lábios fechados e a língua no céu da boca, com a ponta atrás dos dentes de cima, isso evitará que haja força errada nas estruturas operadas. Quando for engolir água ou saliva, comece a prestar atenção para a língua ficar também neste lugar.

Depois da cirurgia passe a língua por dentro da boca para perceber a nova forma e ajudar na sensibilidade da região.

\section{Com os lábios}

Tente suavemente fazer biquinho e depois fazer sorriso, sem colocar força ou pressão, alterne entre o biquinho e o sorriso. Repita
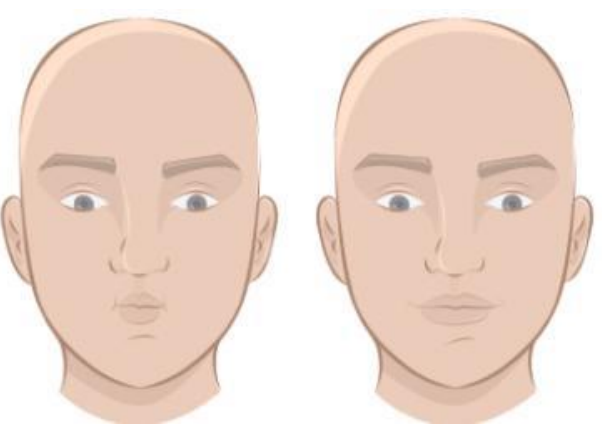
algumas vezes ao dia.

\section{Para ajudar nos movimentos, fala e alimentação,}

procure um fonoaudiólogo. 


\section{Cuidados do Pós-operatório em Casa}

\section{Umidificação dos lábios}

Os lábios podem ficar rachados e ressecados, isso ocorre pela manipulação durante a cirurgia. Procure hidratar os lábios com hidratante, manteiga de cacau, vaselina líquida ou pomada de assadura de nenê oleosa. Faça aplicações várias vezes ao dia.

\section{Exposição ao sol}

Evite o sol durante o pós-operatório, o calor pode aumentar o inchaço e se você tiver hematomas pode deixar a pele manchada. Procure usar filtro solar se tiver que ficar exposto ao sol ou a ambientes com luz fluorescente.

\section{Banho e curativos}

Você pode lavar o rosto normalmente, mas evite água quente, pois o calor aumenta o inchaço.

Em alguns casos o paciente vai para casa com um curativo de fita adesiva segurando o queixo, que será retirado no retorno ao médico após a cirurgia; mas você pode molhar e secar bem com toalha. 


\section{Cuidados do Pós-operatório em Casa}

Os pontos da cirurgia estão em sua gengiva sem curativos e o cuidado com este pontos é uma boa higiene oral após as refeições. Estes pontos são absorvidos pelo seu corpo conforme a cicatrização.

\section{Dor}

Um desconforto é esperado. Alguns pacientes sentem mais dor e devem utilizar a medicação recomendada pelo cirurgião. Em caso de dor que não melhora com a medicação, entre em contato com o seu cirurgião.

\section{Como dormir e respirar}

Ao deitar coloque 2 a 3 travesseiros para deixar a cabeça mais alta, isso facilita a respiração e a diminuir o inchaço.

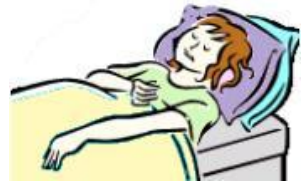

Você pode sentir seu nariz entupido ou dolorido; isso ocorre porque o inchaço comprime muitas estruturas da face e a sensação dolorida pode ser do tubo colocado durante a cirurgia para você respirar (isso melhora dentro de alguns dias). 


\section{Cuidados do Pós-operatório em Casa}

\section{Repouso}

Toda a cirurgia exige nos primeiros dias um repouso; procure realizar poucas atividades durante este período.

Sempre que estiver em repouso procure manter a cabeça mais alta que o corpo ou fique sentado e a cada 40 a 60 minutos movimente as pernas e os pés para melhorar a circulação. Procure caminhar a cada duas a três horas para manter boa circulação.

Evite levantar bruscamente. Você poderá realizar atividades simples, como ficar no computador, ver filmes, jogar com amigos, ver televisão, ler, passear por períodos curtos, de preferência próximo a sua casa, para descansar após o passeio. 


\section{Perguntas Frequentes}

Após a cirurgia posso ir para balada? Festas da família?

Lembre que você estará inchado e com dificuldade para abrir a boca. Se você não se

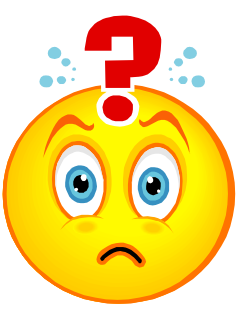
incomodar com os comentários das outras pessoas sobre seu rosto, poderá se divertir sem exageros; mas você continua com sua dieta.

\section{Após a cirurgia quando posso beijar?}

Logo após a cirurgia, o que vai ficar diferente é que a sensibilidade dos lábios estará diminuída e com isso você não sentirá muito bem a região. Beijos de língua levarão mais tempo para ocorrer, devido a limitação da abertura da boca. Mas com o tempo você mesmo saberá os seus limites.

\section{Após a cirurgia quando posso fazer exercícios físicos?}

A cirurgia exige repouso nos primeiros dias, e no primeiro mês evite exercícios de peso, ou que podem machucar. Restrinja toda atividade que exige força dos músculos do rosto e mordida. Lembre-se que a estrutura óssea precisa de um tempo para se fixar na nova posição. 


\section{Perguntas Frequentes}

\section{Após a cirurgia posso dirigir?}

Dentro de alguns dias e se você estiver se sentindo bem, mas não abuse, procure dirigir apenas em percursos pequenos, e tenha muito cuidado no trânsito para evitar um acidente e prejudicar a cirurgia.

Há tratamentos para ajudar a melhorar a sensibilidade?

Alguns tratamentos podem ajudar a diminuir a sensação de anestesia e dependem de cada caso. O melhor a fazer é conversar sobre o seu caso com o cirurgião. Mas lembre-se que esta sensibilidade demora até 18 meses para retornar ao normal.

\section{Minha boca está sangrando, e agora?}

Algumas vezes é normal ter sangramento, que pode ser do local da cirurgia, do dente, de alguma mordida na lingua, ou até de uma escovação com muita força. Fazer bochechos com água gelada vai ajudar a parar o sangramento. Se o sangramento for grande, entre em contato com o cirurgião 
"Cirurgia Ortognática para pacientes" consiste em um material educativo para pacientes em perioperatório desta modalidade cirúrgica; construído com auxilio de especialistas e pacientes para auxiliar no autocuidado.

Realização

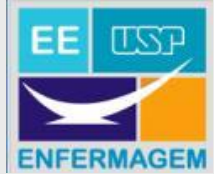

ISBN $978-85-912862-0-1$

|||||||||||||||||| ||||||| 